\title{
FEIJÃO: CARACTERIZAÇÃO FITOTÉCNICA, EXTRAÇÃO E EXPORTAÇÃO DE MACRONUTRIENTES
}

\author{
MÁRIO DA SILVA TELES NETO \\ Engenheiro Agrônomo
}

Orientador: Prof. Dr. DURVAL DOURADO NETO

Dissertação apresentada à Escola Superior de Agricultura "Luiz de Queiroz", Universidade de São Paulo, para obtenção do título de Mestre em Agronomia, Área de Concentração: Fitotecnia.

P I R A C I C A B A

Estado de São Paulo - Brasil

Abril -2001 
Dados Internacionais de Catalogação na Publicação (CIP) DIVISĀO DE BIBLIOTECA E DOCUMENTAÇĀO - Campus "Luiz de Queiroz"/USP

Teles Neto, Mário da Silva

Feijāo : caracterização fitotécnica, extração e exportação de macronutrientes / Mário da Silva Teles Neto. - - Piracicaba, 2001.

$84 \mathrm{p}$.

Tese (doutorado) - Escola Superior de Agricultura Luiz de Queiroz, 2001. Bibliografia.

1. Feijāo 2. Horticultura 3. Macronutriente 4. Nutrição vegetal I. Titulo 
DEDICO o presente trabalho a todos que o apoiaram.

OFEREÇO aos meus pais (Mário Roberto e Cidinha), minha irmã (Maria Roberta) e minha noiva (Luciana). 


\section{AGRADECIMENTOS}

Meus sinceros agradecimentos:

Ao Departamento de Produção Vegetal (ESALQ) da Universidade de São Paulo, pela oportunidade de realização do Curso de Pós-Graduação em Agronomia (área de concentração: Fitotecnia), ao nível de Mestrado.

Aos Engenheiros Agrônomos, Paula Munhoz Antunes (Experimento I) e Dr. Hudson Santos Pimenta (Experimento II), pela cessão dos dados.

À Fundação de Amparo a Pesquisa do Estado de São Paulo (FAPESP), pela Bolsa de Mestrado.

À bibliotecária Eliana Maria Garcia pela correção do item REFERÊNCIAS BIBLIOGRÁFICAS, bem como a verificação das NORMAS para publicação desta Dissertação.

Em especial ao Prof. Dr. Durval Dourado Neto, pelo inestimável apoio, e a sua família, pela acolhida. 


\section{SUMÁRIO}

Página

LISTA DE FIGURAS. viii

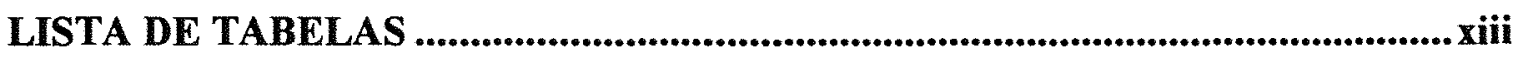

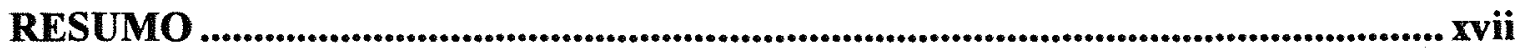

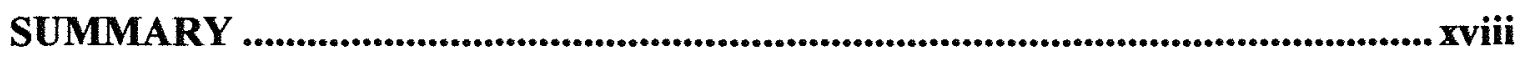

1 INTRODUÇÃO

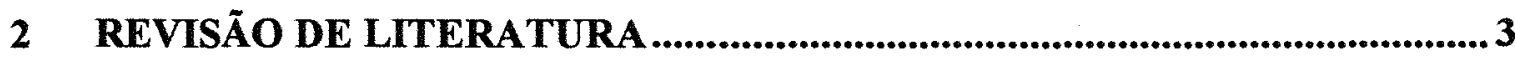

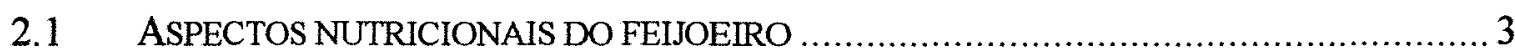

2.2 SINTOMAS DE DEFICIÊNCIA E FUNÇÃO DOS MACRONUTRIENTES MINERAIS............. 4

2.3 AVALIAÇÃO DA FERTLIDADE DO SOLO ATRAVÉS DA DIAGNOSE FOLIAR …............5

2.4 ADUBAÇÃO VERDE E ADUBAÇÃO ORGÂNICA …................................................ 7

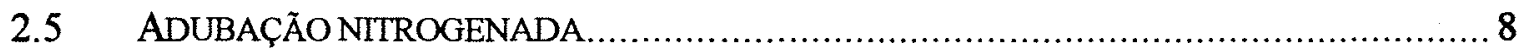

2.6 FENOLOGIA

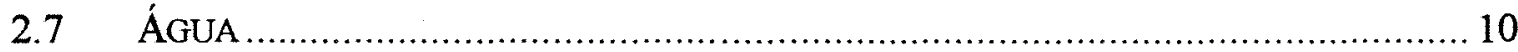

2.8 TEMPERATURA

2.9 DESENVOLVIMENTO RELATIVO DA CULTURA DE FEIJÃO................................... 14

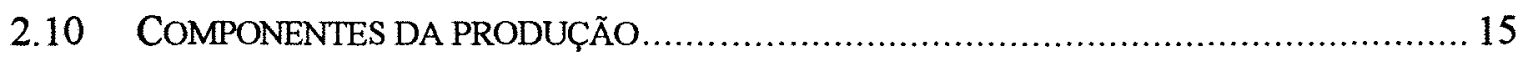

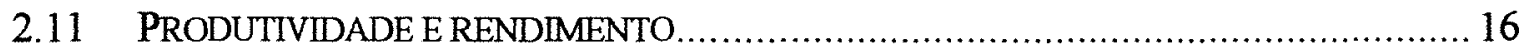

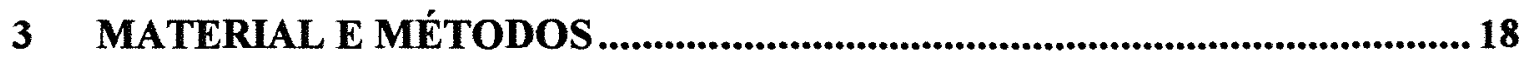

3.1 CARACTERIZAÇÃO DA ÁREA EXPERIMENTAL E VARIEDADE UTILIZADA................. 18

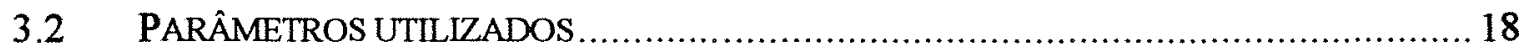

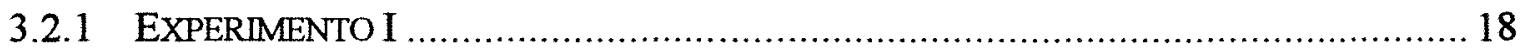

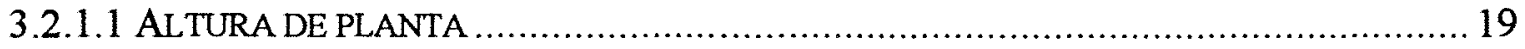

3.2.1.2 MASSA DE MATÉRIA SECA DE RAIZ, FOLHA, HASTE, VAGEM E TOTAL ................. 19

3.2.1.3 RENDIMENTO DE GRÃOS E ÍNDICE DE COLHEITA …........................................ 20 


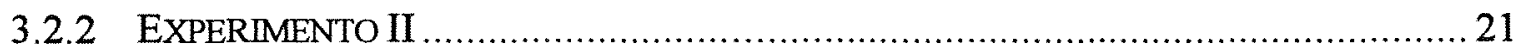

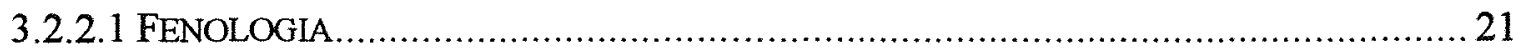

3.2.2.2 MASSA DE MATÉRIA SECA DE FOLHA, HASTE, BOTÃO FLORAL E VAGEM ….......... 21

3.2.2.3 TEOR DE MACRONUTRIENTES NA PARTE AÉREA DO FEIJOEIRO ............................ 21

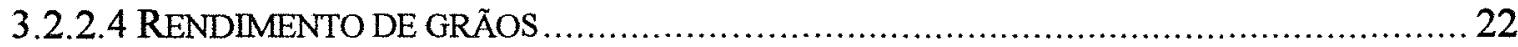

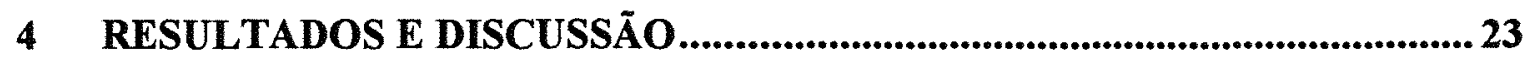

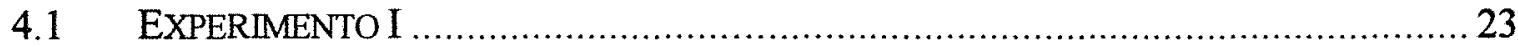

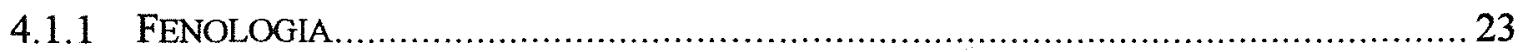

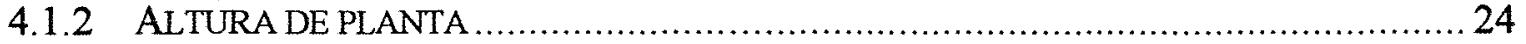

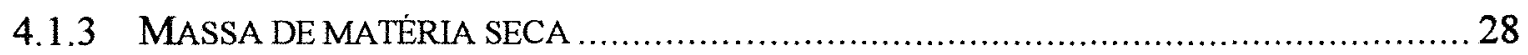

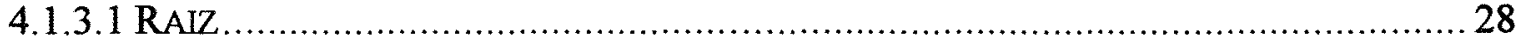

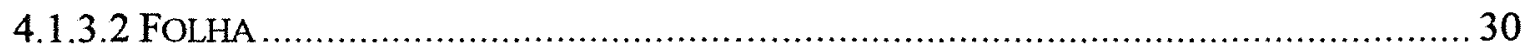

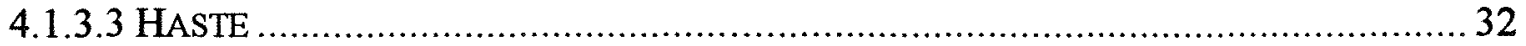

4.1.3.4 VAGEM

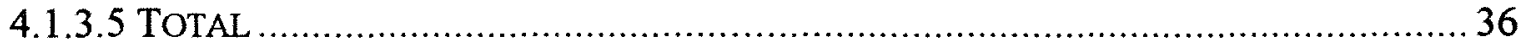

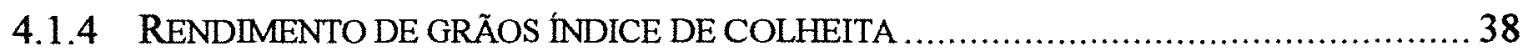

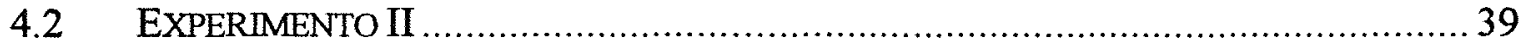

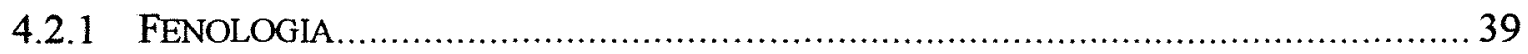

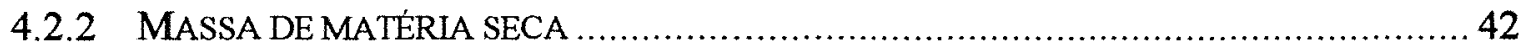

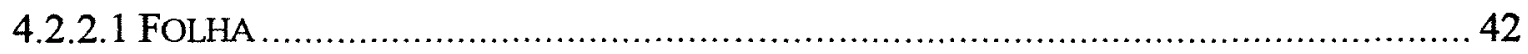

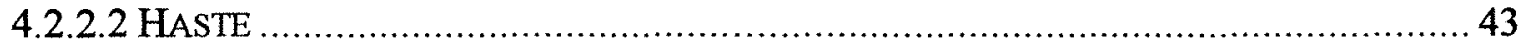

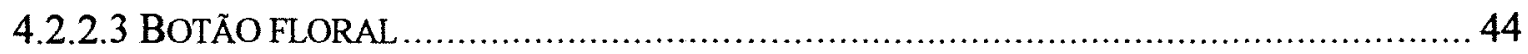

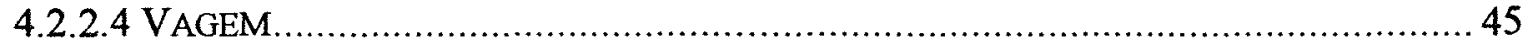

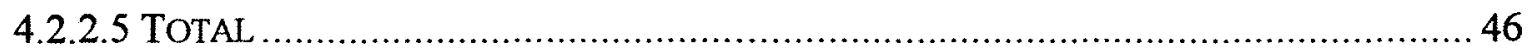

4.2.3 TEOR DE MACRONUTRIENTES NA PARTE AÉREA DO FEIJOEIRO ............................47

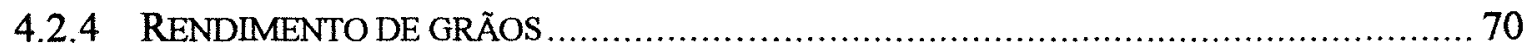

4.2.5 EXTRAÇÃO E EXPORTAÇÃO DE MACRONUTRIENTES …..................................... 70

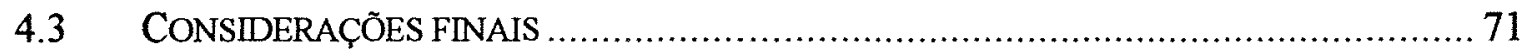

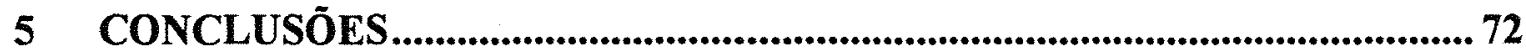




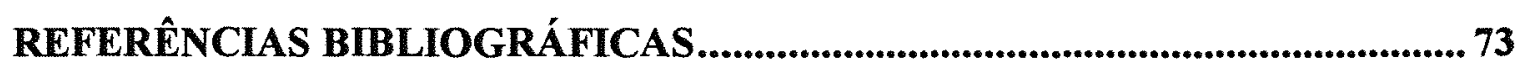

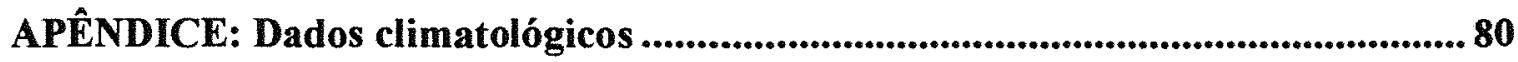




\section{LISTA DE FIGURAS}

Página

1. Ciclo da cultura de feijão sob condição de irrigação e de sequeiro especificando a duração relativa de cada um dos estádios fenológicos $\left(1: V_{0}\right.$, $2: V_{1} ; 3: V_{2} ; 4: V_{3} ; 5: V_{4}: 6: R_{5} ; 7 . R_{6} ; 8: R_{7} ; 9: R_{8}$ e 10: $\left.R_{9}\right)$.

2. Variação da altura de planta $(\mathrm{Ap}, \mathrm{cm})$ do feijoeiro comum sob irrigação e em condição de sequeiro em função das datas de coleta.

3. Variação da altura de planta $(\mathrm{Ap}, \mathrm{cm})$ do feijoeiro sob irrigação em função do número de dias após a semeadura (DAS).

4. Variação da altura de planta $(\mathrm{Ap}, \mathrm{cm})$ do feijoeiro sob condição de sequeiro em função do número de dias após a semeadura (DAS).

5. Variação da massa das raízes $(\mathrm{Mr}, \mathrm{g} / 5 \mathrm{pl})$ do feijoeiro sob irrigação em função do número de dias após a semeadura (DAS).

6. Variação da massa de matéria seca das raizes $(\mathrm{Mr}, \mathrm{g} / 5 \mathrm{pl})$ do feijoeiro sob condição de sequeiro em função do número de dias após a semeadura (DAS).

7. Variação da massa de matéria seca das folhas (Mf, g/5 pl) do feijoeiro sob irrigação em função do número de dias após a semeadura (DAS).

8. Variação da massa de matéria seca de folhas (Mf, g/5 pl) do feijoeiro em condição de sequeiro em função do número de dias após a semeadura (DAS).

9. Variação da massa de matéria seca das hastes $(\mathrm{Mh}, \mathrm{g} / 5 \mathrm{pl})$ do feijoeiro sob irrigação em função do número de dias após a semeadura (DAS).

10. Variação da massa de matéria seca das hastes (Mh, $\mathrm{g} / 5 \mathrm{pl}$ ) do feijoeiro sob condição de sequeiro em função do número de dias após a semeadura (DAS).

11. Variação da massa de matéria seca das vagens $(\mathrm{Mv}, \mathrm{g} / 5 \mathrm{pl})$ do feijoeiro sob irrigação em função do número de dias após a semeadura (DAS). 
12. Variação da massa de matéria seca das vagens $(\mathrm{Mv}, \mathrm{g} / 5 \mathrm{pl})$ do feijoeiro sob condição de sequeiro em função do número de dias após a semeadura (DAS).

13. Variação da massa de matéria seca total $(\mathrm{Mt}$, g) do feijoeiro sob irrigação em função do número de dias após a semeadura (DAS).

14. Variação da massa de matéria seca total ( $\mathrm{Mt}, \mathrm{g} / 5 \mathrm{pl}$ ) do feijoeiro sob condição de sequeiro em função do número de dias após a semeadura (DAS).

15. Partição relativa $(\%)$ e absoluta $(\mathrm{kg} / \mathrm{ha})$ de massa de matéria seca de raiz, folha, haste e vagem do feijoeiro sob condição de irrigação e de sequeiro.

16. Rendimento de grãos ( $\mathrm{kg} / \mathrm{ha})(\mathrm{A})$ e índice de colheita (\%) (B) referente à cultura de feijão sob condição de irrigação e de sequeiro.

17. Variação da massa de matéria seca de folha (Mf, g/5 pl) do feijoeiro sob irrigação em função do desenvolvimento relativo da cultura (Dr).

18. Variação da massa de matéria seca das hastes $(\mathrm{Mh}, \mathrm{g} / 5 \mathrm{pl})$ do feijoeiro sob irrigação em função do desenvolvimento relativo da cultura (Dr).

19. Variação da massa de matéria seca de botão floral $(\mathrm{Mb}, \mathrm{g} / 5 \mathrm{pl})$ do feijoeiro em função do desenvolvimento relativo da cultura (Dr).

20. Variação da massa de matéria seca de vagem $(\mathrm{Mv}, \mathrm{g} / 5 \mathrm{pl})$ do feijoeiro sob irrigação em função do desenvolvimento relativo da cultura (Dr).

21. Variação da massa de matéria seca total $(\mathrm{Mt}, \mathrm{g} / 5 \mathrm{pl})$ do feijoeiro sob irrigação em função do desenvolvimento relativo da cultura (Dr).

22. Variação dos teores $(\%)$ de nitrogênio $(\mathrm{N})$, fósforo $(\mathrm{P})$, potássio $(\mathrm{K})$, cálcio $(\mathrm{Ca})$, magnésio $(\mathrm{Mg})$ e enxofre $(\mathrm{S})$ na haste do feijoeiro em função da fenologia referente à testemunha $(0 \mathrm{~kg} / \mathrm{ha}$ de nitrogênio).

23. Variação dos teores $(\%)$ de nitrogênio $(\mathrm{N})$, fósforo $(\mathrm{P})$, potássio $(\mathrm{K})$, cálcio (Ca), magnésio $(\mathrm{Mg})$ e enxofre $(\mathrm{S})$ na haste do feijoeiro em função da fenologia referente à dose de $45 \mathrm{~kg} / \mathrm{ha}$ de nitrogênio. 
24. Variação dos teores $(\%)$ de nitrogênio $(\mathrm{N})$, fósforo $(\mathrm{P})$, potássio $(\mathrm{K})$, cálcio $(\mathrm{Ca})$, magnésio $(\mathrm{Mg})$ e enxofre $(\mathrm{S})$ na haste do feijoeiro em função da fenologia referente à dose de $90 \mathrm{~kg} / \mathrm{ha}$ de nitrogênio.

25. Variação dos teores $(\%)$ de nitrogênio $(N)$, fósforo $(P)$, potássio $(K)$, cálcio (Ca), magnésio ( $\mathrm{Mg}$ ) e enxofre $(\mathrm{S})$ na haste do feijoeiro em função da fenologia referente à dose de $135 \mathrm{~kg} /$ ha de nitrogênio.

26. Variação dos teores $(\%)$ de nitrogênio $(\mathrm{N})$, fósforo $(\mathrm{P})$, potássio $(\mathrm{K})$, cálcio $(\mathrm{Ca})$, magnésio $(\mathrm{Mg})$ e enxofre $(\mathrm{S})$ na haste do feijoeiro em função da fenologia referente à dose de $180 \mathrm{~kg} / \mathrm{ha}$ de nitrogênio.

27. Variação dos teores $(\%)$ de nitrogênio $(\mathrm{N})$, fósforo $(\mathrm{P})$, potássio $(\mathrm{K})$, cálcio (Ca), magnésio $(\mathrm{Mg})$ e enxofre $(\mathrm{S})$ na folha do feijoeiro em função da fenologia referente à testemunha $(0 \mathrm{~kg} / \mathrm{ha}$ de nitrogênio $)$.

28. Variação dos teores $(\%)$ de nitrogênio $(\mathrm{N})$, fósforo $(\mathrm{P})$, potássio $(\mathrm{K})$, cálcio $(\mathrm{Ca})$, magnésio $(\mathrm{Mg})$ e enxofre $(\mathrm{S})$ na folha do feijoeiro em função da fenologia referente à dose de $45 \mathrm{~kg} / \mathrm{ha}$ de nitrogênio.

29. Variação dos teores $(\%)$ de nitrogênio $(N)$, fósforo $(P)$, potássio $(K)$, cálcio $(\mathrm{Ca})$, magnésio $(\mathrm{Mg})$ e enxofre $(\mathrm{S})$ na folha do feijoeiro em função da fenologia referente à dose de $90 \mathrm{~kg} / \mathrm{ha}$ de nitrogênio.

30. Variação dos teores $(\%)$ de nitrogênio $(N)$, fósforo $(P)$, potássio $(K)$, cálcio $(\mathrm{Ca})$, magnésio $(\mathrm{Mg})$ e enxofre $(\mathrm{S})$ na folha do feijoeiro em função da fenologia referente à dose de $135 \mathrm{~kg} / \mathrm{ha}$ de nitrogênio.

31. Variação dos teores $(\%)$ de nitrogênio $(N)$, fósforo $(P)$, potássio $(K)$, cálcio (Ca), magnésio $(\mathrm{Mg})$ e enxofre $(\mathrm{S})$ na folha do feijoeiro em função da fenologia referente à dose de $180 \mathrm{~kg} / \mathrm{ha}$ de nitrogênio.

32. Variação dos teores $(\%)$ de nitrogênio $(\mathrm{N})$, fósforo $(\mathrm{P})$, potássio $(\mathrm{K})$, cálcio (Ca), magnésio (Mg) e enxofre (S) no botão floral do feijoeiro em função da fenologia referente à testemunha $(0 \mathrm{~kg} / \mathrm{ha}$ de nitrogênio $)$.

33. Variação dos teores $(\%)$ de nitrogênio $(\mathrm{N})$, fósforo $(\mathrm{P})$, potássio $(\mathrm{K})$, cálcio (Ca), magnésio $(\mathrm{Mg})$ e enxofre (S) no botão floral do feijoeiro em função da fenologia referente à dose de $45 \mathrm{~kg} / \mathrm{ha}$ de nitrogênio. 
34. Variação dos teores $(\%)$ de nitrogênio $(\mathrm{N})$, fósforo $(\mathrm{P})$, potássio $(\mathrm{K})$, cálcio (Ca), magnésio (Mg) e enxofre (S) no botão floral do feijoeiro em função da fenologia referente à dose de $90 \mathrm{~kg} / \mathrm{ha}$ de nitrogênio.

35. Variação dos teores $(\%)$ de nitrogênio $(N)$, fósforo $(P)$, potássio $(K)$, cálcio (Ca), magnésio (Mg) e enxofre (S) no botão floral do feijoeiro em função da fenologia referente à dose de $135 \mathrm{~kg} /$ ha de nitrogênio.

36. Variação dos teores $(\%)$ de nitrogênio $(\mathrm{N})$, fósforo $(\mathrm{P})$, potássio $(\mathrm{K})$, cálcio $(\mathrm{Ca})$, magnésio $(\mathrm{Mg})$ e enxofre (S) no botão floral do feijoeiro em função da fenologia referente à dose de $180 \mathrm{~kg} / \mathrm{ha}$ de nitrogênio.

37. Variação dos teores $(\%)$ de nitrogênio $(N)$, fósforo $(P)$, potássio $(K)$, cálcio (Ca), magnésio ( $\mathrm{Mg}$ ) e enxofre (S) na vagem do feijoeiro em função da fenologia referente à testemunha $(0 \mathrm{~kg} / \mathrm{ha}$ de nitrogênio).

38. Variação dos teores $(\%)$ de nitrogênio $(\mathrm{N})$, fósforo $(\mathrm{P})$, potássio $(\mathrm{K})$, cálcio (Ca), magnésio (Mg) e enxofre (S) na vagem do feijoeiro em função da fenologia referente à dose de $45 \mathrm{~kg} / \mathrm{ha}$ de nitrogênio.

39. Variação dos teores $(\%)$ de nitrogênio $(\mathrm{N})$, fósforo $(\mathrm{P})$, potássio $(\mathrm{K})$, cálcio (Ca), magnésio (Mg) e enxofre (S) na vagem do feijoeiro em função da fenologia referente à dose de $90 \mathrm{~kg} / \mathrm{ha}$ de nitrogênio.

40. Variação dos teores $(\%)$ de nitrogênio $(\mathrm{N})$, fósforo $(\mathrm{P})$, potássio $(\mathrm{K})$, cálcio $(\mathrm{Ca})$, magnésio $(\mathrm{Mg})$ e enxofre $(\mathrm{S})$ na vagem do feijoeiro em função da fenologia referente à dose de $135 \mathrm{~kg} / \mathrm{ha}$ de nitrogênio.

41. Variação dos teores $(\%)$ de nitrogênio $(N)$, fósforo $(P)$, potássio $(K)$, cálcio (Ca), magnésio (Mg) e enxofre (S) na vagem do feijoeiro em função da fenologia referente à dose de $180 \mathrm{~kg} /$ ha de nitrogênio.

42. Teores $(\%)$ de nitrogênio $(\mathrm{N})$, fósforo $(\mathrm{P})$, potássio $(\mathrm{K})$, cálcio $(\mathrm{Ca})$, magnésio (Mg) e enxofre (S) no grão do feijoeiro referentes à (A) $0 \mathrm{~kg} / \mathrm{ha}$ de nitrogênio, (B) $45 \mathrm{~kg} / \mathrm{ha}$ de nitrogênio, (C) $90 \mathrm{~kg} / \mathrm{ha}$ de nitrogênio, (D) $135 \mathrm{~kg} / \mathrm{ha}$ de nitrogênio, e (E) $180 \mathrm{~kg} / \mathrm{ha}$ de nitrogênio. 
43. Teores médios (\%) (média de todos os tratamentos) de nitrogênio $(\mathrm{N})$, fósforo $(\mathrm{P})$, potássio $(\mathrm{K})$, cálcio $(\mathrm{Ca})$, magnésio $(\mathrm{Mg})$ e enxofre $(\mathrm{S})$ na haste (A), folha (B), botão floral (C), vagem (D) e grão (E) do feijoeiro em função da fenologia. 


\section{LISTA DE TABELAS}

Página

1. Sintomas de deficiência e função dos macronutrientes minerais primários (Thung \& Oliveira, 1998, Vitti et al., 1999).

2. Sintomas de deficiência e função dos macronutrientes minerais secundários (Thung \& Oliveira, 1998, Vitti et al., 1999).

3. Fenologia da cultura de feijão (Phaseolus vulgaris L.) (CIAT, 1981; Gepts \& Fernández, 1982; Fancelli \& Dourado-Neto, 1997, 1999).

4. Modelos referentes à altura de planta (Ap), em função do número de dias após a semeadura, para o feijoeiro sob condição de irrigação e de sequeiro.

5. Modelos referentes à massa de matéria seca de raiz (Mr), de folha (Mf), de haste (Mh), de vagem (Mv) e total (Mt), em função do número de dias após a semeadura, para o feijoeiro sob condição de irrigação.

6. Modelos referentes à massa de matéria seca de raiz ( $\mathrm{Mr})$, de folha (Mf), de haste (Mh), de vagem (Mv) e total (Mt), em função do número de dias após a semeadura, para o feijoeiro sob condição de sequeiro.

7. Modelos referentes à massa de matéria seca de raiz (Mr), de folha (Mf), de haste (Mh), de botão floral (Mb), de vagem (Mv) e total (Mt), em função do desenvolvimento relativo da cultura (Dr) de feijão.

8. Fenologia observada da cultura de feijão (Experimento I).

9. Altura de planta $(\mathrm{cm})$ referente à cultura de feijão especificando a data, a repetição (R: 1,2,3,4), e os tratamentos (I: irrigado; $\mathrm{S}$ : sequeiro).

10. Análise de variância e parâmetros empíricos (a, b, c e d) referentes ao modelo para estimativa da altura de planta $(\mathrm{Ap}, \mathrm{cm})$ do feijoeiro sob irrigação em função do número de dias após semeadura (DAS).

11. Análise de variância e parâmetros empíricos ( $a, b, c$ e d) referentes ao modelo para estimativa da altura das plantas $(\mathrm{Ap}, \mathrm{cm})$ do feijoeiro sob condição de sequeiro em função do número de dias após semeadura (DAS). 
12. Análise de variância e parâmetros empíricos (a, b, c e d) referentes ao modelo para estimativa da massa das raizes $(\mathrm{Mr}, \mathrm{g} / 5 \mathrm{pl})$ do feijoeiro sob irrigação em função do número de dias após semeadura (DAS).

13. Análise de variância e parâmetros empíricos (a, b, c e d) referentes ao modelo para estimativa da massa de matéria seca das raizes $(\mathrm{Mr}, \mathrm{g} / 5 \mathrm{pl})$ do feijoeiro sob condição de sequeiro em função do número de dias após semeadura (DAS).

14. Análise de variância e parâmetros empíricos (a, b, c e d) referentes ao modelo para estimativa da massa de matéria seca das folhas (Mf, $\mathrm{g} / 5 \mathrm{pl}$ ) do feijoeiro sob irrigação em função do número de dias após semeadura (DAS).

15. Análise de variância e parâmetros empíricos ( $a, b, c$ e d) referentes ao modelo para estimativa da massa de matéria seca de das folhas (Mf, $\mathrm{g} / 5 \mathrm{pl}$ ) do feijoeiro em condição de sequeiro em função do número de dias após semeadura (DAS).

16. Análise de variância e parâmetros empíricos ( $a, b, c$ e d) referentes ao modelo para estimativa da massa de matéria seca das hastes $(\mathrm{Mh}, \mathrm{g} / 5 \mathrm{pl})$ do feijoeiro sob irrigação em função do número de dias após semeadura (DAS).

17. Análise de variância e parâmetros empíricos ( $a, b, c$ e d) referentes ao modelo para estimativa da massa de matéria seca das hastes $(\mathrm{Mh}, \mathrm{g} / 5 \mathrm{pl})$ do feijoeiro sob condição de sequeiro em função do número de dias após semeadura (DAS).

18. Análise de variância e parâmetros empíricos (a, b, c e d) referentes ao modelo para estimativa da massa de matéria seca das vagens $(\mathrm{Mv}, \mathrm{g} / 5 \mathrm{pl})$ do feijoeiro sob irrigação em função do número de dias após semeadura (DAS).

19. Análise de variância e parâmetros empíricos (a, b, c e d) referentes ao modelo para estimativa da massa das vagens $(\mathrm{Mv}, \mathrm{g} / 5 \mathrm{pl})$ em função do número de dias após semeadura (DAS). 
20. Análise de variância e parâmetros empíricos (a, b, c e d) referentes ao modelo para estimativa da massa de matéria seca total ( $\mathrm{Mt}, \mathrm{g})$ do feijoeiro sob irrigação em função do número de dias após semeadura (DAS).

21. Análise de variância e parâmetros empíricos ( $a, b, c$ e d) referentes ao modelo para estimativa da massa de matéria seca total (Mt, g) do feijoeiro sob condição de sequeiro em função do número de dias após semeadura (DAS).

22. Dias após a emergência (DAE), temperatura média do ar $\left(\mathrm{T},{ }^{\circ} \mathrm{C}\right)$, estádio fenológico, graus-dia (GD, ${ }^{\circ} \mathrm{C}$.dia) e desenvolvimento relativo (Dr) da cultura de feijão durante a fase vegetativa (0).

23. Dias após a emergência (DAE), temperatura média do ar $\left(\mathrm{T},{ }^{\circ} \mathrm{C}\right)$, estádio fenológico, graus-dia (GD, ${ }^{\circ} \mathrm{C}$.dia) e desenvolvimento relativo (Dr) da cultura de feijão durante a fase reprodutiva (1).

24. Análise de variância e parâmetros empíricos (a, b, c, d e e) referentes ao modelo para estimativa da massa de matéria seca de folha (Mf, $\mathrm{g} / 5 \mathrm{pl}$ ) do feijoeiro sob irrigação em função do desenvolvimento relativo da cultura (Dr).

25. Análise de variância e parâmetros empíricos (a, b, c, d e e) referentes ao modelo para estimativa da massa de matéria seca das hastes $(\mathrm{Mh}, \mathrm{g} / 5 \mathrm{pl})$ do feijoeiro sob irrigação em função do desenvolvimento relativo da cultura (Dr).

26. Análise de variância e parâmetros empíricos ( $\mathrm{a}$ e b) referentes ao modelo para estimativa da massa de matéria seca de vagem $(\mathrm{Mv}, \mathrm{g} / 5 \mathrm{pl})$ do feijoeiro sob irrigação em função do desenvolvimento relativo da cultura (Dr).

27. Análise de variância e parâmetros empíricos (a, b e c) referentes ao modelo para estimativa da massa de matéria seca total (Mt, g/5 pl) do feijoeiro sob irrigação em função do desenvolvimento relativo da cultura (Dr). 
28. Radiação solar (Rs, cal/ $\mathrm{cm}^{2}$.dia), insolação (I, horas/dia), chuva (C, mm), umidade relativa (UR, \%), velocidades do vento máxima $(V \max , \mathrm{km} / \mathrm{h}$ ) e média (Vmed, $\mathrm{m} / \mathrm{s})$, temperaturas máxima $\left(\mathrm{T} \max ,{ }^{\circ} \mathrm{C}\right)$, mínima $\left(\mathrm{Tmin},{ }^{\circ} \mathrm{C}\right) \mathrm{e}$ média (Tmed, ${ }^{\circ} \mathrm{C}$ ), evaporação do tanque classe $\mathrm{A}$ e direção do vento (Dv) às $7\left(D_{7}\right), 14\left(D_{14}\right)$ e $21\left(D_{21}\right)$ horas referentes ao mês de abril de $1995 \mathrm{em}$ Piracicaba, SP.

29. Radiação solar (Rs, cal/cm².dia), insolação (I, horas/dia), chuva (C, mm), umidade relativa (UR, \%), velocidades do vento máxima (Vmax, $\mathrm{km} / \mathrm{h}$ ) e média (Vmed, $\mathrm{m} / \mathrm{s})$, temperaturas máxima $\left(\mathrm{Tmax},{ }^{\circ} \mathrm{C}\right)$, mínima $\left(\mathrm{Tmin},{ }^{\circ} \mathrm{C}\right) \mathrm{e}$ média (Tmed, ${ }^{\circ} \mathrm{C}$ ), evaporação do tanque classe $\mathrm{A}$ e direção do vento (Dv) às $7\left(D_{7}\right), 14\left(D_{14}\right)$ e $21\left(D_{21}\right)$ horas referentes ao mês de maio de $1995 \mathrm{em}$ Piracicaba, SP.

30. Radiação solar (Rs, cal/ $\mathrm{cm}^{2}$.dia), insolação (I, horas/dia), chuva $(\mathrm{C}, \mathrm{mm})$, umidade relativa (UR, \%), velocidades do vento máxima (Vmax, $\mathrm{km} / \mathrm{h}$ ) e média (Vmed, $\mathrm{m} / \mathrm{s})$, temperaturas máxima $\left(\mathrm{T} \max ,{ }^{\circ} \mathrm{C}\right)$, mínima $\left(\mathrm{T} m i n,{ }^{\circ} \mathrm{C}\right) \mathrm{e}$ média (Tmed, ${ }^{\circ} \mathrm{C}$ ), evaporação do tanque classe A e direção do vento (Dv) às $7\left(D_{7}\right), 14\left(D_{14}\right)$ e $21\left(D_{21}\right)$ horas referentes ao mês de junho de 1995 em Piracicaba, SP.

31. Radiação solar (Rs, cal/ $\mathrm{cm}^{2}$.dia), insolação (I, horas/dia), chuva (C, mm), umidade relativa (UR, \%), velocidades do vento máxima $(V \max , \mathrm{km} / \mathrm{h}$ ) e média (Vmed, $\mathrm{m} / \mathrm{s}$ ), temperaturas máxima $\left(\mathrm{Tmax},{ }^{\circ} \mathrm{C}\right)$, mínima $\left(\mathrm{Tmin},{ }^{\circ} \mathrm{C}\right) \mathrm{e}$ média (Tmed, ${ }^{\circ} \mathrm{C}$ ), evaporação do tanque classe $\mathrm{A}$ e direção do vento (Dv) às $7\left(D_{7}\right), 14\left(D_{14}\right)$ e $21\left(D_{21}\right)$ horas referentes ao mês de julho de $1995 \mathrm{em}$ Piracicaba, SP.

32. Radiação solar (Rs, cal/ $\mathrm{cm}^{2}$.dia), insolação (I, horas/dia), chuva $(\mathrm{C}, \mathrm{mm})$, umidade relativa (UR, \%), velocidades do vento máxima (Vmax, $\mathrm{km} / \mathrm{h}$ ) e média $(V m e d, \mathrm{~m} / \mathrm{s})$, temperaturas máxima $\left(\mathrm{Tmax},{ }^{\circ} \mathrm{C}\right)$, mínima $\left(\mathrm{Tmin},{ }^{\circ} \mathrm{C}\right) \mathrm{e}$ média (Tmed, ${ }^{\circ} \mathrm{C}$ ), evaporação do tanque classe A e direção do vento (Dv) às $7\left(D_{7}\right), 14\left(D_{14}\right)$ e $21\left(D_{21}\right)$ horas referentes ao mês de agosto de 1995 em Piracicaba, SP. 


\section{FEIJÃO: CARACTERIZAÇÃO FITOTÉCNICA, EXTRAÇÃO E EXPORTAÇÃO DE MACRONUTRIENTES}

Autor: Mário da Silva Teles Neto

Orientador: Prof. Durval Dourado Neto

\section{RESUMO}

Com o objetivo de caracterizar a partição de massa de matéria seca com e sem irrigação (Experimento I) e de definir a quantidade total de macronutriente absorvido e exportado (Experimento II) pela cultura de feijão, um experimento de campo foi conduzido, utilizando a variedade Carioca, na área experimental do Departamento de Produção Vegetal (ESALQ, Universidade de São Paulo) localizada em Piracicaba, SP. A análise de crescimento da cultura foi feita com mensurações quinzenais de (i) altura de planta, (ii) massa de matéria seca de raiz, haste, folha, vagem e total, e (iii) rendimento de grãos (Experimento I) e mensurações do (i) teor de nitrogênio, fósforo, potássio, cálcio, magnésio e enxofre em diferentes órgãos, (ii) massa de matéria seca de haste, folha, botão floral e vagem, e (iii) rendimento de grãos (Experimento II). Modelos empíricos foram propostos para estimar a massa de matéria seca de diferentes órgãos como função do número de dias após a semeadura (Experimento I), e para determinar a absorção total, máxima taxa de absorção e exportação de macronutrientes (Experimento II). Os resultados permitiram concluir que os modelos propostos são úteis para estimar a massa de matéria seca total e parcial, a quantidade necessária de fertilizante para manutenção de rendimento (em função do grão exportado), periodo crítico de matocompetição e estádio fenológico crítico para aplicação de fertilizante em cobertura. 


\section{COMMON BEAN: FITOTECHNICAL CARACTHERIZATION, AND MACRONUTRIENTS EXTRACTION AND EXPORTATION}

Author: Mário da Silva Teles Neto Adviser: Prof. Durval Dourado Neto

\section{SUMMARY}

With the purpose of characterizing the dry matter mass partition with and without irrigation (Experiment I) and of defining the total quantity of uptaked and exported macronutrients (Experiment II) by common bean crop, a field experiment was carried out, using the cultivar Carioca, at Crop Production Department (ESALQ, Univerisity of São Paulo) experimental area located in Piracicaba, SP, Brazil. The crop growth analysis was done with measurements each fifteen days of (i) plant height, (ii) root, stem, leaf, legume and total dry matter mass, and (iii) grain yield (Experiment I) and measurements of (i) nitrogen, phosphorus, potassium, calcium, magnesium and sulfur contents in different organs, (ii) stem, leaf, flower and legume dry matter mass, and (iii) grain yield (Experiment II). Empirical models were proposed to estimate the dry matter mass of different organs as function of day after sowing date (Experiment I), and to determine the accumulated uptake, maximum uptake rate and macronutrients exportation (Experiment II). The results allow to conclude that the proposed models are useful to estimated total and partial dry matter mass, the needed amount of fertilizer to remain yield (as function of the grain exportation), critical period of weeds competition and the critical phenologic stage to apply fertilizers after emergence. 


\section{INTRODUÇÃO}

O feijão (Phaseolus vulgaris L.) ainda é um importante componente da dieta alimentar do brasileiro, apesar de ter havido, nos últimos cinco anos, declínio no consumo per capita. O Brasil é o maior produtor mundial de feijão (produção anual em torno de três milhões de toneladas) com área total anual de 5,5 milhões de hectares (época das águas, seca e inverno com irrigação). O estado da Bahia se destaca como grande produtor, devido à maior área plantada (cerca de $750.000 \mathrm{ha}$ ) do Brasil (as regiões de Irecê e Barreiras são grandes produtoras) e à agricultura irrigada (60.000 ha). $\mathrm{O}$ volume de produção baiano exerce influência no preço no mercado brasileiro. $\mathrm{O}$ feijoeiro é cultivado por um grande número de agricultores, que exploram diferentes áreas, utilizando diferentes ambientes sociais, econômicos e físicos, bem como diferentes sistemas de produção.

O sistema de produção relativo à cultura de feijão tem apresentado grande evolução na última década, principalmente em função de se utilizar alta tecnologia (a cultura de feijão é uma das principais alternativas em agricultura irrigada). Porém, cada vez mais exige-se um manejo fundamentado em princípios com uma visão global do sistema agrícola.

A busca de uma agricultura racional e sustentável deve ser baseada numa formação científica sólida do Engenheiro Agrônomo, o qual deve estar atualizado e preocupado com intercâmbio de experiência, com a importância da observação, e com a capacidade de integrar informação e conhecimento. Sendo o manejo da fertilidade do solo, associado a condicionantes climáticos, ocorrência de pragas e doenças, um dos fatores que mais limitam o rendimento, deve-se proceder histórico da área, a amostragem e a análise química do solo, e as práticas corretivas e de manutenção. 
O rendimento médio de grãos de feijão no Brasil varia de $600 \mathrm{~kg} / \mathrm{ha}$ (agricultura de sequeiro) a $3000 \mathrm{~kg} / \mathrm{ha}$ (agricultura irrigada), com conseqüente alteração do índice de colheita.

O presente trabalho tem por objetivos propor modelos fitotécnicos para (i) caracterizar altura de planta e a partição da produção de massa de matéria seca de raiz, folha, haste, vagem e total com deficiência e suficiência hídrica (Experimento I caracterização fitotécnica) e (ii) determinar a ordem de grandeza da extração e exportação da cultura de feijão (Experimento II) no intuito de nortear ações de manejo. 


\section{REVISÃo DE LITERATURA}

\subsection{Aspectos nutricionais do feijoeiro}

Como toda planta, o feijoeiro necessita de carbono, hidrogênio e oxigênio (macronutrientes orgânicos), os quais são fornecidos pela atmosfera (gás oxigênio, gás dióxido de carbono e água), nitrogênio (suprimento através do manejo da matéria orgânica utilizando rotação de culturas, fixação simbiótica e adubação mineral), fósforo, potássio, cálcio, magnésio, enxofre, boro, cloro, cobre, ferro, manganês, molibdênio e zinco (fornecimento através da adubação mineral e orgânica) (Marschner, 1986).

Para obtenção do rendimento econômico relativo à exploração da cultura de feijão, é necessário uma adubação balanceada. O usual é fazer a correção da camada superficial com calcário e da camada subsuperficial com gesso (Souza et al., 1996). Um vez feita a calagem, o usual é fornecer nutrientes através da adubação química, principalmente, e orgânica.

Segundo Cantarella et al. (1996), para rendimento de 900 a $2500 \mathrm{~kg} / \mathrm{ha}$, a planta inteira absorve 102, 9, 94 e $15 \mathrm{~kg} / \mathrm{ha}$ de nitrogênio, fósforo, potássio e enxofre, respectivamente, enquanto que a exportação é, respectivamente, de $41,4,9$, e $10 \mathrm{~kg} / \mathrm{ha}$.

Segundo Malavolta \& Lima Filho (1997), para a produção de $1500 \mathrm{~kg} / \mathrm{ha}$ de grãos (população: 250.000 plantas/ha) são extraídos e exportados, respectivamente, (i) nitrogênio: 101 e $34 \mathrm{~kg} / \mathrm{ha}$, (ii) fósforo: 9 e $3 \mathrm{~kg} / \mathrm{ha}$, (iii) potássio: 92 e $20 \mathrm{~kg} / \mathrm{ha}$, (iv) cálcio: 54 e $4 \mathrm{~kg} / \mathrm{ha}$, (v) magnésio: 18 e $4 \mathrm{~kg} / \mathrm{ha}$, e (vi) enxofre: 25 e $9 \mathrm{~kg} / \mathrm{ha}$. Sendo assim, o feijoeiro proporciona na devolução dos restos culturais o retorno de cerca de 67 $\mathrm{kg} / \mathrm{ha}$ de nitrogênio, $5 \mathrm{~kg} / \mathrm{ha}$ de fósforo, $78 \mathrm{~kg} / \mathrm{ha}$ de potássio, $51 \mathrm{~kg} / \mathrm{ha}$ de cálcio, 15 $\mathrm{kg} / \mathrm{ha}$ de magnésio e $9 \mathrm{~kg} / \mathrm{ha}$ de enxofre (Oliveira \& Costa, 1998). 
O feijoeiro, no período entre 45 e 55 dias (período pré-florescimento) após a emergência, acumula diariamente cerca de $67 \mathrm{~kg}$ de matéria seca em média (Cobra Neto et al., 1971).

\subsection{Sintomas de deficiência e função dos macronutrientes minerais}

O conhecimento dos sintomas de deficiência e das funções dos macronutrientes minerais (Tabela 1 e Tabela 2) é de fundamental importância para o produtor rural e para o pesquisador (Thung \& Oliveira, 1998, Vitti et al., 1999).

Tabela 1. Sintomas de deficiência e função dos macronutrientes minerais primários (Thung \& Oliveira, 1998, Vitti et al., 1999).

\begin{tabular}{|l|l|}
\hline Nutriente & \multicolumn{1}{|c|}{ Sintoma de deficiência e função } \\
\hline Nitrogênio & $\begin{array}{l}\text { Sintoma de deficiência: mudança na cor da folha (verde para verde pálida). Sintomas } \\
\text { ocorrem nas folhas inferiores e depois se espalham por toda a planta. Em deficiência } \\
\text { persistente, a cor muda para intenso amarelo-limão uniformemente por toda a lâmina foliar. } \\
\text { Em estágios avançados, manchas marrons se desenvolvem gradualmente por todas as } \\
\text { folhas, semelhantes ao estádio de senescência, ocorrendo morte prematura. As folhas são } \\
\text { menores, e o crescimento da planta é retardado. } \\
\text { Funcão: Constituinte de aminoácidos e proteínas. }\end{array}$ \\
\hline Fósforo & $\begin{array}{l}\text { Sintoma de deficiência: folhas velhas se tormam amarelas e, posteriormente, necróticas e } \\
\text { senescentes. A planta tem o crescimento reduzido, apresentando internódios curtos e } \\
\text { números reduzidos de ramos. O florescimento é retardado e poucas vagens são produzidas. } \\
\text { Maturidade é atrasada. Deficiência de fósforo combinada com estresse de água causa o } \\
\text { aparecimento de folhas verde escuras (produção de clorofila é menos afetada no começo do } \\
\text { estresse de fósforo e o acúmulo de clorofila, com uma pequena expansão da folha, produz } \\
\text { uma cor verde típica). } \\
\text { Funcaão: componente básico de carboidratos fosforilados, nucleotídeos, fosfolipideos e } \\
\text { enzimas envolvidas no uso de energia. }\end{array}$ \\
\hline Potássio & $\begin{array}{l}\text { Sintoma de deficiência: margens de folhas velhas amarelas e, com o avanço da idade da } \\
\text { planta, as pontas e as margens das folhas ficam necróticas. Ocorre amarelecimento } \\
\text { internerval, com maior severidade em direção à ponta da folha. } \\
\text { Funcão: ativador de várias enzimas, como as que participam do desdobramento dos } \\
\text { açúcares na respiração e aquelas responsáveis pela síntese do amido e proteinas. }\end{array}$ \\
\hline
\end{tabular}


Tabela 2. Sintomas de deficiência e função dos macronutrientes minerais secundários (Thung \& Oliveira, 1998, Vitti et al., 1999).

\begin{tabular}{|l|l|}
\hline Nutriente & \multicolumn{1}{|c|}{ Sintoma de deficiência e função } \\
\hline Magnésio & $\begin{array}{l}\text { Sintomas de deficiência: clorose internervural intensa. Com o aumento da severidade, as } \\
\text { margens das folhas ficam encarquilhadas (sintomas podem se espalhar pela planta inteira } \\
\text { incluindo as partes jovens). } \\
\text { Funcão: Constituinte da clorofila. }\end{array}$ \\
\hline Enxofre & $\begin{array}{l}\text { Sintomas de deficiência: coloração pálida uniforme nas folhas primárias (similar à } \\
\text { deficiência de nitrogênio). Os foliolos caem com facilidade com a evolução da deficiência. } \\
\text { Função: componente de aminoácidos (cistina, cisteina, metionina). Participa do } \\
\text { metabolismo de vitaminas. }\end{array}$ \\
\hline Cálcio & $\begin{array}{l}\text { Sintomas de deficiência: deficiência isolada difícil de ser encontrada (deficiências de cálcio } \\
\text { ocorrem em solos ácidos e é mascarada pelas deficiências conjuntas de fósforo e cálcio, } \\
\text { juntamente com toxicidade de aluminio, afetando principalmente o sistema radicular). } \\
\text { Função: constituinte da parede celular das calcideslinas. }\end{array}$ \\
\hline
\end{tabular}

\subsection{Avaliação da fertilidade do solo através da diagnose foliar}

A diagnose da fertilidade do solo indicada pela deficiência nutricional pode ser utilizada para definir a natureza da deficiência e decidir sobre a correção nutricional para a planta. Para tal, recomenda-se coletar de 30 a 40 folhas da área representativa, que deverão ser colhidas do terço médio da planta, no florescimento (Rosolém \& Marubayashi, 1994); ou que seja colhida todas as folhas de dez plantas no florescimento (Wutke et al., 1996).

Os teores adequados para a cultura do feijão, encontrados nas folhas do feijoeiro, variam de autor para autor: (i) nitrogênio: 3,0 a 5,0\% (Ambrosano et al., 1996), e 2,8 a 6,0\% (Embrapa, 1998), (ii) fósforo: 0,25 a 0,40\% (Ambrosano et al., 1996), 0,20 a 0,30\% (Coamo, 1998), e 0,25 a 0,50\% (Embrapa, 1998), (iii) potássio: 2,0 a 2,4\% (Ambrosano et al., 1996), 2,0 a 2,5\% (Coamo, 1998), e 1,80 a 2,50\% (Embrapa, 1998), (iv) cálcio: 1,0 a 2,5\% (Ambrosano et al., 1996), 1,5 a 2,0\% (Coamo, 1998), e 0,8 a 3,0 \% (Embrapa, 1998), (v) magnésio: 0,25 a 0,50\% (Ambrosano et al., 1996), 0,4 a 0,7\% (Coamo, 1998), e 0,25 a 0,70\% (Embrapa, 1998), (vi) enxofre: 0,20 a $0,30 \%$ (Ambrosano et al., 1996), 0,5 a 1,0\% (Coamo, 1998), e 0,20 a 0,25\% (Embrapa, 1998).

A interpretação da análise de solo é variável em função da região (ou do estado) e da instituição de pesquisa: (i) São Paulo (Raij et al., 1996): (a) teor muito baixo 
(rendimento relativo inferior ou igual a $70 \%$ ): até $0,7 \mathrm{mmol}_{\mathrm{d}} / \mathrm{dm}^{3}$ de potássio, até 6 $\mathrm{mg} / \mathrm{dm}^{3}$ de fósforo (resina), e até $2,5 \mathrm{mg} / \mathrm{dm}^{3}$ de S-SO ${ }_{4}\left[\mathrm{Ca}\left(\mathrm{H}_{2} \mathrm{PO}_{4}\right)_{2}, 500 \mathrm{ppm} \mathrm{P],} \mathrm{(b)}\right.$ teor baixo (rendimento relativo entre 71 e $90 \%$ ): 0,8 a $1,5 \mathrm{mmol}_{\mathrm{d}} / \mathrm{dm}^{3}$ de potássio, 7 a 15 $\mathrm{mg} / \mathrm{dm}^{3}$ de fósforo (resina), 2,5 a $5,0 \mathrm{mg} / \mathrm{dm}^{3}$ de S-SO ${ }_{4}\left[\mathrm{Ca}\left(\mathrm{H}_{2} \mathrm{PO}_{4}\right)_{2}, 500 \mathrm{ppm} \mathrm{P}\right.$, (c) teor médio (rendimento relativo entre 91 e $100 \%$ ): 1,6 a $3,0 \mathrm{mmol}_{\mathrm{d}} / \mathrm{dm}^{3}$ de potássio, 16 a $40 \mathrm{mg} / \mathrm{dm}^{3}$ de fósforo (resina), 5,0 a $10,0 \mathrm{mg} / \mathrm{dm}^{3}$ de S-SO $\mathrm{SO}_{4}\left[\mathrm{Ca}\left(\mathrm{H}_{2} \mathrm{PO}_{4}\right)_{2}, 500 \mathrm{ppm} \mathrm{P}\right]$, e (d) teor alto (rendimento relativo igual a $100 \%$ ): superior a $3,0 \mathrm{mmol} / \mathrm{dm}^{3}$ de potássio, superior a $40 \mathrm{mg} / \mathrm{dm}^{3}$ de fósforo (resina), superior a $10 \mathrm{mg} / \mathrm{dm}^{3}$ de $\mathrm{S}_{-} \mathrm{SO}_{4}\left[\mathrm{Ca}\left(\mathrm{H}_{2} \mathrm{PO}_{4}\right)_{2}\right.$, 500 ppm P]; (ii) cerrado (Souza et al., 1997): fósforo extraído pelo método Mehlich I (interpretação dos teores de fósforo dependente do teor de argila no solo): (a) teor de argila entre 61 e $80 \%$ : muito baixo para teor de $P$ até $1,1 \mathrm{mg} / \mathrm{dm}^{3}$, baixo para teor de $P$ entre 1,1 e $2,0 \mathrm{mg} / \mathrm{dm}^{3}$, médio para teor de $P$ entre 2,1 e $3,0 \mathrm{mg} / \mathrm{dm}^{3}$ e bom para teor de P superior a $3,0 \mathrm{mg} / \mathrm{dm}^{3}$, (b) teor de argila entre 41 e $60 \%$ : muito baixo até $3,0 \mathrm{mg} / \mathrm{dm}^{3}$, baixo entre 3,1 e $6,0 \mathrm{mg} / \mathrm{dm}^{3}$, médio entre 6,1 e 8,0 , e bom para superior a $8,0 \mathrm{mg} / \mathrm{dm}^{3}$, (c) teor de argila entre 21 e $40 \%$ : muito baixo até $5,0 \mathrm{mg} / \mathrm{dm}^{3}$, baixo entre 5,1 e 10,0 $\mathrm{mg} / \mathrm{dm}^{3}$, médio entre 10,1 e $14,0 \mathrm{mg} / \mathrm{dm}^{3}$, e bom para superior a $14,0 \mathrm{mg} / \mathrm{dm}^{3}$, (d) teor de argila inferior a $20 \%$ : muito baixo até 6,0 , baixo entre $6,1 \mathrm{e} 12,0 \mathrm{mg} / \mathrm{dm}^{3}$, médio entre 12,1 e $18,0 \mathrm{mg} / \mathrm{dm}^{3}$, e bom para superior a $18,0 \mathrm{mg} / \mathrm{dm}^{3}$. Potássio extraído pelo método de Mehlich I): (a) teor muito baixo: teor de potássio até $25 \mathrm{mg} / \mathrm{dm}^{3}$, (b) teor baixo: entre 26 e $50 \mathrm{mg} / \mathrm{dm}^{3}$, (c) teor médio: entre 51 e $80 \mathrm{mg} / \mathrm{dm}^{3}$, e (d) teor bom: superior a 80 $\mathrm{mg} / \mathrm{dm}^{3}$; (iii) Paraná (Coamo \& Coodetec, 1998): (a) teor baixo: teor inferior a 2,0 $\mathrm{mg} / \mathrm{dm}^{3} \mathrm{de} \mathrm{P}$, e inferior a $10,0 \mathrm{cmol}_{\mathrm{d}} / \mathrm{dm}^{3} \mathrm{de} \mathrm{K}$; (b) teor médio: entre 2,1 e $5,0 \mathrm{mg} / \mathrm{dm}^{3} \mathrm{de}$ $P$, e entre 0,11 e $0,30 \mathrm{cmol}_{d} / \mathrm{dm}^{3}$ de $\mathrm{K}$; (c) teor alto: entre 5,1 e $13,0 \mathrm{mg} / \mathrm{dm}^{3}$ de P, e 0,31 e $0,60 \mathrm{cmol} / \mathrm{dm}^{3} \mathrm{de} \mathrm{K}$, e (d) teor muito alto: superior a $13,0 \mathrm{mg} / \mathrm{dm}^{3}$ de $\mathrm{P}$, e superior a $0,60 \mathrm{cmol}_{\mathcal{C}} / \mathrm{dm}^{3}$ de K; (iv) Rio Grande do Sul e Santa Catarina (CFS-RS/SC, 1994); limites de interpretação dos teores de fósforo extraível do solo em função das diferentes classes do solo [(a) classe 1: superior a 55\% de argila e/ou solos. Erexim, Durox, Vacaria, Santo Ângelo, Aceguá, Pouso Redondo, Boa Vista, (b) classe 2: entre 41 e 55\% de argila e/ou solos. Passo Fundo franco-argiloso e argiloso, Estação, Oásis, Ciríaco, Associação Ciríaco-Charruá, São Borja, Vila, Farroupilha, Rancho Grande, Içara, (c) 
classe 3: entre 26 e $40 \%$ de argila e/ou solos. Passo Fundo franco-arenoso e arenoso, Júlio de Castilhos, São Jerônimo, Alto das Canas, São Gabriel, Canoinhas, Jacinto Machado, Lages, (d) classe 4:11 a 25\% de argila e/ou solos. Cruz Alta, Tupanciretã, Rio Pardo, Camaquã, Bagé, Bexigoso, Pelotas, São Pedro, Santa Maria, Pinheiro Machado, (e) classe 5: 10\% de argila e/ou solos. Bom Retiro, Tuia, Vacaçaí, e (f) Classe 6: Solos alagados (Arroz irrigado por inundação)]. Para cálcio e magnésio, respectivamente: (a) teor baixo: teor inferior a 2,0 e a $0,5 \mathrm{cmol}_{d} \mathrm{dm}^{3}$, (b) teor médio: entre 2,1 e 4,0 e entre 0,6 e $1,0 \mathrm{cmol}_{d} / \mathrm{dm}^{3}$, e (c) teor alto: teor superior a 4,0 e a 1,0. Para potássio: (a) teor limitante: inferior ou igual a $20,0 \mathrm{mg} \cdot \mathrm{dm}^{3}$, (b) teor muito baixo: entre 21,0 e $40,0 \mathrm{mg} \cdot \mathrm{dm}^{3}$, (c) teor baixo: entre 41,0 e $60,0 \mathrm{mg} \cdot \mathrm{dm}^{3}$, (d) teor médio: entre 61,0 e $80,0 \mathrm{mg} \cdot \mathrm{dm}^{3}$, (e) teor suficiente: entre 81,0 e $120,0 \mathrm{mg} \cdot \mathrm{dm}^{3}$, (f) teor alto: superior a $120,0 \mathrm{mg} \cdot \mathrm{dm}^{3}$; (v) Minas Gerais (CFSEMG, 1999): (a) cálcio $\left(\mathrm{cmol}_{\mathrm{d}} / \mathrm{dm}^{3}\right.$ ): teor muito baixo (inferior a 0,4), baixo (entre 0,4 e 1,2), médio (entre 1,2 e 2,4), bom (entre 2,4 e 4,0 ) e muito bom (superior a 4,0 ); e magnésio $\left(\mathrm{cmolc}^{\mathrm{d}} \mathrm{dm}^{3}\right.$ ): muito baixo (inferior a 0,15 ), baixo (entre 0,16 e 0,45), médio (entre 0,46 e 0,9), bom (entre 0,9 e 1,5) e muito bom (superior a 1,5). A interpretação da disponibilidade de fósforo é de acordo com o teor de argila do solo ou com o valor de fósforo remanescente. Para o potássio $\left(\mathrm{mmol}_{\mathrm{d}} / \mathrm{dm}^{3}\right.$ ): (a) teor muito baixo: inferior a 15, (b) teor baixo: entre 16 e 40 , (c) teor médio: entre 40 e 70, (d) teor bom: entre 70 e 120, e (e) teor muito bom: acima de 120 .

\subsection{Adubação verde e adubação orgânica}

Elevado teor de matéria orgânica no solo acarreta alto rendimento da cultura de feijão. Nesse sentido, apesar de não haver consenso, a produção de massa matéria seca vem sendo utilizada com diferentes espécies de adubos verdes. Vigna sp. e Crotalarea mucronata produzem, respectivamente, cerca de1000 e $27000 \mathrm{~kg} / \mathrm{ha}$ de massa matéria seca num período de 8 meses (Embrapa-Arroz e Feijão citado por Vitti et al., 1999).

Sistemas como rotação de cultura favorecem a redução da resistência do solo à penetração, a manutenção do teor normal de matéria orgânica do solo, a redução da acidez, e o aumento da saturação por bases em profundidade (Ambrosano et al., 2000), 
bem como para aumentar o rendimento das espécies envolvidas (Silveira \& Silva, 1996, Silveira et al., 1999).

Adubação orgânica com esterco apresenta efeito positivo em termos de rendimento do feijoeiro (Scherer \& Bartz, 1982, Ambrosano et al., 1996). Porém, a aplicação em extensas áreas apresenta limitações. A aplicação de $10000 \mathrm{~kg} / \mathrm{ha}$ de esterco de aves apresenta $570,378,300,860$ e $42 \mathrm{~kg} / \mathrm{ha}$ de nitrogênio, fósforo, potássio, cálcio e magnésio (Embrapa, 1998).

\subsection{Adubação nitrogenada}

Em função da baixa eficiência da fixação biológica de nitrogênio referente ao feijoeiro, na prática faz-se adubação mineral. No intuito de maximizar eficiência do nitrogênio proveniente do fertilizante, recomenda-se (Vitti et al., 1999, Lopes, 1999): (i) corrigir o solo com o fornecimento de cálcio e magnésio através da calagem, (ii) fornecer cerca de $33 \%$ do nitrogênio total por ocasião da semeadura e o restante quando a cultura apresentar $50 \%$ das plantas com pelo menos três trifólios completamente desenvolvidos (a enzima nitrogenase apresenta máxima eficiência de fixação em período anterior a da enzima nitrato redutase); e (iii) fornecer outros nutrientes associados ao processo de fixação biológica de nitrogênio, como fósforo, enxofre e molibdênio (seja via semente ou via foliar na fase de enchimento de grãos), principalmente.

As recomendações oficiais para o suprimento de nitrogênio para a cultura de feijão variam entre estados (ou regiões): (i) São Paulo (Ambrosano et al., 1996): (a) rendimento esperado: entre 1000 e $1500 \mathrm{~kg} / \mathrm{ha}: 0 \mathrm{~kg} / \mathrm{ha}$ de $\mathrm{N}$ (adubação na semeadura). Classe de alta resposta a nitrogênio: $40 \mathrm{~kg} / \mathrm{ha}$ de nitrogênio ou classe de média e baixa resposta a nitrogênio: $20 \mathrm{~kg} / \mathrm{ha}$ de nitrogênio; (b) rendimento esperado: entre $1500 \mathrm{e}$ $2500 \mathrm{~kg} / \mathrm{ha}: 10 \mathrm{~kg} / \mathrm{ha}$ de nitrogênio (adubação na semeadura). Classe de alta resposta a nitrogênio: $50 \mathrm{~kg} / \mathrm{ha}$ de nitrogênio. Classe de média e baixa resposta a nitrogênio: 30 $\mathrm{kg} / \mathrm{ha}$ de nitrogênio; (c) rendimento esperado: entre 2500 e $3500 \mathrm{t} / \mathrm{ha}: 10 \mathrm{~kg} / \mathrm{ha}$ de nitrogênio (adubação na semeadura). Classe de alta resposta a nitrogênio: $70 \mathrm{~kg} / \mathrm{ha}$ de nitrogênio. Classe de média e baixa resposta a nitrogênio: $40 \mathrm{~kg} / \mathrm{ha}$ de nitrogênio, (d) rendimento esperado: entre 3500 e $4500 \mathrm{~kg} / \mathrm{ha}: 20 \mathrm{~kg} / \mathrm{ha}$ de nitrogênio. Classe de alta 
resposta a nitrogênio: $90 \mathrm{~kg} / \mathrm{ha}$ de nitrogênio. Classe de média e baixa respostas a nitrogênio: $50 \mathrm{~kg} / \mathrm{ha}$ de nitrogênio; (ii) cerrado (Embrapa, 1998): recomendação de adubação nitrogenada para a cultura de feijão irrigado: $20 \mathrm{~kg} / \mathrm{ha}$ de nitrogênio (semeadura), 20 a $40 \mathrm{~kg} / \mathrm{ha}$ de nitrogênio (20 a 30 dias após emergência) e $20 \mathrm{~kg} / \mathrm{ha}$ de nitrogênio (30 a 40 dias após emergência); (iii) Paraná (Coamo \& Coodetec, 1998): quantidade recomendada para adubação nitrogenada da cultura de feijão: (a) semeadura: 10 a $15 \mathrm{~kg} / \mathrm{ha}$ de nitrogênio, (b) cobertura: 30 a $60 \mathrm{~kg} /$ ha de nitrogênio; (iv) Minas Gerais (CFSEMG, 1999): recomendação oficial de adubação nitrogenada: (a) rendimento esperado: até $1200 \mathrm{~kg} / \mathrm{ha}, 20 \mathrm{~kg} / \mathrm{ha}$ (semeadura) mais $20 \mathrm{~kg} / \mathrm{ha}$ de nitrogênio (em cobertura), (b) rendimento esperado: entre 1200 e $1800 \mathrm{~kg} / \mathrm{ha:} 20 \mathrm{~kg} / \mathrm{ha}$ (semeadura) mais $30 \mathrm{~kg} /$ ha de nitrogênio (em cobertura), (c) rendimento esperado: entre 1800 e 2500: $30 \mathrm{~kg} / \mathrm{ha}$ (semeadura) mais $40 \mathrm{~kg} / \mathrm{ha}$ de nitrogênio (em cobertura), (d) rendimento esperado: superior a $2500 \mathrm{~kg} / \mathrm{ha}: 40 \mathrm{~kg} / \mathrm{ha}$ (semeadura) mais $60 \mathrm{~kg} / \mathrm{ha}$ de nitrogênio (em cobertura).

\subsection{Fenologia}

A fenologia (Tabela 3) é a principal ferramenta de manejo. A sua utilização permite extrapolar resultados de pesquisa de uma localidade para outra (Fancelli \& Dourado-Neto, 1999).

Tabela 3. Fenologia da cultura de feijão (Phaseolus vulgaris L.) (CIAT, 1981; Gepts \& Fernández, 1982; Fancelli \& Dourado-Neto, 1997, 1999).

\begin{tabular}{|c|c|c|}
\hline Fase & Código & Caracterização do estádio \\
\hline \multirow[t]{5}{*}{ Vegetativa } & $\mathrm{V}_{\mathrm{O}}$ & Germinação \\
\hline & $V_{1}$ & $50 \%$ das plantas apresentando cotilédones acima da superficie do solo \\
\hline & $\mathrm{V}_{2}$ & $50 \%$ das plantas apresentando folhas simples expandidas em posição horizontal \\
\hline & $\mathrm{V}_{3}$ & $\begin{array}{l}50 \% \text { das plantas apresentando o primeiro trifólio completamente desenvolvido } \\
\text { (queda dos cotilédones) }\end{array}$ \\
\hline & $\mathrm{V}_{4}$ & $\begin{array}{l}50 \% \text { das plantas apresentando o terceiro trifólio completamente desenvolvido } \\
\text { (início do processo de ramificação da planta) }\end{array}$ \\
\hline \multirow[t]{5}{*}{ Reprodutiva } & $\mathbf{R}_{5}$ & $50 \%$ das plantas apresentando botðes florais \\
\hline & $\mathrm{R}_{6}$ & $50 \%$ das plantas apresentando a primeira flor aberta \\
\hline & $\mathrm{R}_{7}$ & $50 \%$ das plantas apresentando a primeira vagem \\
\hline & $\mathbf{R}_{8}$ & $50 \%$ das plantas apresentando a primeira vagem cheia \\
\hline & $\mathrm{R}_{9}$ & $\begin{array}{l}\text { Ponto de maturidade fisiológica (alteração da cor das vagens). Senescênc } \\
\text { planta }\end{array}$ \\
\hline
\end{tabular}




\section{7 Água}

A cultura de feijão é uma espécie pouco tolerante a deficiência hídrica, o que causa redução do ciclo da planta e queda de rendimento (Fancelli \& Dourado-Neto, 1999).

O uso consuntivo médio referente à cultura de feijão é em torno de $400 \mathrm{~mm}$. Regiões cujas precipitações anuais durante o ciclo da cultura oscilem entre 300 a 450 mm são consideradas aptas para a implantação da mencionada espécie (Fancelli \& Dourado-Neto, 1999).

No início da fase de desenvolvimento vegetativo (até seis trifólios), deficiências hídricas restringem o porte e a área foliar do feijoeiro, sendo que a magnitude do efeito está relacionada à fertilidade do solo e à população de plantas (Fancelli \& DouradoNeto, 1999).

A fase referente ao aparecimento dos botões florais é considerada como a mais crítica à falta de água (Dubetz \& Mahalle, 1969; Magalhães et al., 1979, Hostalácio \& Válio, 1984).

A deficiência hídrica ocorrido durante o florescimento acarreta a redução de novas folhas (plantas de hábito de crescimento indeterminado), e perda de rendimento entre 15 a $55 \%$ (Fancelli \& Dourado-Neto, 1999).

A evapotranspiração média durante o ciclo do feijoeiro gira em torno de 3,0 a 4,0 $\mathrm{mm} /$ dia nos primeiros estádios de desenvolvimento $\left(V_{1}, V_{2}\right.$ e $\left.V_{3}\right)$. Após a emissão do terceiro trifólio $\left(V_{4}\right)$, florescimento $\left(R_{5} / R_{6}\right)$ e enchimento de vagens $\left(R_{7}\right.$ e $\left.R_{8}\right)$, a evapotranspiração média diária pode chegar de 4,0 a 7,0 mm.

Segundo Silva (1982) todos os componentes da produção são afetados pelo excesso de água. No florescimento, o encharcamento reduz o rendimento de 50 a $70 \%$.

A falta de água durante a formação de vagens reduz drasticamente o rendimento, devido a acentuada queda de folhas, redução da fotossíntese e diminuição da translocação de fotoassimilados, que ocasiona a abscisão de vagens jovens. Essas perdas podem variar entre 40 e $60 \%$ (Garrido et al., 1979). 
\&O tamanho da vagem se encontra definido durante o enchimento das mesmas (estádio $\mathrm{R}_{\mathbf{8}}$ ). A ocorrência de deficiência hídrica ocasiona a redução do número e massa específica dos grãos (Fancelli \& Dourado-Neto, 1999).

O aumento da concentração iônica (principalmente potássio) nas células-guarda determina a permeabilidade à água, o que provoca sensível redução no potencial osmótico (-40 a $-50 \mathrm{~atm})$, com a diminuição do potencial total de água. Essa condição resulta no movimento de água das células adjacentes para as células-guarda, aumentando o seu potencial total. Assim, valores próximos a $-50 \mathrm{~atm}$ promovem a abertura dos estômatos pela dilatação das células-guarda (Awad \& Castro, 1983).

A abertura dos estômatos depende de processos fotoquímicos, sendo função da densidade de fluxo quântico, da diferença de tensão de vapor de água da folha e do ar, da concentração de dióxido de carbono, da velocidade do vento e do estado hídrico da folha (Meidner \& Mansfield, 1968).

A senescência de raízes pode ser provocada pela baixa umidade no solo. A dessecação da camada de solo que envolve o sistema radicular provoca o acúmulo de magnésio e boro, que em concentrações elevadas são danosos à vida vegetal, ocasionando a murcha das plantas (Schwartz \& Gálvez, 1980).

A deficiência hídrica ocorre quando a perda de água pela planta excede a sua capacidade de absorção. Contudo, a maioria das plantas está sujeita a períodos de deficiência hídrica durante o dia com recuperação à noite. Dentro de certos limites, a presença de reservas de água dentro dos vacúolos das células ou no xilema possibilita a planta suportar níveis severos de falta de água (Sutcliffe, 1980).

Segundo Schwartz \& Gálvez (1980), o encharcamento afeta o desempenho e reduz o rendimento da cultura, por provocar lixiviação de nutrientes, redução do conteúdo de oxigênio às raízes, indução de clorose generalizada da planta e aumento dos níveis de subprodutos tóxicos resultantes do metabolismo anaeróbio.

\subsection{Temperatura}

Os fatores climáticos que mais interferem na duração das etapas de desenvolvimento do feijoeiro são temperatura e água (Sutclifffe, 1980). As regiões que 
apresentem valores médios diários de temperaturas entre 15 e $29^{\circ} \mathrm{C}$ são consideradas aptas para o cultivo de feijão, sendo que a temperatura média diária ideal para feijoeiro corresponde a $21^{\circ} \mathrm{C}$ (CIAT, 1981; Gepts \& Fernández, 1982; White, 1985; Vieira, 1978).

Gepts \& Fernández (1982) encontram duração da fase vegetativa variando de 49 a 99 dias em função da temperatura média diária no referido período (oscilou entre 13 a $\left.24^{\circ} \mathrm{C}\right)$.

Temperatura próxima a $25^{\circ} \mathrm{C}$ favorece a germinação e a emergência. Temperaturas baixas (inferiores a $12^{\circ} \mathrm{C}$ ) reduzem a velocidade de germinação das sementes, e aumentam o número de plântulas anormais.

Segundo Crookston et al. (1974, 1975), o feijoeiro quando exposto a temperaturas noturnas baixas (entre 5 e $10^{\circ} \mathrm{C}$ ), reduzem a taxa fotossintética no dia seguinte, com conseqüente diminuição da fixação de dióxido de carbono e menor taxa transpiratória.

Quando a temperatura noturna é inferior a $15^{\circ} \mathrm{C}$, ocorre redução da altura de planta e a alteração do angulo dos ramos laterais (a planta apresenta um aspecto arbustivo). Sendo assim, nessas condições, em função da redução da área foliar da planta, recomenda-se o aumento da população com melhor distribuição espacial possível dos indivíduos na área (Fancelli \& Dourado-Neto, 1999).

Segundo Monterroso (1990), temperaturas elevadas (superior a $32^{\circ} \mathrm{C}$ ) durante a fase vegetativa provoca aumento da fotorrespiração, com conseqüente redução da expansão foliar e acúmulo de clorofila nas folhas.

Segundo Farlow et al. (1979), temperaturas baixas durante o florescimento afetam a fecundação das flores. A germinação do pólen do feijoeiro é reduzida por temperaturas inferiores a $10^{\circ} \mathrm{C}$. O crescimento do tubo polínico é reduzido em temperaturas abaixo de $16,8^{\circ} \mathrm{C}$. Em função disso, temperaturas inferiores a $12^{\circ} \mathrm{C}$ reduzem o número de vagens por planta e de sementes por vagens (Farlow et al., 1981).

Segundo Halterlein et al. (1980), temperatura elevada reduz em cerca de 15 a $20 \%$ a viabilidade do grão de pólen e, sobretudo do crescimento do tubo polínico. Os autores relatam que o efeito é mais danoso às estruturas reprodutivas quando na ausência de luz. 
Segundo Wolfe (1991), a fotossíntese é restringida pela ocorrência de baixas temperaturas, devido à redução da formação da protoclorofila, redução da condutância estomática e à interferência na cadeia de transporte de elétrons.

O feijoeiro apresenta maior concentração de etileno quando submetido a temperaturas noturnas altas. $O$ que pode ser verificado pela maior taxa de abscisão de flores e vagens jovens. (Sauter et al., 1990). Por outro lado, há relatos na literatura que pode-se reduzir do abortamento de botões florais e de flores, em condições de alta temperatura com a aplicação de ethefon (Wein, 1988).

A alteração morfológica encontrada em plantas de feijão é o espessamento da folha, representado pela formação de camadas extras de parênquima paliçádico (Siebeneichler, 1996).

Temperaturas superiores a $35^{\circ} \mathrm{C}$, durante o início de formação de vagens, acarreta alta taxa de abortamento de vagens jovens (Stobbe et al., 1966).

$\mathrm{O}$ efeito de queda de rendimento atribuído à baixa temperatura é resultante da redução da translocação de fotoassimilados, a qual é decorrente da obstrução dos poros da placa crivada do floema (Taiz \& Zieger, 1991).

Temperaturas superiores a $30^{\circ} \mathrm{C}$, durante o dia, e $25^{\circ} \mathrm{C}$ no período noturno, favorecem abortamento de vagens jovens (Kay, 1979), resultando no aumento da respiração, e redução no número de grãos por vagem (Dickson \& Boettger, 1984), bem como podem provocam o aumento da queda de folhas, flores e vagens, devido à maior produção de etileno na planta (Abeles \& Gahagan, 1968).

Segundo Griffith et al. (1994), o efeito de baixas temperaturas, isoladamente ou associada a estresse de luz, pode provocar injúrias morfológicas, fisiológicas, anatômicas e bioquímicas à planta.

Segundo Field (1981), temperaturas baixas alteram o estado físico das membranas, passando do estado de cristal líquido para um gel mais espesso, reduzindo sua fluidez. A alteração da composição lipídica da membrana constitui-se em eficiente estratégia preventiva da planta.

Plantas submetidas a baixas temperaturas produzem e acumulam trissacaridios, polióis, sorbitol, poliaminas e prolina (Koster \& Lynch, 1992). 
A fase anterior à fertilização, cerca de 4 a 7 dias antes da antese, constitui-se no período mais sensível à ocorrência de temperatura elevada, resultando em cerca de 40 a $80 \%$ de taxa de abscisão de flores e vagens jovens. (Monterroso, 1990).

Altas temperaturas afetam o transporte de elétrons e o funcionamento das mitocôndrias, sendo a espécie Phaseolus acutifolius menos sensivel a essa alteração fisiológica que o Phaseolus vulgaris. (Lin \& Markhart, 1990).

$O$ heliotropismo (movimentação das folhas) pode minimizar o efeito das altas temperaturas por parte do feijoeiro. Esse controle parcial da temperatura da folha é independente da umidade da atmosfera, da concentração de dióxido de carbono, do potencial de água da folha e da taxa transpiratória. O referido movimento de orientação da lâmina foliar é determinado pela sensibilização da região do pulvino pela temperatura. Assim, o aumento da temperatura provoca a disposição mais oblíqua das folhas na planta, em relação à fonte de luz. Ressalta-se que em condições de escuro (ausência de luz) e em dias frios o movimento heliotrópico das folhas não se processa (Fu \& Ehleringer, 1989).

Os tilacóides, por serem estruturas altamente sensíveis ao calor, desorganizam-se em temperaturas acima de $30^{\circ} \mathrm{C}$, acarretando o aumento do nível de excitação do fotossistema I, induzindo um incremento no transporte cíclico do elétron e o decréscimo no suprimento do NADPH, resultando na limitação da assimilação do carbono por parte da planta (Pastenes \& Horton, 1996).

Segundo Schwartz \& Gálvez (1980), temperaturas elevadas associadas à elevada intensidade luminosa pode provocar queimaduras. Os sintomas comumente relacionados a esse tipo de estresse são representados por pequenas manchas aquosas nas partes expostas à luz, as quais evoluem para lesões maiores de coloração avermelhada ou castanha, culminando na necrose dos tecidos afetados.

\subsection{Desenvolvimento relativo da cultura de feijão}

Desenvolvimento relativo da cultura $\left(\mathrm{Dr}_{\mathrm{n}}\right)$ no n-ésimo dia após a emergência pode ser definido como sendo a relação entre a soma calórica atual e a soma calórica da 
cultura correspondente ao ponto de maturidade fisiológica $\left(\mathrm{GD}_{\mathrm{pmf}},{ }^{\circ} \mathrm{C}\right.$.dia $)$, definida pela seguinte expressão:

$$
D r_{n}=\frac{\sum_{i=1}^{n} T_{i}-T b}{G D_{p m f}}\left(T b \leq T_{i} \leq T_{m}\right)
$$

em que $\mathrm{Ti}$ à temperatura média do ar no i-ésimo dia após a emergência, $\mathrm{Tb}$ à temperatura base inferior $\left(10^{\circ} \mathrm{C}\right)$, e $\mathrm{Tm}$ à temperara base superior $\left(28\right.$ a $\left.30^{\circ} \mathrm{C}\right)$.

A soma calórica da cultura correspondente ao ponto de maturidade pode ser calculada pela seguinte equação:

$$
G D_{p m f}=\int_{0}^{t_{p m f}} T_{i}(t) d t-T b . t_{p m f}
$$

em que $T(t)$ refere-se à variação temporal da temperatura entre a emergência e o ponto de maturidade fisiológica, e $t_{\mathrm{pmf}}$ ao número de dias após a emergência para atingir o ponto de maturidade fisiológica. A soma calórica da cultura correspondente ao ponto de maturidade pode ser aproximada, numa escala diária, pelo numerador da equação anterior (onde $\mathrm{n}=\mathrm{t}_{\mathrm{pmf}}$ ).

A temperatura média do ar $\left(\mathrm{T}_{\mathrm{i}},{ }^{\circ} \mathrm{C}\right)$ é estimada pela média entre as temperaturas máxima $\left(\operatorname{Tmax}_{\mathrm{i}},{ }^{\circ} \mathrm{C}\right)$ e mínima $\left(\mathrm{Tmin}_{\mathrm{i}},{ }^{\circ} \mathrm{C}\right)$ :

$$
T_{i}=\frac{T \max _{i}+T \min _{i}}{2}
$$

\subsection{Componentes da produção}

Número de nós por área, área foliar; duração da área foliar e número de vagens por planta são os componentes de produção dependentes de manejo. Sendo assim, devese procurar manter as folhas do feijoeiro sadias (livres de patógenos e pragas) desde o início da cultura mas, sobretudo, após o florescimento. A aplicação de fungicidas tardiamente na lavoura de feijão tem contribuído para redução da perda de produtividade, devido à manutenção de folhas fotossinteticamente ativas até o ponto de maturidade fisiológica (Fancelli \& Dourado-Neto, 1997). 
A estratégia a ser utilizada para os componentes da produção relacionados ao manejo é de otimização, e não de maximização. As estratégias dependem da população utilizada, do programa de adubação adotado, e da disponibilidade de água e luz, principalmente. Já com relação aos componentes de produção de natureza genética (componentes pouco variáveis), a estratégia se refere à maximização desses componentes objetivando atingir o máximo valor inerente à variedade utilizada (Fancelli \& Dourado-Neto, 1999).

\subsection{Produtividade e rendimento}

O genótipo e o clima condicionam a produtividade do feijoeiro. A variedade selecionada define o potencial de produção, o qual depende do clima (temperatura, disponibilidade de água, e qualidade e intensidade de luz, principalmente). Portanto, cabe ao Engenheiro Agrônomo estabelecer estratégias de manejo objetivando a adequação dessas exigências (escolha da época de semeadura, população de plantas, adubação a ser empregada, por exemplo) (Fancelli \& Dourado-Neto, 1999).

Em condições ideais, a produtividade de grãos pode atingir de 5000 a 6000 $\mathrm{kg} / \mathrm{ha}$. Em função da tecnologia disponível e às limitações do ambiente agrícola, o rendimento de grãos a nível comercial raramente excede a 3600 a $4200 \mathrm{~kg} / \mathrm{ha}$. em algumas situações especiais, pode-se obter rendimentos superiores ao mencionado (Fancelli \& Dourado-Neto, 1999).

Os fatores redutores de produtividade podem ser natureza abiótica (elementos minerais, poluentes e elementos de clima) ou biótica (pragas, patógenos, plantas daninhas e outros organismos vivos) (Fancelli \& Dourado-Neto, 1999).

A espécie Phaseolus vulgaris L. apresenta metabolismo C3, com características (respiração, fotossíntese, transpiração e partição de fotoassimilados) que acarretam diferentes comportamentos quando submetido a condições desfavoráveis (Fancelli \& Dourado-Neto, 1999).

Condição ou ação que promova a elevação da taxa respiratória, pode reduzir significativamente o potencial de produção do feijoeiro, bem como torná-lo mais 
susceptível à incidência de doenças e pragas, provocando estresse da planta (Kanemasu, 1969, Mariot, 1989). 


\section{MATERIAL E MÉTODOS}

\subsection{Caracterização da área experimental e variedade utilizada}

Os experimentos de campo (Experimento I: semeado em 26 de março de $1997 \mathrm{e}$ Experimento II: semeado 14 de abril de 1995) foram conduzidos com a cultura de feijão (variedade Carioca) na área do Departamento de Produção Vegetal da Universidade de São Paulo (campus "Luiz de Queiroz" da Escola Superior de Agricultura "Luiz de Queiroz"), em Piracicaba, SP, cujas coordenadas geográficas são $22^{\circ} 42^{\prime}$ de latitude sul, $47^{\circ} 38^{\prime}$ de longitude oeste e altitude de $540 \mathrm{~m}$.

As médias anuais de temperatura, precipitação pluviométrica e umidade relativa do ar em Piracicaba são de $21,1^{\circ} \mathrm{C}, 1247 \mathrm{~mm}$ e $74 \%$, respectivamente. Segundo classificação de Köppen, o clima é do tipo Cwa (clima tropical de altitude, mesotérmico de inverno seco, em que a temperatura média do mês mais frio é inferior a $18^{\circ} \mathrm{C}$ e a do mês mais quente ultrapassa $22{ }^{\circ} \mathrm{C}$. A estação seca ocorre entre o mês de abril e setembro, sendo julho o mês mais seco, e o meses de janeiro e fevereiro os mais chuvosos, sendo que o total das chuvas do mês mais seco não ultrapassa $30 \mathrm{~mm}$, e a temperatura do mês mais quente oscila entre $22^{\circ} \mathrm{C}$ e $24^{\circ} \mathrm{C}$ ) (Serviço Nacional de Pesquisas Agronômicas, 1960).

\subsection{Parâmetros utilizados}

\subsubsection{Experimento I}

Para ajustar os modelos empíricos aos valores observados, foi utilizado o programa computacional Table Curve. Os modelos foram escolhidos em função da 
análise de variância, do coeficiente de determinação e do comportamento biológico esperado em função de conhecimento prévio e dos valores observados.

Utilizou-se procedimento similar para altura de planta e massa de matéria seca dos diferentes órgãos da planta (raiz, folha, haste, vagem e total).

Os parâmetros empíricos foram determinados através de análise de regressão não linear minimizando a soma dos quadrados dos desvios.

\subsubsection{Altura de planta}

A altura $(\mathrm{cm})$ de planta foi medida como sendo a distância entre o colo da planta e a extremidade da haste mais distante.

Para determinação da altura de planta foi utilizada uma trena com precisão de 0,1 $\mathrm{cm}$, onde foram coletadas três repetições compostas por cinco plantas escolhidas aleatoriamente na área útil da parcela experimental.

Tabela 4. Modelos referentes à altura de planta (Ap), em função do número de dias após a semeadura, para o feijoeiro sob condição de irrigação e de sequeiro.

\begin{tabular}{|c|c|}
\hline Irrigado & Equação \\
\hline $\ln A p=a+b D A S+c D A S^{2}+d D A S^{3}$ & (4) \\
\hline Sequeiro & Equação \\
\hline$A p^{0,5}=a+b D A S+c D A S^{2}+d D A S^{3}$ & (5) \\
\hline
\end{tabular}

\subsubsection{Massa de matéria seca de raiz, folha, haste, vagem e total}

Os modelos utilizados para estimativa da massa de matéria seca de raiz, folha, haste, vagem e total, em função do número de dias após a semeadura (critério prático) estão relacionados na Tabela 5 (feijão irrigado) e na Tabela 6 (feijão de sequeiro). 
Tabela 5. Modelos referentes à massa de matéria seca de raiz (Mr), de folha (Mf), de haste $(\mathrm{Mh})$, de vagem $(\mathrm{Mv})$ e total $(\mathrm{Mt})$, em função do número de dias após a semeadura, para o feijoeiro sob condição de irrigação.

\begin{tabular}{|c|c|c|}
\hline Órgão & Modelo & Equação \\
\hline Raiz & $\ln M r=a+b D A S+c D A S^{2}+d D A S$ & $(6)$ \\
\hline Folha & $M f=a+b D A S+c D A S^{2}+d D A S^{3}+e D A S^{4}$ & $(7)$ \\
\hline Haste & $M h^{0,5}=a+b D A S+c D A S^{2}$ & $(8)$ \\
\hline Vagem & $\ln M v=a+b D A S^{1,5}$ & $(9)$ \\
\hline Total & $M t=a+b D A S+c D A S^{2}+d D A S^{3}+e D A S^{4}$ & $(10)$ \\
\hline
\end{tabular}

Tabela 6. Modelos referentes à massa de matéria seca de raiz $(\mathrm{Mr})$, de folha (Mf), de haste $(\mathrm{Mh})$, de vagem $(\mathrm{Mv})$ e total $(\mathrm{Mt})$, em função do número de dias após a semeadura, para o feijoeiro sob condição de sequeiro.

\begin{tabular}{|c|c|c|}
\hline Orgão & Modelo & Equação \\
\hline Raiz & $M r^{0,5}=a+b D A S+c D A S^{2}+d D A S^{3}$ & (11) \\
\hline Folha & $M f^{0,5}=a+b D A S+c D A S^{2}+d D A S^{3}$ & $(12)$ \\
\hline Haste & $\ln M h+\frac{a+c D A S+e D A S^{2}}{1+b D A S+d D A S^{2}}$ & \\
\hline Vagem & $M v=\frac{a+c D A S+e D A S^{2}}{1+b D A S+d D A S^{2}+f D A S^{3}}$ & $(14)$ \\
& $M t^{0,5}=a+b D A S+c D A S^{2}+d D A S^{3}$ & \\
\hline Total & \multirow{2}{*}{} & \\
\hline
\end{tabular}

\subsubsection{Rendimento de grãos e índice de colheita}

O rendimento de grãos foi estimado através da seguinte equação:

$$
R g=R p P
$$

em que $\mathrm{Rg}$ se refere ao rendimento médio de grãos por unidade de área $(\mathrm{kg} / \mathrm{ha}), \mathrm{Rp}$ ao rendimento médio de grãos por planta $(\mathrm{kg} /$ planta) e $\mathrm{P}$ à população média de plantas na colheita (plantas/ha).

$\mathrm{O}$ indice de colheita pode ser definido com a relação entre o rendimento médio de grãos por unidade de área $(\mathrm{kg} / \mathrm{ha})$ e o rendimento médio $(\mathrm{kg} / \mathrm{ha})$ contemplando todas as partes da planta (tais como grão, raiz, haste, folha e vagem). 


\subsubsection{Experimento $\mathbf{I}$}

Com o objetivo de fornecer subsídio para planejamento, foi utilizada a soma calórica expressa em termos de desenvolvimento relativo da cultura de feijão e relacionada à fenologia.

\subsubsection{Fenologia}

Foi feito o acompanhamento dos estádios fenológicos conforme CIAT (1981); Gepts \& Fernández (1982); e Fancelli \& Dourado-Neto (1997, 1999).

\subsubsection{Massa de matéria seca de folha, haste, botão floral e vagem}

Tabela 7. Modelos referentes à massa de matéria seca de raiz $(\mathrm{Mr})$, de folha $(\mathrm{Mf})$, de haste $(\mathrm{Mh})$, de botão floral $(\mathrm{Mb})$, de vagem $(\mathrm{Mv})$ e total $(\mathrm{Mt})$, em função do desenvolvimento relativo da cultura (Dr) de feijão.

\begin{tabular}{|c|c|c|}
\hline Orgão & Modelo & Equação \\
\hline Folha & $M f=\frac{a+c D r+e D r^{2}}{1+b D r+d D r^{2}}$ & $(17)$ \\
\hline Haste & $M h=\frac{a+c D r+e D r^{2}}{1+b D r+d D r^{2}}$ & $(18)$ \\
& $M v^{1}$ & $(19)$ \\
\hline Botão floral & $M v^{0,5}=a+b D r^{2}$ & $(20)$ \\
\hline Vagem & $\ln M t=a+b D r+c D r^{2,5}$ & $(21)$ \\
\hline Total & &
\end{tabular}

Mo: média dos valores observados

\subsubsection{Teor de macronutrientes na parte aérea do feijoeiro}

Para determinação do teor de macronutrientes na parte aérea do feijoeiro, foram coletadas 5 plantas ao acaso por repetição (foram utilizadas duas repetições por tratamento).

Para tal, foram feitas amostragens aproximadamente quinzenais, onde foram determinados os teores de nitrogênio, fósforo, potássio, cálcio, magnésio e enxofre na folha, haste, botão floral, vagem e grão.

Para cada órgão(folha, haste, botão floral e vagem), bem como para todos os órgãos conjuntamente (total), calcula-se o valor médio (quando não há diferença estatística entre os diferentes tratamentos) ou faz-se uma análise de regressão (teor do 
elemento em questão em função da dose de nitrogênio aplicada, quando há diferença estatística entre os diferentes tratamentos).

\subsubsection{Rendimento de grãos}

O rendimento de grãos foi avaliado na metade da área útil da parcela, não utilizada na retirada de plantas para análise de crescimento (Pimenta, 1998).

Para estimativa do rendimento foi feita a estimativa de rendimento pela determinação dos componentes de produção de grãos (Pimenta, 1998).

Para estimativa do rendimento pela determinação dos componentes de produção de grãos, utilizou-se a seguinte equação (Pimenta, 1998):

$$
R=\frac{P \cdot(V t-V c) \cdot S v \cdot M s}{10 \cdot(100-u)}
$$

em que $\mathrm{R}$ refere-se ao rendimento estimado $\left(\mathrm{kg} \cdot \mathrm{ha}^{-1}\right), \mathrm{P}$ à população (plantas/ha), Vt ao número total de vagens totais por planta (vagens/planta), Vc ao número de vagens chochas por planta (vagens/planta), Sv número de sementes por vagem, Ms à massa média de matéria seca de uma semente ( $\mathrm{g} / \mathrm{grão}$ ) e $\mathrm{u}$ ao conteúdo de água no grão, a base de massa - base úmida (14\%). 


\section{RESULTADOS E DISCUSSÃO}

\subsection{Experimento I}

\subsubsection{Fenologia}

A cultura de feijão (variedade Carioca) apresentou o ciclo variável em função do sistema de produção (irrigado ou sequeiro). Houve uma diferença de 12 dias no ciclo (Tabela 8).
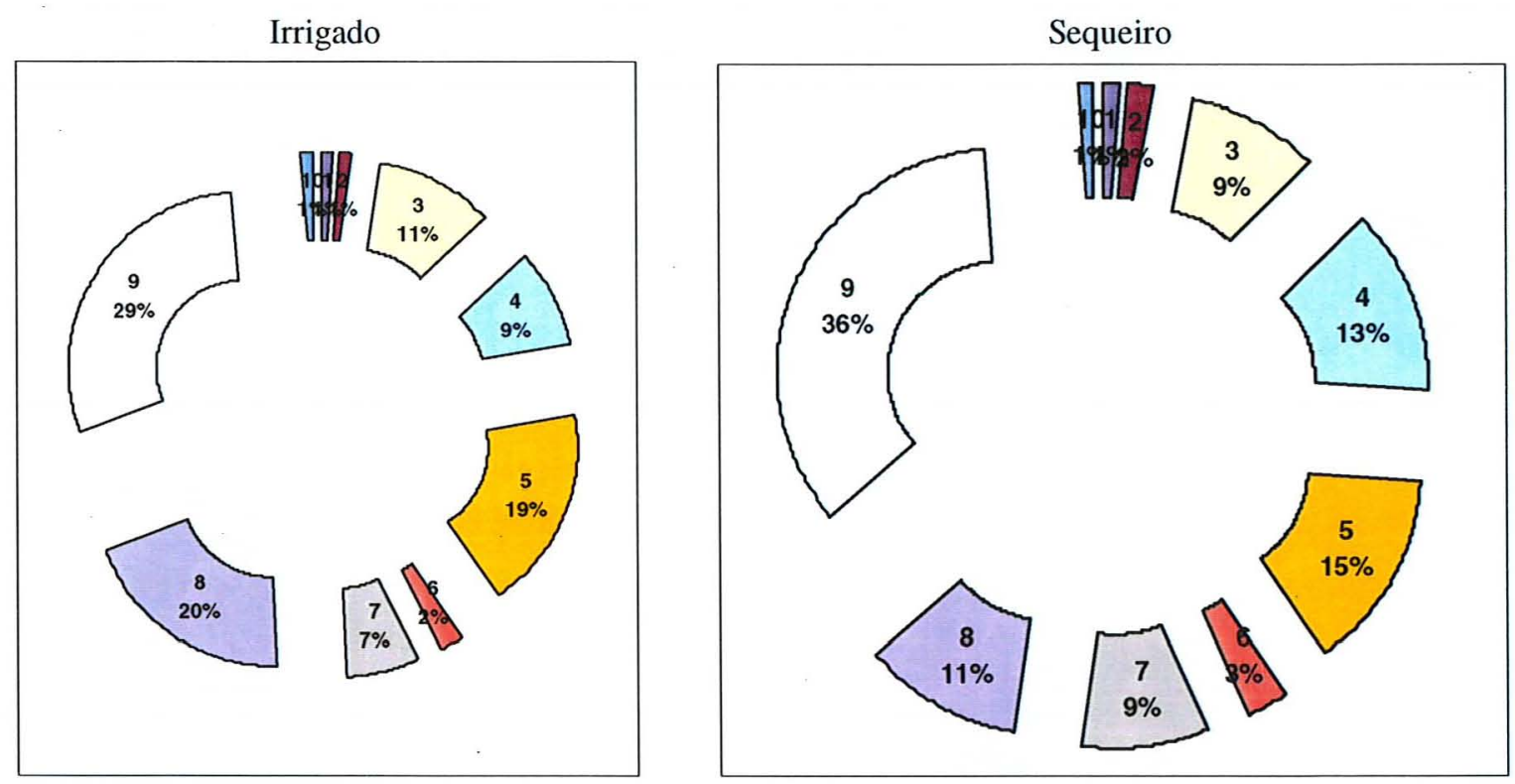

Figura 1. Ciclo da cultura de feijão sob condição de irrigação e de sequeiro especificando a duração relativa de cada um dos estádios fenológicos $\left(1: \mathrm{V}_{0}\right.$, 2: $\mathrm{V}_{1} ; 3: \mathrm{V}_{2} ; 4: \mathrm{V}_{3} ; 5: \mathrm{V}_{4}: 6: \mathrm{R}_{5} ; 7 . \mathrm{R}_{6} ; 8: \mathrm{R}_{7} ; 9: \mathrm{R}_{8}$ e $\left.10: \mathrm{R}_{9}\right)$. 
Tabela 8. Fenologia observada da cultura de feijão (Experimento I).

\begin{tabular}{|c|c|c|c|c|c|}
\hline \multirow[t]{2}{*}{ Data } & \multicolumn{2}{|c|}{ Irrigado } & \multicolumn{2}{|c|}{ Sequeiro } & \multirow[t]{2}{*}{ DAS } \\
\hline & Folhas & Fenologia & Folhas & Fenologia & \\
\hline $26 / 03 / 1997$ & 0 & 0 & 0 & 0 & 0 \\
\hline $31 / \mathrm{mar}$ & 0 & Vo & 0 & 0 & 5 \\
\hline $01 / a b r$ & 0 & V1 & 0 & 0 & 6 \\
\hline $06 / \mathrm{abr}$ & 0 & V2 & 0 & vo & 11 \\
\hline $08 / a b r$ & 0 & V2 & 0 & V1 & 13 \\
\hline 11/abr & 0 & V2. & 0 & V2 & 16 \\
\hline 14/abr & 1 & V3 & 0 & $\underline{\mathbf{V}}$ & 19 \\
\hline$\overline{17 / a b r}$ & 2 & $\overline{\mathrm{V} 3}$ & 0 & $\overline{\mathbf{V}}$ & 22 \\
\hline $19 / \mathrm{abr}$ & 2 & V3 & 1 & V3 & 24 \\
\hline 28/abr & 6 & V4 & 2 & V3 & 33 \\
\hline $30 / a b r$ & 7 & V4 & 2 & $\overline{\mathrm{V3}}$ & 35 \\
\hline $01 / \mathrm{mai}$ & 7 & V4 & 3 & V4 & 36 \\
\hline 06/mai & 9 & V4 & 4 & V4 & 41 \\
\hline 07/mai & 10 & R5 & 4 & V4 & 42 \\
\hline 08/mai & 10 & R5 & 5 & $\overline{\mathrm{V} 4}$ & 43 \\
\hline 09/mai & 11 & R6 & 5 & V4 & 44 \\
\hline 14/mai & 13 & R6 & 7 & V4 & 49 \\
\hline $15 /$ mai & 13 & R7 & 7 & R5 & 50 \\
\hline 17/mai & 14 & R7 & 7 & $\mathbf{R 5}$ & 52 \\
\hline $18 / \mathrm{mai}$ & 14 & R7 & 7 & R6 & 53 \\
\hline $19 / \mathrm{mai}$ & 14 & R7 & 8 & R6 & 54 \\
\hline $25 / \mathrm{mai}$ & 16 & $\overline{\mathrm{R} 7}$ & 8 & $\overline{\mathrm{R} 6}$ & 60 \\
\hline $26 / \mathrm{mai}$ & 16 & R7 & 8 & R6 & 61 \\
\hline 29/mai & 17 & R7 & 9 & R7 & 64 \\
\hline 30/mai & 17 & R7 & 9 & $\overline{\mathrm{R} 7}$ & 65 \\
\hline 31/mai & 17 & R7 & 9 & R7 & 66 \\
\hline $01 /$ jun & 17 & R7 & 9 & R7 & 67 \\
\hline $02 / \mathrm{jun}$ & 17 & R8 & 9 & R7 & 68 \\
\hline $06 /$ jun & 18 & R8 & 9 & R7 & 72 \\
\hline $08 /$ jun & 18 & $\mathrm{R} 8$ & 9 & R8 & 74 \\
\hline 09/jun & 18 & R8 & 9 & $\underline{\mathbf{R 8}}$ & 75 \\
\hline 10/jun & 18 & $\mathrm{R} 8$ & 9 & $\overline{\mathrm{R} 8}$ & 76 \\
\hline 21/iun & 19 & R8 & 9 & $\mathbf{R 8}$ & 87 \\
\hline $22 /$ jun & 19 & R8 & 9 & $\overline{\mathrm{R} 8}$ & 88 \\
\hline $23 /$ jun & 19 & R8 & 9 & R8 & 89 \\
\hline $24 /$ jun & 19 & R8 & 9 & $\mathrm{R} 8$ & 90 \\
\hline 25/jun & 19 & R8 & 9 & R8 & 91 \\
\hline 26/iun & 19 & $\underline{\mathbf{R 8}}$ & 9 & $\underline{\mathbf{R} 8}$ & 92 \\
\hline 27/jun & 19 & $\overline{\mathrm{R} 8}$ & 9 & $\mathrm{R} 8$ & 93 \\
\hline 28/jun & 19 & R8 & 9 & R8 & 94 \\
\hline 29/jun & 19 & $\mathbf{R} 9$ & 9 & R8 & 95 \\
\hline $10 /$ jul & & & 9 & $\mathbf{R 8}$ & 106 \\
\hline 11/iul & & R9 & 9 & R9 & 107 \\
\hline
\end{tabular}

\subsubsection{Altura de planta}

A Tabela 9 e a Figura 2 apresentam os valores medidos de altura de planta do feijoeiro comum. Para cada repetição (R) foram medidas alturas (cm) de 5 plantas. 


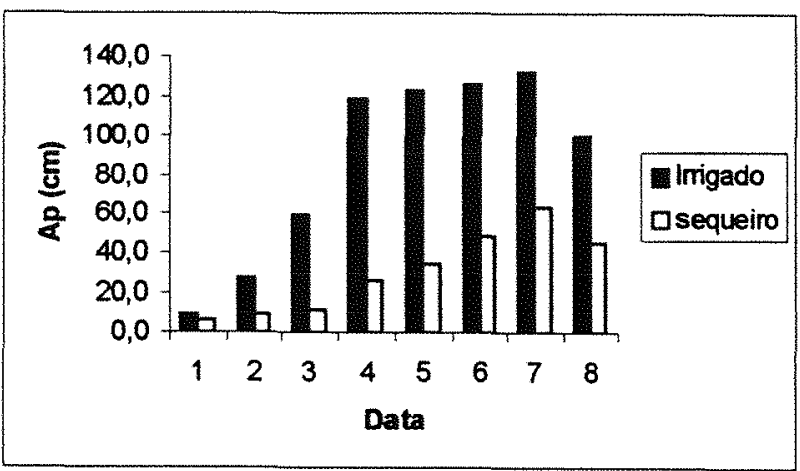

Figura 2. Variação da altura de planta (Ap, $\mathrm{cm})$ do feijoeiro comum sob irrigação e em condição de sequeiro em função das datas de coleta.

Tabela 9. Altura de planta $(\mathrm{cm})$ referente à cultura de feijão especificando a data, a repetição ( $R: 1,2,3,4)$, e os tratamentos (I: irrigado; $\mathrm{S}$ : sequeiro).

\begin{tabular}{|c|c|c|c|c|c|c|c|c|c|c|c|c|c|c|c|}
\hline Data & $\mathbf{R}$ & I & $\mathrm{S}$ & Data & $\mathbf{R}$ & I & $S$ & Data & $\mathbf{R}$ & I & $S$ & Data & $\overline{\mathbf{R}}$ & I & $S$ \\
\hline \multirow[t]{15}{*}{$14 / \mathrm{Abr}$} & 1 & 12,0 & 6,4 & 07/Mai & 1 & 118,0 & 12,0 & 29/Mai & 1 & 117,0 & 38,0 & $21 / \mathrm{Jun}$ & 1 & 162,0 & 97,0 \\
\hline & & 8,9 & 4,5 & & & 91,5 & 12,3 & & & 125,0 & 31,0 & & & 125,0 & 89,0 \\
\hline & & 10,3 & 9,2 & & & 83,2 & 11,5 & & & 127,0 & 25,0 & & & 161,0 & 44,0 \\
\hline & & 12,0 & 7,0 & & & 76,4 & 15,5 & & & 145,0 & 53,0 & & & 119,0 & 80,0 \\
\hline & & 8,5 & 6,0 & & & 60,0 & 13,3 & & & 100,0 & 29,0 & & & 189,0 & 65,0 \\
\hline & 2 & 9,0 & 6,2 & & 2 & 49,7 & 11,4 & & 2 & 122,0 & 56,0 & & 2 & 143,0 & 64,0 \\
\hline & & 10,4 & 5,2 & & & 68,7 & 12,0 & & & 188,0 & 30,0 & & & 82,0 & 65,0 \\
\hline & & 11,3 & 6,7 & & & 48,0 & 12,0 & & & 140,0 & 24,0 & & & 96,0 & 68,0 \\
\hline & & 10,8 & 7,3 & & & 45,0 & 11,5 & & & 130,0 & 47,0 & & & 106,0 & 49,0 \\
\hline & & 9,5 & 6,2 & & & 63,0 & 10,2 & & & 104,0 & 35,0 & & & 98,0 & 67,0 \\
\hline & 3 & 9,9 & 5,0 & & 3 & 41,0 & 10,0 & & 3 & 124,0 & 37,0 & & 3 & 138,5 & 62,0 \\
\hline & & 9,3 & 7,8 & & & 40,0 & 10,3 & & & 86,0 & 23,0 & & & 135,5 & 48,0 \\
\hline & & 8,5 & 8,3 & & & 41,0 & 10,0 & & & 94,0 & 22,0 & & & 182,0 & 37,0 \\
\hline & & 8,8 & 9,2 & & & 35,5 & 12,0 & & & 140,0 & 28,0 & & & 128,5 & 44,0 \\
\hline & & 10,0 & 7,4 & & & 33,0 & 13,5 & & & 107,0 & 48,0 & & & 130,0 & 72,0 \\
\hline \multirow[t]{15}{*}{ 28/Abr } & 1 & 18,5 & 9,5 & 19/Mai & 1 & 82,5 & 48,0 & 09/Jun & 1 & 75,0 & 101,0 & 29/Jun & 1 & 104,0 & 36,0 \\
\hline & & $24,0 \mid 1$ & 10,6 & & & 79,0 & 29,0 & & & 55,0 & 69,0 & & & 101,0 & 46,0 \\
\hline & & 22,5 & 9,9 & & & 104,5 & 37,0 & & & 126,0 & 50,5 & & & 111,0 & 61,0 \\
\hline & & $23,7 \mid 1$ & 10,1 & & & 109,5 & 20,0 & & & 187,5 & 59,0 & & & 108,0 & 50,0 \\
\hline & & 23,9 & 8,4 & & & 120,0 & 22,0 & & & 107,0 & 37,0 & & & 89,0 & 40,0 \\
\hline & 2 & $28,5 \mid 1$ & 11,5 & & 2 & 137,0 & 23,0 & & 2 & 140,0 & 54,0 & & 2 & 115,0 & 43,0 \\
\hline & & 28,4 & 9,6 & & & 157,0 & 22,0 & & & 117,0 & 53,0 & & & 84,0 & 55,0 \\
\hline & & 33,0 & 9,9 & & & 138,0 & 25,0 & & & 146,0 & 32,0 & & & 88,0 & 25,0 \\
\hline & & 29,3 & 8,9 & & & 134,0 & 22,0 & & & 148,0 & 32,0 & & & 71,0 & 58,0 \\
\hline & & $26,5 \mid 1$ & 11,8 & & & 141,0 & 17,0 & & & 139,5 & 56,5 & & & 90,0 & 52,0 \\
\hline & 3 & $37,4 \mid 1$ & 11,3 & & 3 & 108,0 & 34,0 & & 3 & 132,0 & 75,0 & & 3 & 94,0 & 33,0 \\
\hline & & 27,5 & 6,0 & & & 132,0 & 35,0 & & & 150,0 & 35,0 & & & 120,0 & 51,0 \\
\hline & & 30,0 & 7,5 & & & 109,0 & 30,0 & & & 100,0 & 31,0 & & & 67,0 & 34,0 \\
\hline & & $30,0 \mid 1$ & 11,0 & & & 89,0 & 15,0 & & & 109,0 & 30,0 & & & 138,0 & 54,0 \\
\hline & & $24,5 \mid 1$ & 13,2 & & & 139,0 & 18,5 & & & 166,0 & 21,0 & & & 114,0 & 46,0 \\
\hline
\end{tabular}




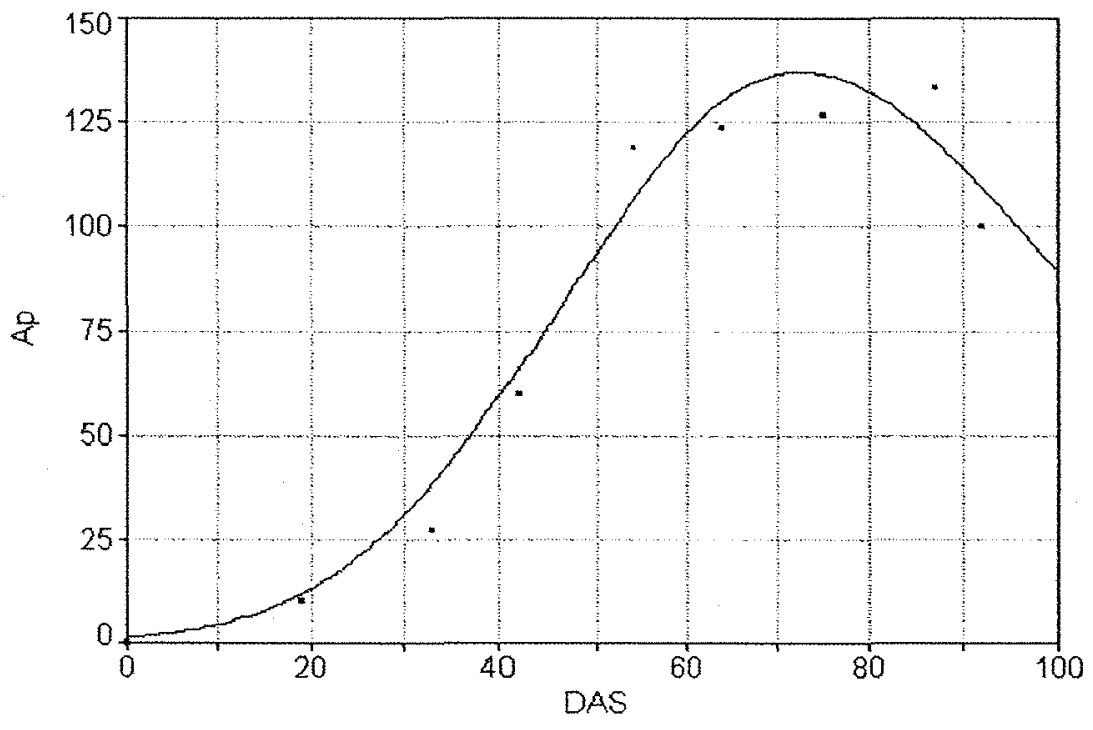

Figura 3. Variação da altura de planta $(\mathrm{Ap}, \mathrm{cm})$ do feijoeiro sob irrigação em função do número de dias após a semeadura (DAS).

Tabela 10. Análise de variância e parâmetros empíricos (a, b, c e d) referentes ao modelo para estimativa da altura de planta $(\mathrm{Ap}, \mathrm{cm})$ do feijoeiro sob irrigação em função do número de dias após semeadura (DAS).

\begin{tabular}{|c|c|c|c|c|c|c|}
\hline $\mathrm{FV}^{1}$ & $\mathrm{SQ}^{2}$ & $\mathrm{GL}^{3}$ & $\mathrm{QM}^{4}$ & \multicolumn{2}{|c|}{$F$} & $r^{2}$ \\
\hline Regressão & 22474,121 & 3 & 7491,3738 & \multicolumn{2}{|c|}{52,6633} & 0,9386464 \\
\hline Erro & 711,25209 & 5 & 142,25042 & \multicolumn{3}{|c|}{ Modelo } \\
\hline Total & 23185,373 & 8 & \multicolumn{4}{|c|}{$\ln A p=a+b D A S+c D A S^{2}+d D A S^{3}$} \\
\hline \multicolumn{3}{|c|}{ Parâmetro empírico } & Erro padrão & Valor $\mathrm{t}$ & \multicolumn{2}{|c|}{ Intervalo de confiança (95\%) } \\
\hline $\mathrm{a}$ & \multicolumn{2}{|c|}{0,007443522} & 0,00082686 & 9,002176900 & 0,005310149 & 0,009576895 \\
\hline b & \multicolumn{2}{|c|}{0,154008772} & 0,01710303 & 9,004764677 & 0,109881312 & 0,198136231 \\
\hline $\mathrm{c}$ & \multirow{2}{*}{\multicolumn{2}{|c|}{$\frac{-0,00144884}{356825 \mathrm{e}-06}$}} & 0,00048186 & $-3,00674060$ & $-0,00269209$ & $-0,00020558$ \\
\hline $\mathrm{d}$ & & & $3,30189 \mathrm{e}-06$ & 1,080669445 & $-4,9509 \mathrm{e}-06$ & $1,20874 \mathrm{e}-05$ \\
\hline
\end{tabular}

${ }^{1}$ Fonte de variação

${ }^{2}$ Soma dos quadrados

${ }^{3}$ Graus de liberdade

${ }^{4}$ Quadrado médio

* Nivel de significância: $1 \%$ 


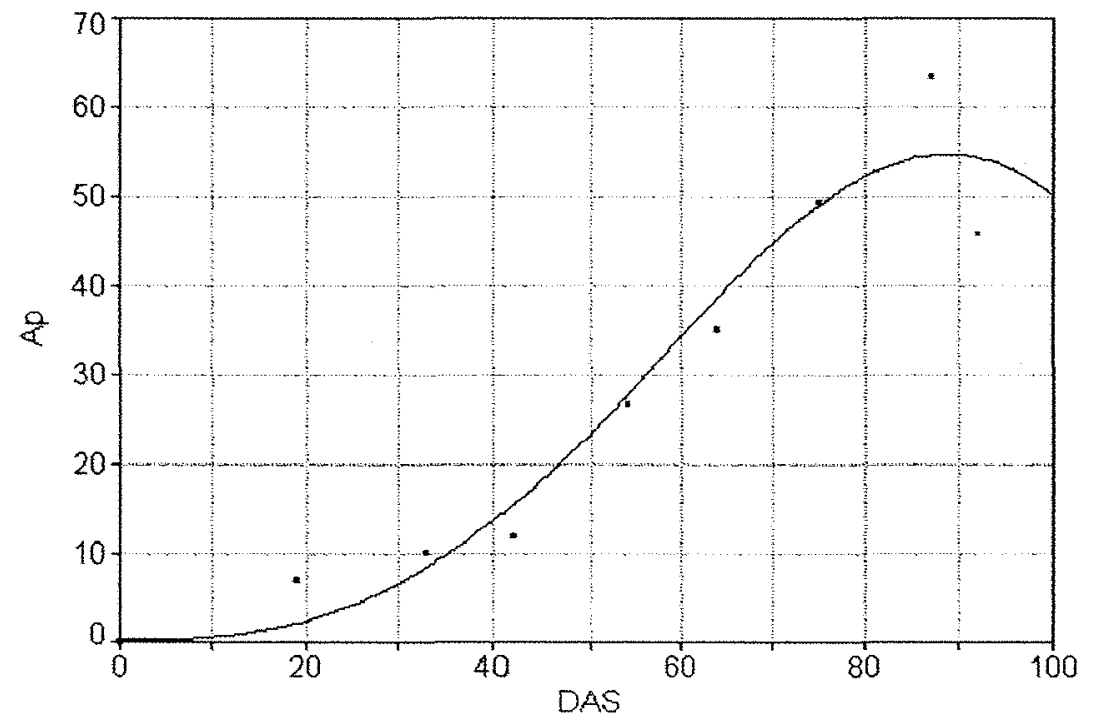

Figura 4. Variação da altura de planta $(\mathrm{Ap}, \mathrm{cm})$ do feijoeiro sob condição de sequeiro em função do número de dias após a semeadura (DAS).

Tabela 11. Análise de variância e parâmetros empíricos (a, b, c e d) referentes ao modelo para estimativa da altura das plantas $(\mathrm{Ap}, \mathrm{cm})$ do feijoeiro sob condição de sequeiro em função do número de dias após semeadura (DAS).

\begin{tabular}{|c|c|c|c|c|c|c|}
\hline $\mathrm{FV}^{1}$ & $\mathrm{SQ}^{2}$ & $\mathrm{GL}^{3}$ & $\mathrm{QM}^{4}$ & \multicolumn{2}{|c|}{$\mathbf{F}$} & $r^{2}$ \\
\hline Regressão & 3671,9747 & 3 & 1223,9916 & \multicolumn{2}{|c|}{29,8592} & 0,8942666723 \\
\hline Erro & 204,96064 & 5 & 40,992128 & \multicolumn{3}{|c|}{ Modelo } \\
\hline Total & 3876,9354 & 8 & \multicolumn{4}{|c|}{$A p^{0,5}=a+b D A S+c D A S^{2}+d D A S^{3}$} \\
\hline \multicolumn{3}{|c|}{ Parâmetro empírico } & Erro padrão & Valor $t$ & \multicolumn{2}{|c|}{ Intervalo de confiança (95\%) } \\
\hline $\mathrm{a}$ & \multicolumn{2}{|c|}{0,002546719} & 0,006936779 & 0,367132869 & $-0,01535083$ & 0,020444273 \\
\hline $\mathrm{b}$ & \multicolumn{2}{|c|}{0,043910723} & 0,119459646 & 0,367577880 & $-0,26430661$ & 0,352128056 \\
\hline c & \multirow{2}{*}{\multicolumn{2}{|c|}{$\frac{0,001822098}{-1.5545 \mathrm{e}-05}$}} & 0,003413125 & 0,533850312 & $-0,00698409$ & 0,010628287 \\
\hline $\mathrm{d}$ & & & $2,37611 \mathrm{e}-05$ & $-0,65421477$ & $-7,6851 \mathrm{e}-05$ & $4,5761 \mathrm{e}-05$ \\
\hline
\end{tabular}

Fonte de variação

${ }^{2}$ Soma dos quadrados

${ }^{3}$ Graus de liberdade

${ }^{4}$ Quadrado médio

* Nivel de significância: $1 \%$ 


\subsubsection{Massa de matéria seca}

\subsubsection{Raiz}

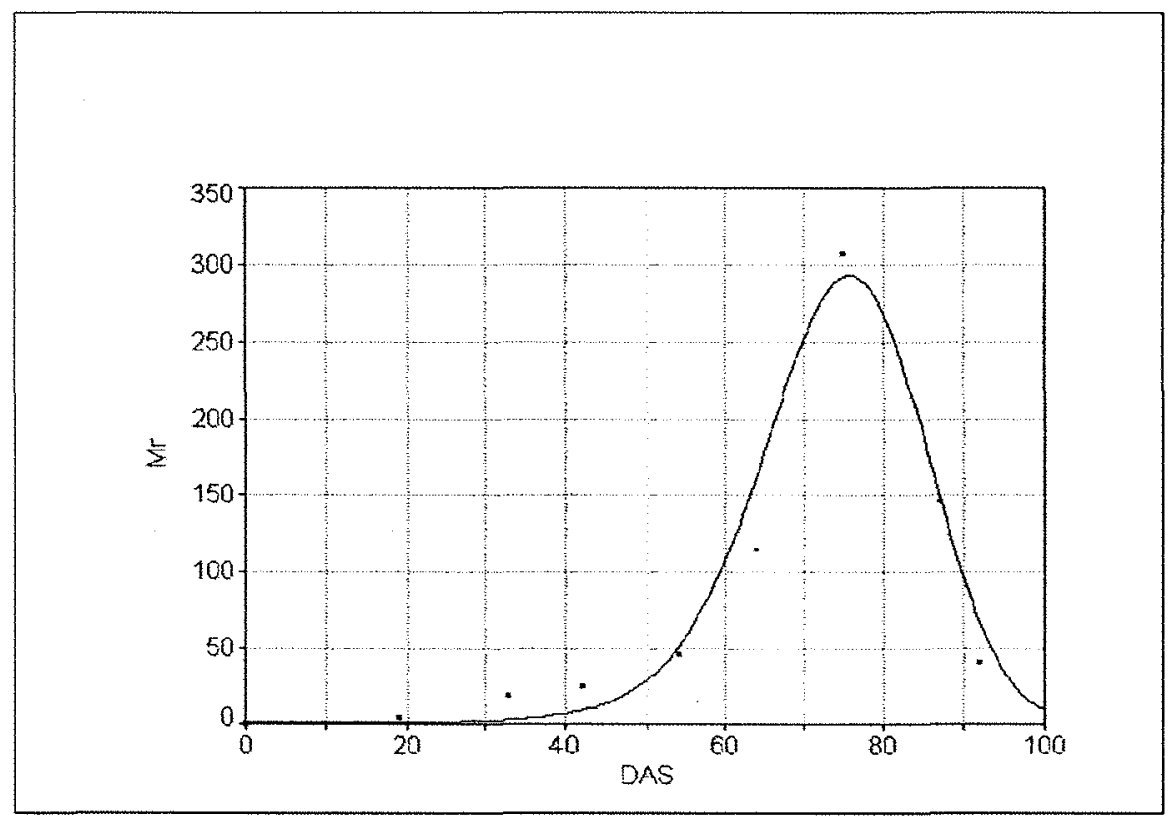

Figura 5. Variação da massa das raízes $(\mathrm{Mr}, \mathrm{g} / 5 \mathrm{pl})$ do feijoeiro sob irrigação em função do número de dias após a semeadura (DAS).

Tabela 12. Análise de variância e parâmetros empíricos (a, b, c e d) referentes ao modelo para estimativa da massa das raízes $(\mathrm{Mr}, \mathrm{g} / 5 \mathrm{pl})$ do feijoeiro sob irrigação em função do número de dias após semeadura (DAS).

\begin{tabular}{|c|c|c|c|c|c|c|}
\hline $\mathrm{FV}^{1}$ & $\mathbf{S Q}^{2}$ & $\mathrm{GL}^{3}$ & $\mathrm{QM}^{4}$ & \multicolumn{2}{|c|}{ F } & $r^{2}$ \\
\hline Regressão & 75068,251 & 3 & 25022,75 & \multicolumn{2}{|c|}{33,0124} & 0,9038805767 \\
\hline Erro & 3789,9 & 5 & 757,98 & \multicolumn{3}{|c|}{ Modelo } \\
\hline Total & 78858,151 & 8 & \multicolumn{4}{|c|}{$\ln M r=a+b D A S+c D A S^{2}+d D A S$} \\
\hline \multicolumn{3}{|c|}{ Parâmetro empírico } & Erro padrão & Valor $\mathrm{t}$ & \multicolumn{2}{|c|}{ Intervalo de confiança (95\%) } \\
\hline $\mathrm{a}$ & \multirow{2}{*}{\multicolumn{2}{|c|}{$\begin{array}{r}-0,00657619 \\
-014161058\end{array}$}} & 0,002921834 & $-2,25070686$ & $-0,01411481$ & 0,000962420 \\
\hline b & & & 0,062942259 & $-2,24999198$ & $-0,30401664$ & 0,020777481 \\
\hline c & \multicolumn{2}{|c|}{0,006702354} & 0,001645266 & 4,073721529 & 0,002457411 & 0,010947296 \\
\hline $\mathrm{d}$ & \multicolumn{2}{|c|}{$-5,0724 \mathrm{e}-05$} & $1,07499 \mathrm{e}-05$ & $-4,71857602$ & $-7,846 \mathrm{e}-05$ & $-2,2988 \mathrm{e}-05$ \\
\hline
\end{tabular}

Fonte de variação

${ }^{2}$ Soma dos quadrados

${ }^{3}$ Graus de liberdade

${ }^{4}$ Quadrado médio

* Nivel de significância: $1 \%$ 


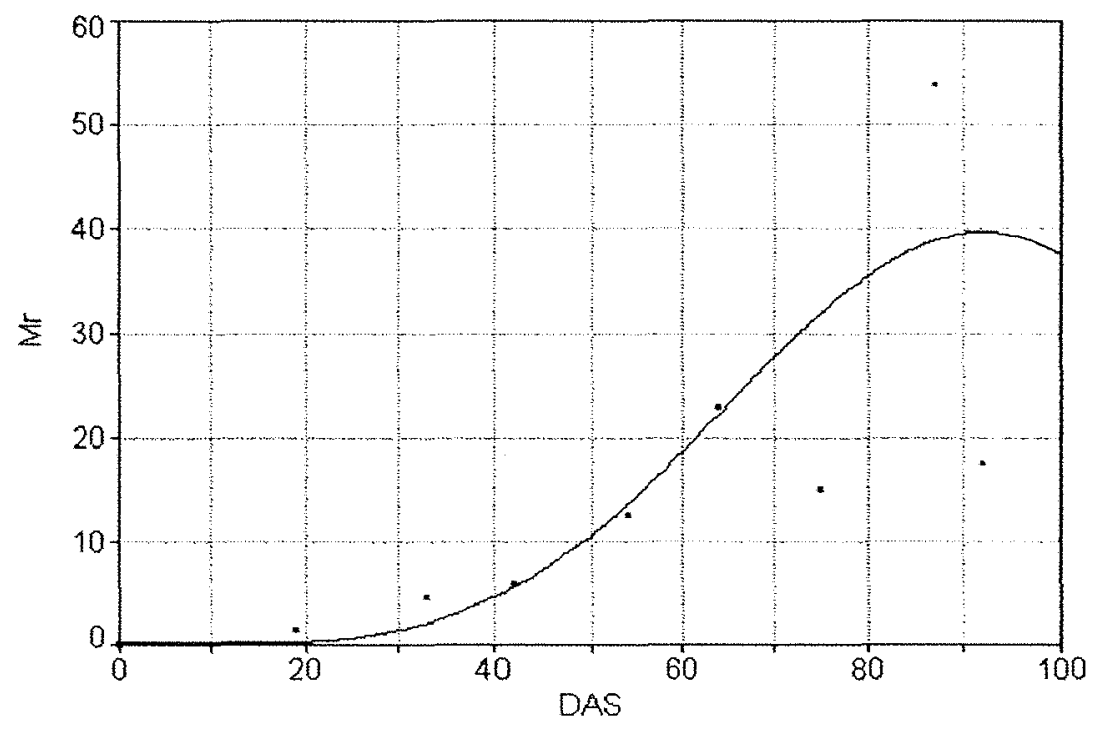

Figura 6. Variação da massa de matéria seca das raízes $(\mathrm{Mr}, \mathrm{g} / 5 \mathrm{pl})$ do feijoeiro sob condição de sequeiro em função do número de dias após a semeadura (DAS).

Tabela 13. Análise de variância e parâmetros empíricos (a, b, c e d) referentes ao modelo para estimativa da massa de matéria seca das raízes $(\mathrm{Mr}, \mathrm{g} / 5 \mathrm{pl})$ do feijoeiro sob condição de sequeiro em função do número de dias após semeadura (DAS).

\begin{tabular}{|c|c|c|c|c|c|c|}
\hline $\mathrm{FV}^{1}$ & $\mathbf{S Q}^{2}$ & $\mathrm{GL}^{3}$ & $\mathrm{QM}^{4}$ & \multicolumn{2}{|c|}{$F$} & $r^{2}$ \\
\hline Regressão & 1176,6333 & 3 & 392,21108 & \multicolumn{2}{|c|}{1,93584} & 0,0747194655 \\
\hline Erro & 1013,0233 & 5 & 202,60466 & \multicolumn{3}{|c|}{ Modelo } \\
\hline Total & 2189,6565 & 8 & \multicolumn{4}{|c|}{$M r^{0,5}=a+b D A S+c D A S^{2}+d D A S^{3}$} \\
\hline \multicolumn{3}{|c|}{ Parâmetro empirico } & Erro padrão & Valor $\mathrm{t}$ & \multicolumn{2}{|c|}{ Intervalo de confiança (95\%) } \\
\hline $\mathbf{a}$ & \multirow{2}{*}{\multicolumn{2}{|c|}{$\begin{array}{r}-0,00174039 \\
-0,03179240\end{array}$}} & 0,023959930 & $-0,07263772$ & $-0,06355931$ & 0,060078521 \\
\hline $\mathrm{b}$ & & & 0,438151845 & $-0,07256024$ & $-1,162266$ & 1,098681342 \\
\hline c & \multicolumn{2}{|c|}{0,002915736} & 0,012540838 & 0,232499298 & $-0,02944083$ & 0,035272298 \\
\hline $\mathrm{d}$ & \multicolumn{2}{|c|}{$-1,9864 \mathrm{e}-05$} & $8,71238 \mathrm{e}-05$ & $-0,22799862$ & $-0,00024465$ & 0,000204924 \\
\hline
\end{tabular}

Fonte de variação

${ }^{2}$ Soma dos quadrados

${ }^{3}$ Graus de liberdade

${ }^{4}$ Quadrado médio

* Nível de significância: $1 \%$ 


\subsubsection{Folha}

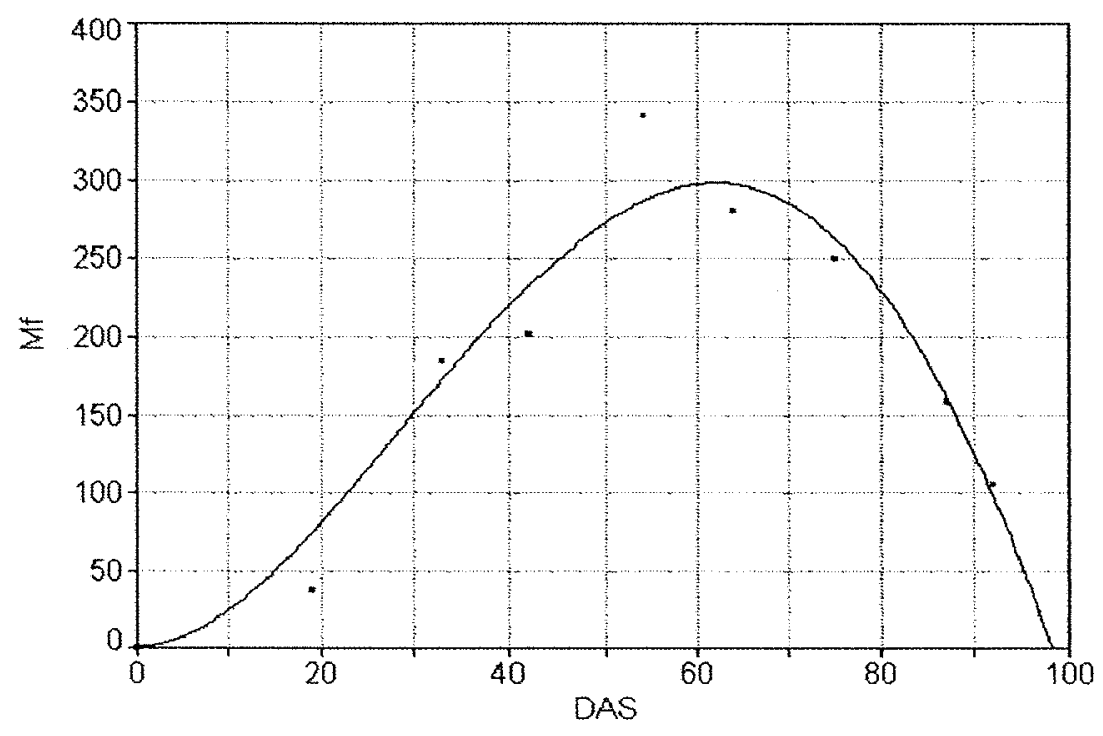

Figura 7. Variação da massa de matéria seca das folhas (Mf, g/5 pl) do feijoeiro sob irrigação em função do número de dias após a semeadura (DAS).

Tabela 14. Análise de variância e parâmetros empíricos (a, b, c e d) referentes ao modelo para estimativa da massa de matéria seca das folhas (Mf, $\mathrm{g} / 5 \mathrm{pl}$ ) do feijoeiro sob irrigação em função do número de dias após semeadura (DAS).

\begin{tabular}{|c|c|c|c|c|c|c|}
\hline $\mathrm{FV}^{1}$ & $\mathrm{SQ}^{2}$ & $\mathrm{GL}^{3}$ & $\mathbf{Q M}^{4}$ & \multicolumn{2}{|c|}{$\mathbf{F}$} & $r^{2}$ \\
\hline Regressão & 93521,935 & 4 & 23380,484 & \multicolumn{2}{|c|}{15,9765} & 0,8429196636 \\
\hline Erro & 5853,7365 & 4 & 1463,4341 & \multicolumn{3}{|c|}{ Modelo } \\
\hline Total & 99375,672 & 8 & \multicolumn{4}{|c|}{$M f=a+b D A S+c D A S^{2}+d D A S^{3}+e D A S^{4}$} \\
\hline \multicolumn{3}{|c|}{ Parâmetro empírico } & Erro padrão & Valor $\mathrm{t}$ & \multicolumn{2}{|c|}{ Intervalo de confiança (95\%) } \\
\hline a & \multicolumn{2}{|c|}{0,000577478} & 0,000147437 & 3,916771145 & 0,000167626 & 0,000987331 \\
\hline b & \multirow{2}{*}{\multicolumn{2}{|c|}{$\begin{array}{l}0,014541065 \\
0269386070\end{array}$}} & 0,003712228 & 3,917071746 & 0,004221652 & 0,024860477 \\
\hline c & & & 0,068756158 & 3,917991890 & 0,078254738 & 0,460517402 \\
\hline d & \multicolumn{2}{|c|}{$-0,00371783$} & 0,001946791 & $-1,90972244$ & $-0,00912960$ & 0,001693943 \\
\hline $\mathrm{e}$ & \multicolumn{2}{|c|}{$9,93302 \mathrm{e}-06$} & $1,33924 \mathrm{e}-05$ & 0,741691655 & $-2,7296 e-05$ & $4,71618 \mathrm{e}-05$ \\
\hline
\end{tabular}

Fonte de variação

${ }^{2}$ Soma dos quadrados

${ }^{3}$ Graus de liberdade

${ }^{4}$ Quadrado médio

* Nível de significância: 1\% 


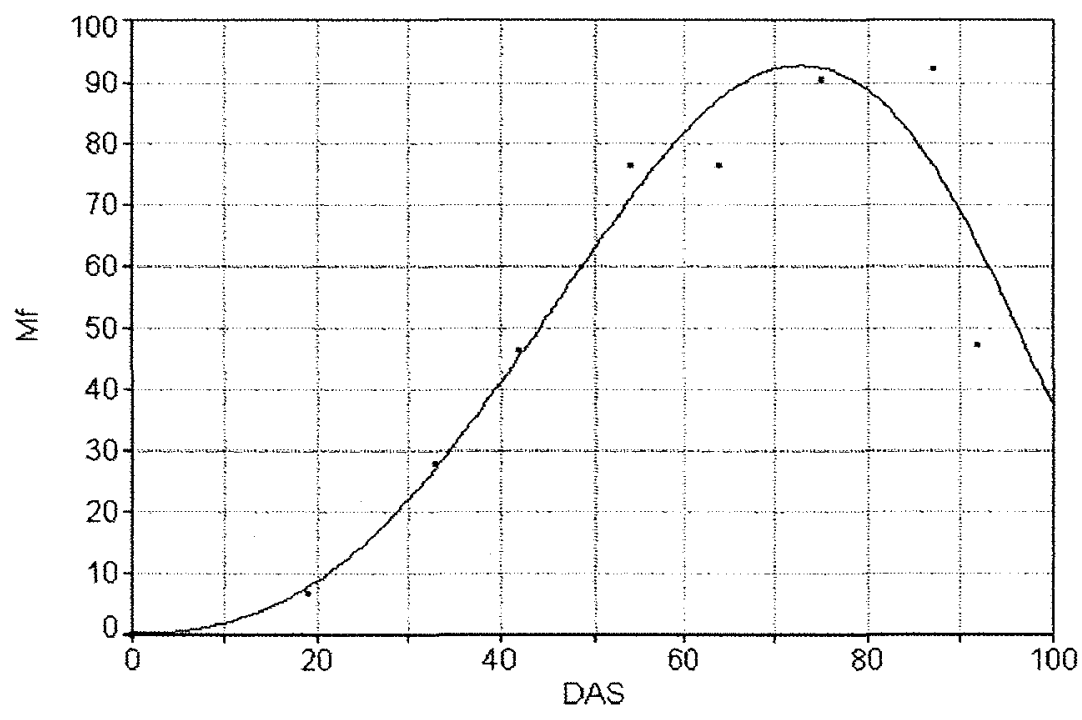

Figura 8. Variação da massa de matéria seca de folhas (Mf, g/5 pl) do feijoeiro em condição de sequeiro em função do número de dias após a semeadura (DAS).

Tabela 15. Análise de variância e parâmetros empíricos (a, b, c e d) referentes ao modelo para estimativa da massa de matéria seca de das folhas (Mf, g/5 pl) do feijoeiro em condição de sequeiro em função do número de dias após semeadura (DAS).

\begin{tabular}{|c|c|c|c|c|c|c|}
\hline $\mathrm{FV}^{\mathrm{I}}$ & $\mathrm{SQ}^{2}$ & $\mathrm{GL}^{3}$ & $\mathrm{QM}^{4}$ & \multicolumn{2}{|c|}{$\mathbf{F}$} & $\mathrm{r}^{2}$ \\
\hline Regressão & 8991,0859 & 3 & 2997,0286 & \multicolumn{2}{|c|}{22,9332} & 0,8644979806 \\
\hline Erro & 653,42538 & 5 & 130,68508 & \\
\hline Total & 9644,5113 & 8 & \multicolumn{4}{|c|}{$M f^{0,5}=a+b D A S+c D A S^{2}+d D A S^{3}$} \\
\hline \multicolumn{3}{|c|}{ Parâmetro empírico } & Erro padrão & Valor $\mathbf{t}$ & \multicolumn{2}{|c|}{ Intervalo de confiança (95\%) } \\
\hline $\mathbf{a}$ & \multicolumn{2}{|c|}{0,005905644} & 0,008007917 & 0,737475653 & $-0,01475555$ & 0,026566836 \\
\hline b & \multicolumn{2}{|c|}{0,108012387} & 0,146333306 & 0,738125787 & $-0,26954157$ & 0,485566339 \\
\hline $\mathbf{c}$ & \multicolumn{2}{|c|}{0,002467970} & 0,004331338 & 0,569793875 & $-0,00870730$ & 0,013643238 \\
\hline $\mathrm{d}$ & \multicolumn{2}{|c|}{$-2,9383 \mathrm{e}-05$} & $3,09881 \mathrm{e}-05$ & $-0,94821126$ & $-0,00010934$ & $5,05691 \mathrm{e}-05$ \\
\hline
\end{tabular}

\footnotetext{
Fonte de variação

${ }^{2}$ Soma dos quadrados

${ }^{3}$ Graus de liberdade

${ }^{4}$ Quadrado médio

* Nível de significância: $1 \%$
} 


\subsubsection{Haste}

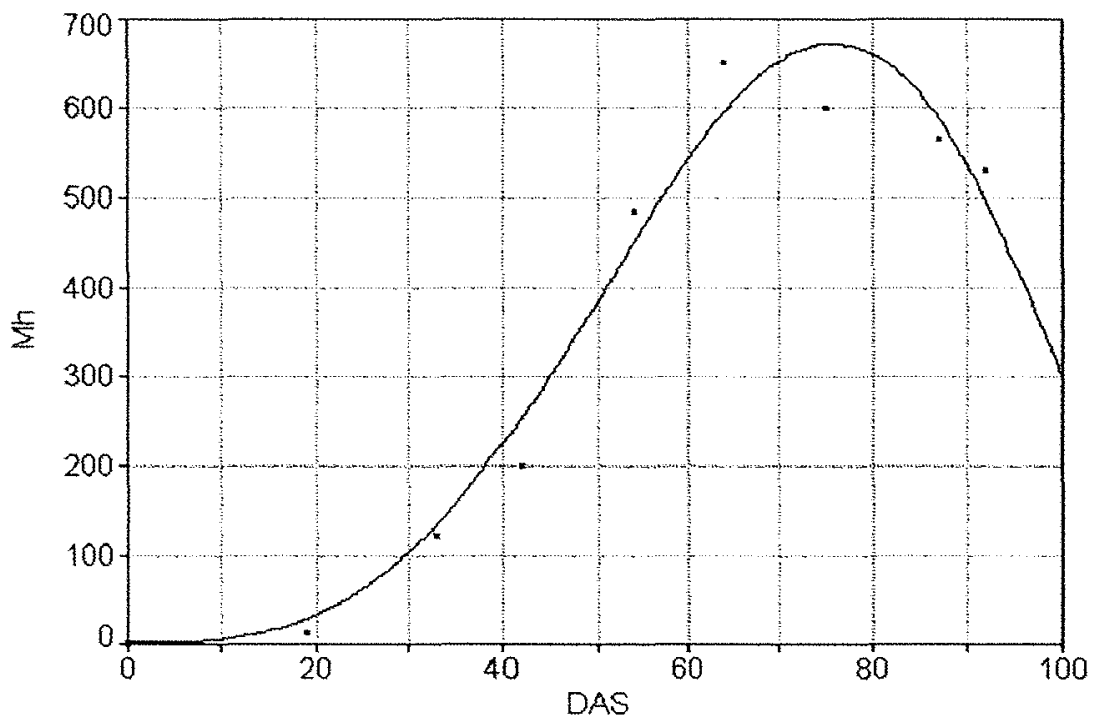

Figura 9. Variação da massa de matéria seca das hastes $(\mathrm{Mh}, \mathrm{g} / 5 \mathrm{pl})$ do feijoeiro sob irrigação em função do número de dias após a semeadura (DAS).

Tabela 16. Análise de variância e parâmetros empíricos (a, b, c e d) referentes ao modelo para estimativa da massa de matéria seca das hastes $(\mathrm{Mh}, \mathrm{g} / 5 \mathrm{pl})$ do feijoeiro sob irrigação em função do número de dias após semeadura (DAS).

\begin{tabular}{|c|c|c|c|c|c|c|}
\hline $\mathrm{FV}^{1}$ & $\mathrm{SQ}^{2}$ & $\mathrm{GL}^{3}$ & $\mathrm{QM}^{4}$ & \multicolumn{2}{|c|}{$F$} & $r^{2}$ \\
\hline Regressão & 546154,59 & 3 & 182051,53 & \multicolumn{2}{|c|}{63,041} & 0,9484862719 \\
\hline Erro & 14439,136 & 5 & 2887,8273 & \multicolumn{3}{|c|}{ Modelo } \\
\hline Total & 560593,73 & 8 & \multicolumn{4}{|c|}{$M h^{0,5}=a+b D A S+c D A S^{2}$} \\
\hline \multicolumn{3}{|c|}{ Parâmetro empírico } & Erro padrão & Valor $\mathrm{t}$ & \multirow{2}{*}{\multicolumn{2}{|c|}{ Intervalo de confiança (95\%) }} \\
\hline$a$ & \multirow{2}{*}{\multicolumn{2}{|c|}{0,005325906}} & 0,015902426 & 0,334911565 & & \\
\hline$b$ & & & 0,307244069 & 0,335635640 & $-0,68959708$ & 0,895841199 \\
\hline c & \multicolumn{2}{|c|}{$\frac{0,103122060}{0,010804954}$} & 0,008762466 & 1,233095123 & $-0,01180305$ & 0,033412955 \\
\hline $\mathrm{d}$ & \multicolumn{2}{|c|}{$-0,00010105$} & $6,06567 \mathrm{e}-05$ & $-1,66596076$ & $-0,00025755$ & $5,54484 \mathrm{e}-05$ \\
\hline
\end{tabular}

\footnotetext{
${ }^{\top}$ Fonte de variação

${ }^{2}$ Soma dos quadrados

${ }^{3}$ Graus de liberdade

${ }^{4}$ Quadrado médio
}

* Nível de significância: $1 \%$ 


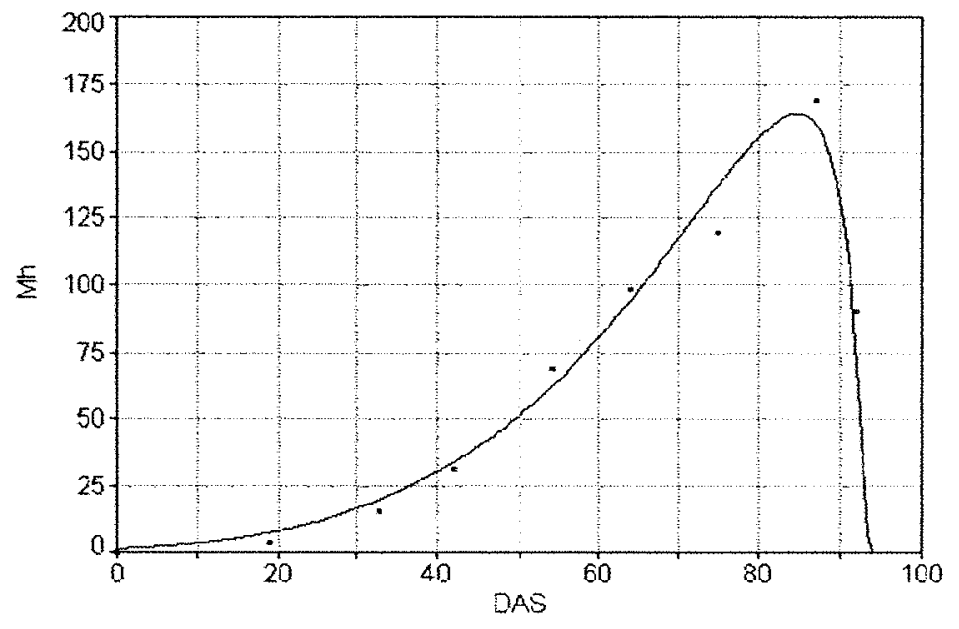

Figura 10. Variação da massa de matéria seca das hastes $(\mathrm{Mh}, \mathrm{g} / 5 \mathrm{pl})$ do feijoeiro sob condição de sequeiro em função do número de dias após a semeadura (DAS).

Tabela 17. Análise de variância e parâmetros empíricos (a, b, c e d) referentes ao modelo para estimativa da massa de matéria seca das hastes $(\mathrm{Mh}, \mathrm{g} / 5 \mathrm{pl})$ do feijoeiro sob condição de sequeiro em função do número de dias após semeadura (DAS).

\begin{tabular}{|c|c|c|c|c|c|c|}
\hline $\mathrm{FV}^{1}$ & $\mathbf{S Q}^{2}$ & $\mathrm{GL}^{3}$ & $\mathbf{Q M}^{4}$ & \multicolumn{2}{|c|}{ F } & $\mathrm{r}^{2}$ \\
\hline Regressão & 26195,788 & 4 & 6548,9469 & \multicolumn{2}{|c|}{31,3349} & 0,9175297986 \\
\hline Erro & 835,99367 & $\overline{4}$ & 208,99842 & \multicolumn{3}{|c|}{ Modelo } \\
\hline Total & 27031,781 & 8 & \multirow{2}{*}{\multicolumn{4}{|c|}{$\ln M h+\frac{a+c D A S+e D A S^{2}}{1+b D A S+d D A S^{2}}$}} \\
\hline & & & & & & \\
\hline \multicolumn{3}{|c|}{ Parâmetro empírico } & Erro padrão & Valor t & \multicolumn{2}{|c|}{ Intervalo de confiança (95\%) } \\
\hline $\mathbf{a}$ & \multicolumn{2}{|c|}{0,007827154} & 0,004073556 & 1,921454756 & $-0,00349669$ & 0,019151002 \\
\hline b & \multirow{2}{*}{\multicolumn{2}{|c|}{0,000663209}} & 0,014122175 & 0,046962246 & $-0,03859422$ & 0,039920640 \\
\hline c & & & 0,062494962 & 1,975338083 & $-0,05027751$ & 0,297174868 \\
\hline $\mathrm{d}$ & \multicolumn{2}{|c|}{$-0,00012006$} & 0,000168317 & $-0,71329417$ & $-0,00058795$ & 0,000347835 \\
\hline $\mathrm{e}$ & \multicolumn{2}{|c|}{$-0,00132013$} & 0,000754265 & $-1,75022093$ & $-0,00341687$ & 0,000776608 \\
\hline
\end{tabular}

Fonte de variação

${ }^{2}$ Soma dos quadrados

${ }^{3}$ Graus de liberdade

${ }^{4}$ Quadrado médio

* Nível de significância: $1 \%$ 


\subsubsection{Vagem}

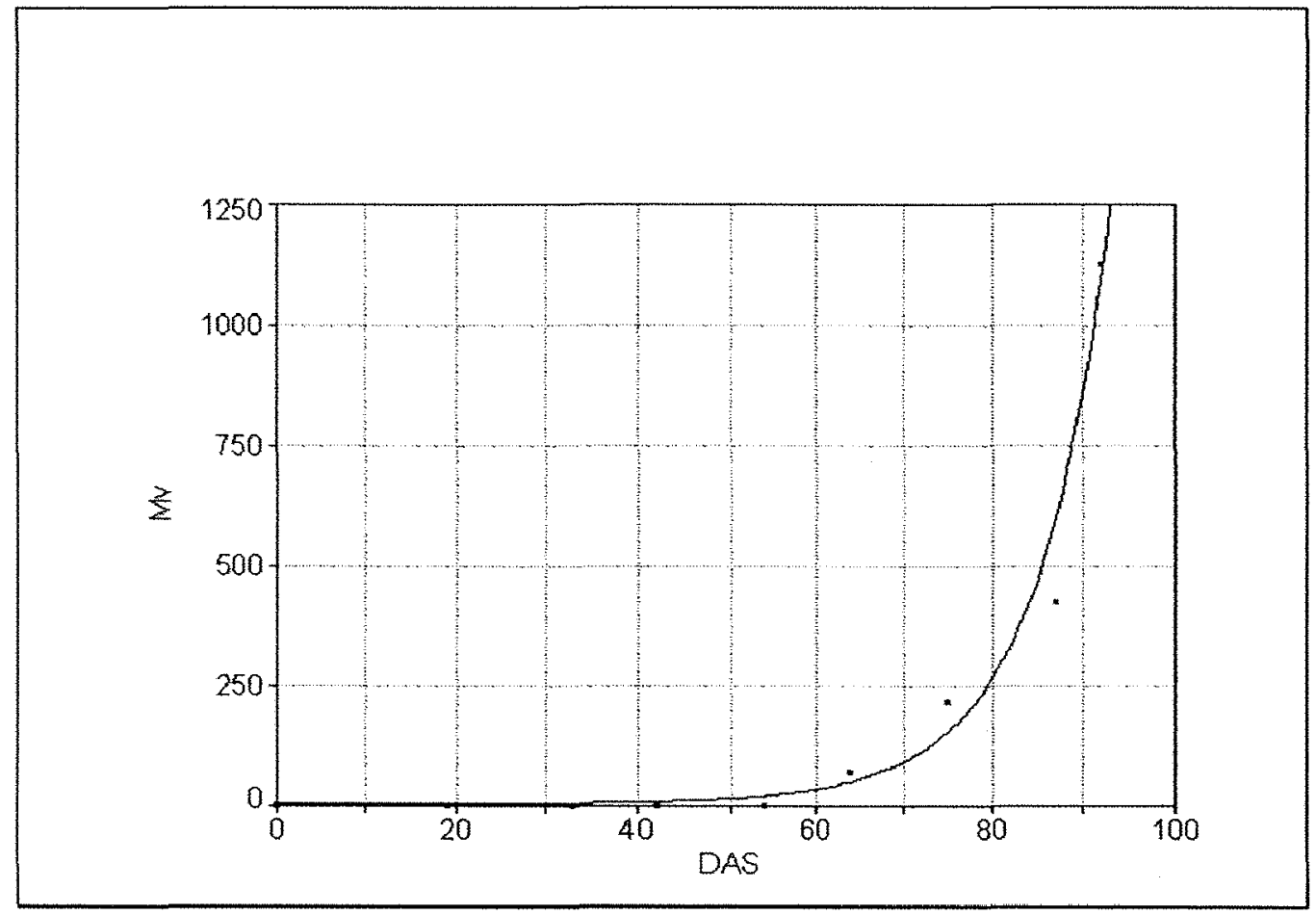

Figura 11. Variação da massa de matéria seca das vagens $(\mathrm{Mv}, \mathrm{g} / 5 \mathrm{pl})$ do feijoeiro sob irrigação em função do número de dias após a semeadura (DAS).

Tabela 18. Análise de variância e parâmetros empíricos (a, b, c e d) referentes ao modelo para estimativa da massa de matéria seca das vagens $(\mathrm{Mv}, \mathrm{g} / 5 \mathrm{pl})$ do feijoeiro sob irrigação em função do número de dias após semeadura (DAS).

\begin{tabular}{|c|c|c|c|c|c|c|}
\hline $\mathrm{FV}^{1}$ & $\mathrm{SQ}^{2}$ & $\mathrm{GL}^{3}$ & $\mathrm{QM}^{4}$ & \multicolumn{2}{|c|}{$\mathrm{F}$} & $\mathrm{r}^{2}$ \\
\hline Regressão & 1083401,7 & 1 & 1083401,7 & \multicolumn{2}{|c|}{211,903} & 0,9573631827 \\
\hline Erro & 35789,047 & 7 & 5112,721 & \multicolumn{3}{|c|}{ Modelo } \\
\hline Total & 1119190,7 & 8 & \multicolumn{5}{|c|}{$\ln M v=a+b D A S^{1,5}$} \\
\hline \multicolumn{2}{|c|}{ Parâmetro empírico } & Erro padrão & Valor t & Intervalo de confiança (95\%) \\
\hline a & $-0,45215687$ & 1,029457697 & $-0,43921851$ & $-2,89602436$ & 1,991710614 \\
\hline b & 0,008432463 & 0,001187527 & 7,100861424 & 0,005613350 & 0,011251577 \\
\hline
\end{tabular}

Fonte de variação

${ }^{2}$ Soma dos quadrados

${ }^{3}$ Graus de liberdade

${ }^{4}$ Quadrado médio

* Nível de significância: 1\% 


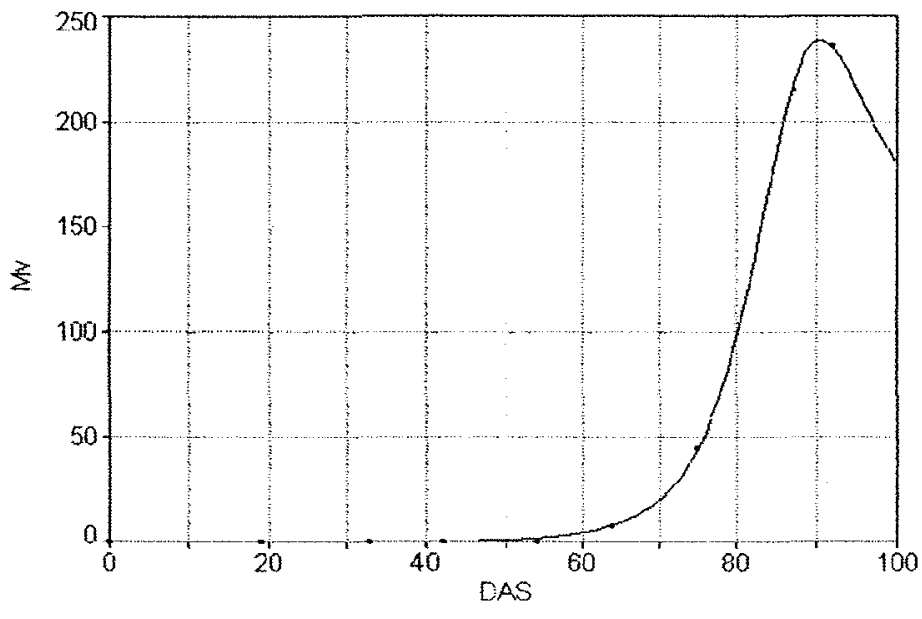

Figura 12. Variação da massa de matéria seca das vagens $(\mathrm{Mv}, \mathrm{g} / 5 \mathrm{pl})$ do feijoeiro sob condição de sequeiro em função do número de dias após a semeadura (DAS).

Tabela 19. Análise de variância e parâmetros empíricos (a, b, c e d) referentes ao modelo para estimativa da massa das vagens $(\mathrm{Mv}, \mathrm{g} / 5 \mathrm{pl})$ em função do número de dias após semeadura (DAS).

\begin{tabular}{|c|c|c|c|c|c|c|}
\hline $\mathrm{FV}^{1}$ & $\mathrm{SQ}^{2}$ & $\mathrm{GL}^{3}$ & $\mathrm{QM}^{4}$ & \multicolumn{2}{|c|}{$\mathrm{F}$} & $r^{2}$ \\
\hline Regressão & 75536,484 & 5 & 15107,297 & \multicolumn{2}{|c|}{4258,13} & 0,9994364514 \\
\hline Erro & 10,64362 & 3 & 3,5478733 & \multicolumn{3}{|c|}{ Modelo } \\
\hline Total & 75547,128 & 8 & \multicolumn{4}{|c|}{$M v=\frac{a+c D A S+e D A S^{2}}{1+b D A S+d D A S^{2}+f D A S^{3}}$} \\
\hline \multicolumn{3}{|c|}{ Parâmetro empírico } & Erro padrão & Valor $\mathrm{t}$ & \multicolumn{2}{|c|}{ Intervalo de confiança (95\%) } \\
\hline a & \multicolumn{2}{|c|}{$-0,00050054$} & 0,000515182 & $-0,97157745$ & $-0,00212791$ & 0,001126836 \\
\hline b & \multirow{2}{*}{\multicolumn{2}{|c|}{$\begin{array}{r}-0,03043928 \\
-0,01257734\end{array}$}} & 0,031310843 & $-0,97216403$ & $-0,12934515$ & 0,068466603 \\
\hline c & & & 0,012948638 & $-0,97132515$ & $-0,05347999$ & 0,028325313 \\
\hline $\mathrm{d}$ & \multicolumn{2}{|c|}{0,000306288} & 0,000707230 & 0,433081653 & $-0,00192774$ & 0,002540312 \\
\hline $\mathrm{e}$ & \multicolumn{2}{|c|}{0,000270997} & 0,000312031 & 0,868493948 & $-0,00071466$ & 0,001256652 \\
\hline$f$ & \multicolumn{2}{|c|}{$-1,0109 \mathrm{e}-06$} & $4,00513 \mathrm{e}-06$ & $-0,25239638$ & $-1,3662 e-05$ & $1,16407 \mathrm{e}-05$ \\
\hline
\end{tabular}

\footnotetext{
Fonte de variação

${ }^{2}$ Soma dos quadrados

${ }^{3}$ Graus de liberdade

${ }^{4}$ Quadrado médio

* Nível de significância: $1 \%$
} 


\subsubsection{Total}

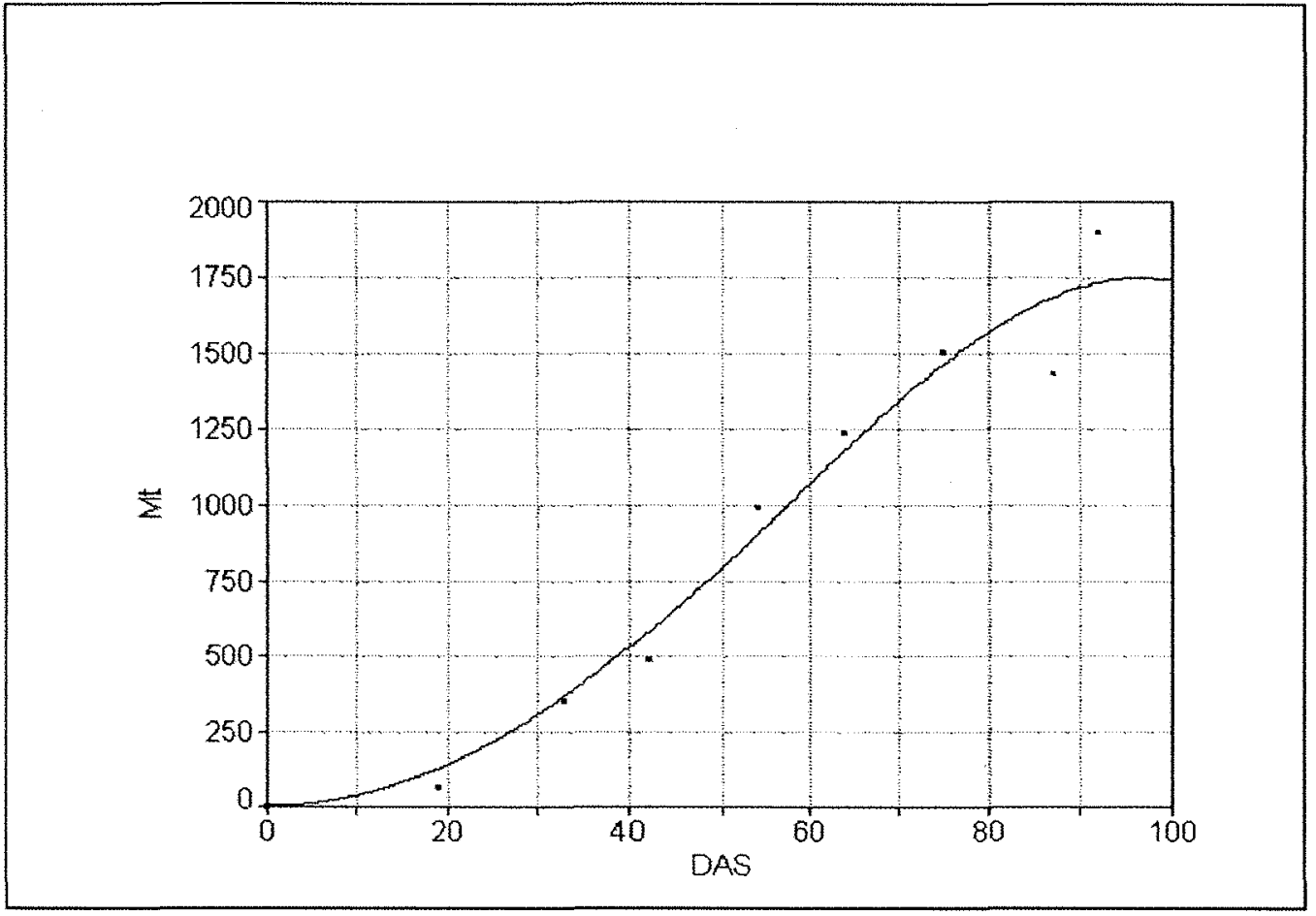

Figura 13. Variação da massa de matéria seca total (Mt, g) do feijoeiro sob irrigação em função do número de dias após a semeadura (DAS).

Tabela 20. Análise de variância e parâmetros empíricos (a, b, c e d) referentes ao modelo para estimativa da massa de matéria seca total (Mt, g) do feijoeiro sob irrigação em função do número de dias após semeadura (DAS).

\begin{tabular}{|c|c|c|c|c|c|c|}
\hline $\mathrm{FV}^{1}$ & $\mathrm{SQ}^{2}$ & $\mathrm{GL}^{3}$ & $\mathbf{Q M}^{4}$ & \multicolumn{2}{|c|}{$\mathrm{F}$} & $r^{2}$ \\
\hline Regressão & 3609887,4 & 4 & 902471,85 & \multicolumn{2}{|c|}{30,8597} & 0,9162998049 \\
\hline Erro & 116977,24 & 4 & 29244,309 & \multicolumn{3}{|c|}{ Modelo } \\
\hline Total & 3726864,6 & 8 & \multicolumn{4}{|c|}{$M t=a+b D A S+c D A S^{2}+d D A S^{3}+e$} \\
\hline \multicolumn{3}{|c|}{ Parâmetro empírico } & Erro padrão & Valor $\mathrm{t}$ & \multicolumn{2}{|c|}{ Intervalo de confiança $(95 \%)$} \\
\hline$a$ & \multirow{2}{*}{\multicolumn{2}{|c|}{0,000710819}} & 0,000659085 & 1,078492928 & $-0,00112133$ & 0,002542972 \\
\hline$\frac{a}{b}$ & & & 0,016594676 & 1,078671883 & $-0,02823039$ & 0,064030806 \\
\hline c & \multicolumn{2}{|c|}{0,017900210} & 0,307358831 & 1,079219672 & $-0,52270163$ & 1,186117026 \\
\hline $\mathrm{d}$ & \multicolumn{2}{|c|}{0,000878166} & 0,008702687 & 0,100907429 & $-0,02331394$ & 0,025070271 \\
\hline $\mathrm{e}$ & \multicolumn{2}{|c|}{$-2,4629 \mathrm{e}-05$} & $5,98676 \mathrm{e}-05$ & $-0,41139415$ & $-0,00019105$ & 0,000141793 \\
\hline
\end{tabular}

\footnotetext{
Fonte de variação

${ }^{2}$ Soma dos quadrados

${ }^{3}$ Graus de liberdade

${ }^{4}$ Quadrado médio
}

* Nível de significância: $1 \%$ 


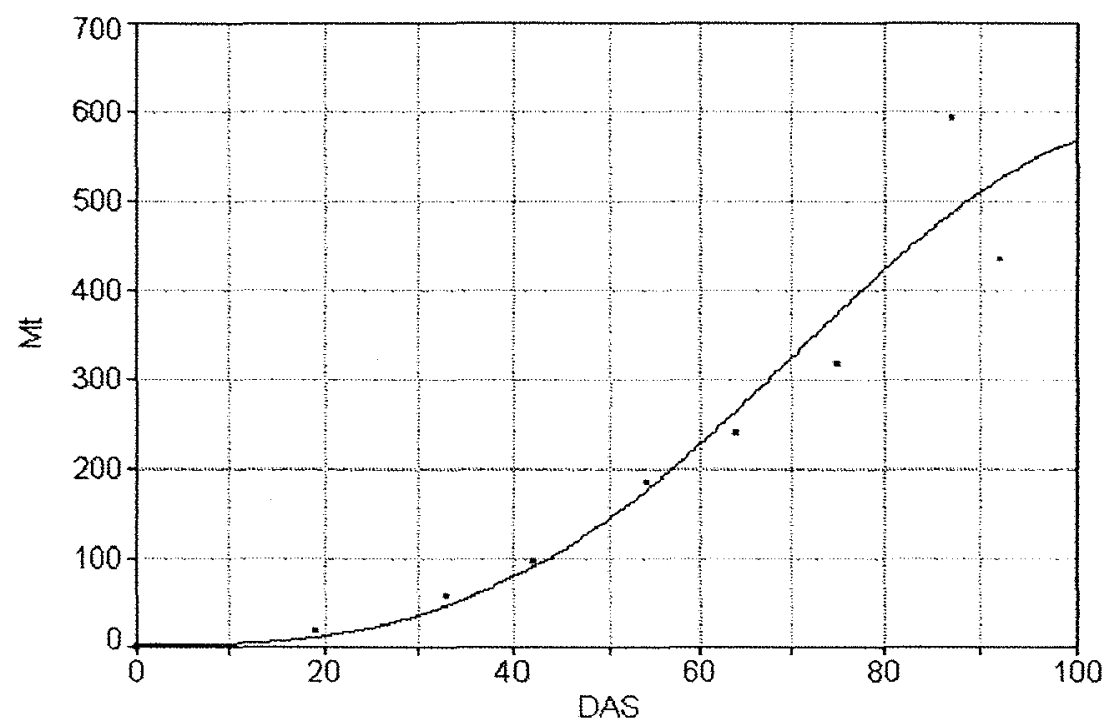

Figura 14. Variação da massa de matéria seca total (Mt, $\mathrm{g} / 5 \mathrm{pl})$ do feijoeiro sob condição de sequeiro em função do número de dias após a semeadura (DAS).

Tabela 21. Análise de variância e parâmetros empíricos (a, b, c e d) referentes ao modelo para estimativa da massa de matéria seca total $(\mathrm{Mt}, \mathrm{g})$ do feijoeiro sob condição de sequeiro em função do número de dias após semeadura (DAS).

\begin{tabular}{|c|c|c|c|c|c|c|}
\hline $\mathrm{FV}^{1}$ & $\mathbf{S Q}^{2}$ & $\mathrm{GL}^{3}$ & $\mathbf{Q M}^{4}$ & \multicolumn{2}{|c|}{$F$} & $r^{2}$ \\
\hline Regressão & 304166,35 & 3 & 101388,78 & \multicolumn{2}{|c|}{21,6796} & 0,8572221949 \\
\hline Erro & 23383,419 & 5 & 4676,6838 & \multicolumn{3}{|c|}{ Modelo } \\
\hline Total & 327549,77 & 8 & \multicolumn{4}{|c|}{$M t^{0,5}=a+b D A S+c D A S^{2}+d D A S^{3}$} \\
\hline \multicolumn{3}{|c|}{ Parâmetro empírico } & Erro padrão & Valor $\mathrm{t}$ & \multicolumn{2}{|c|}{ Intervalo de confiança $(95 \%)$} \\
\hline $\mathrm{a}$ & \multirow{2}{*}{\multicolumn{2}{|c|}{0,004415203}} & 0,028318419 & 0,155912758 & $-0,06864903$ & 0,077479437 \\
\hline$b$ & & & 0,52951 & 017 & $-1,28$ & 1,448860304 \\
\hline c & \multicolumn{2}{|c|}{0,004658409} & 0,014989525 & 0,310777617 & $-0,03401600$ & 0,043332821 \\
\hline $\mathrm{d}$ & \multicolumn{2}{|c|}{$-3,1053 e-05$} & 0,000103159 & $-0,30102113$ & $-0,00029721$ & 0,000235107 \\
\hline
\end{tabular}

\footnotetext{
${ }^{1}$ Fonte de variação

${ }^{2}$ Soma dos quadrados

${ }^{3}$ Graus de liberdade

${ }^{4}$ Quadrado médio

* Nível de significância: $1 \%$
} 
Irrigado
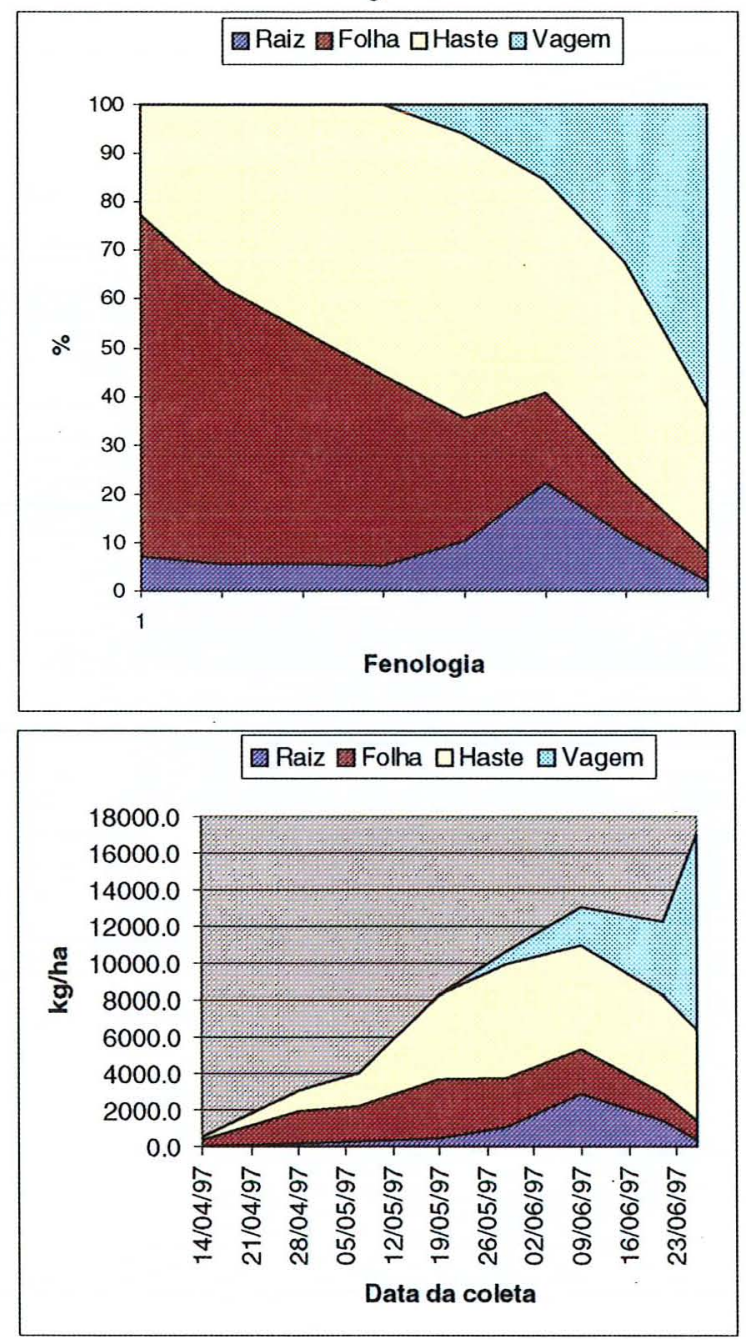

Sequeiro
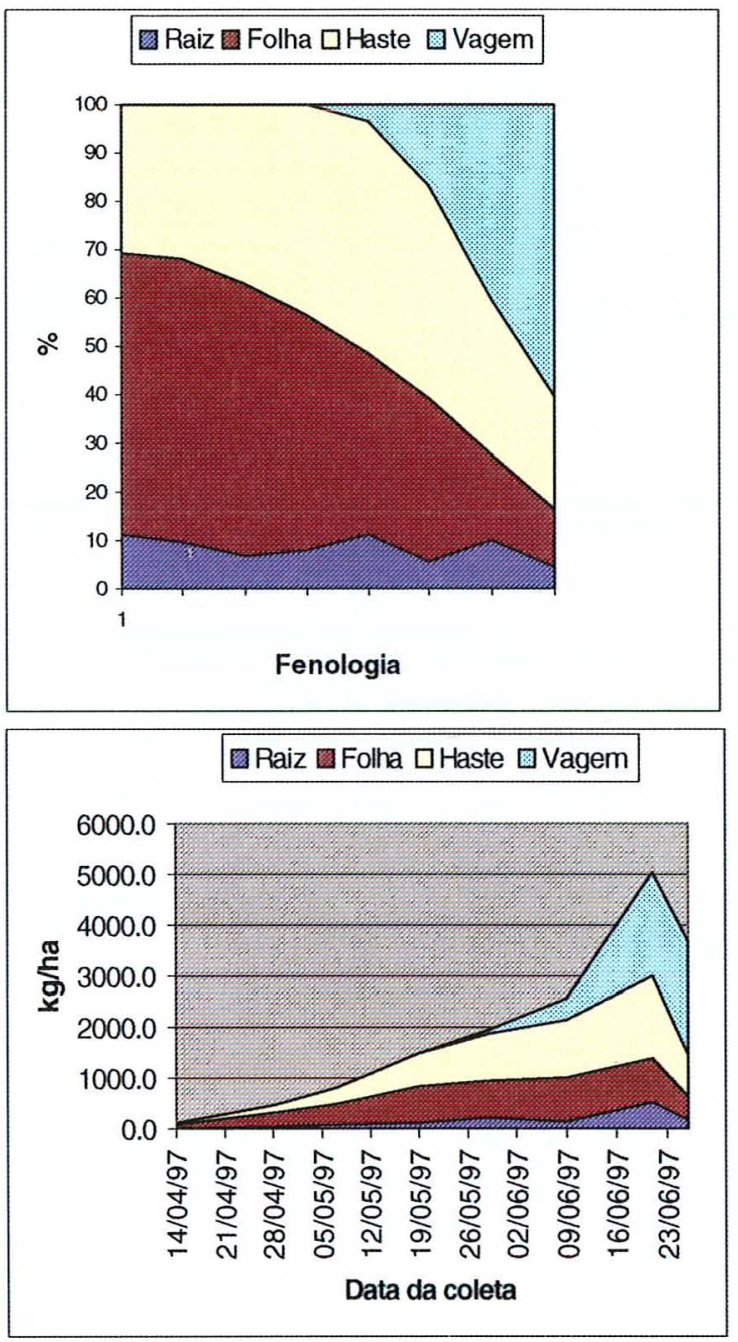

Figura 15. Partição relativa (\%) e absoluta $(\mathrm{kg} / \mathrm{ha})$ de massa de matéria seca de raiz, folha, haste e vagem do feijoeiro sob condição de irrigação e de sequeiro.

A Figura 15 ilustra a diferença de produção de massa de matéria seca de raiz, folha, haste e vagem da cultura de feijão sob condição de irrigação e de sequeiro.

\subsubsection{Rendimento de grãos índice de colheita}

A Figura 16A mostra que o rendimento de grãos é superior cerca de quatro vezes quando sob condição de irrigação quando comparado com a condição de sequeiro. Essa informação é importante para estudos de viabilidade econômica da adoção da técnica de 
irrigação. A Figura 16B mostra que o índice de colheita é variável com a condição de deficiência ou suficiência hídrica.

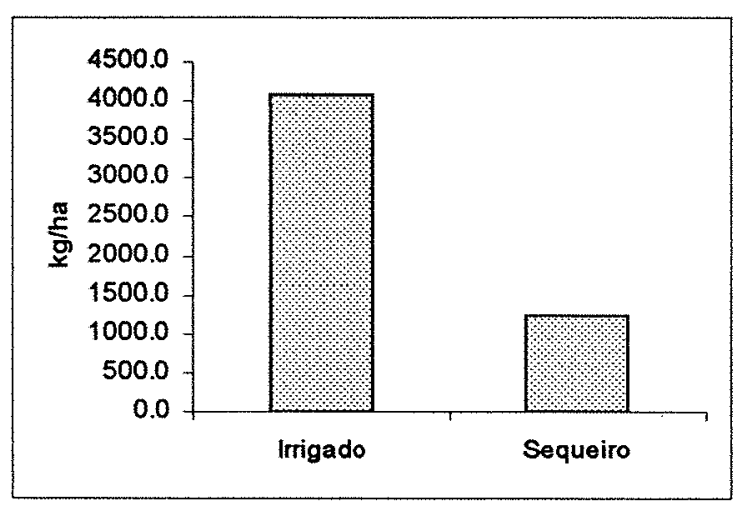

(A)

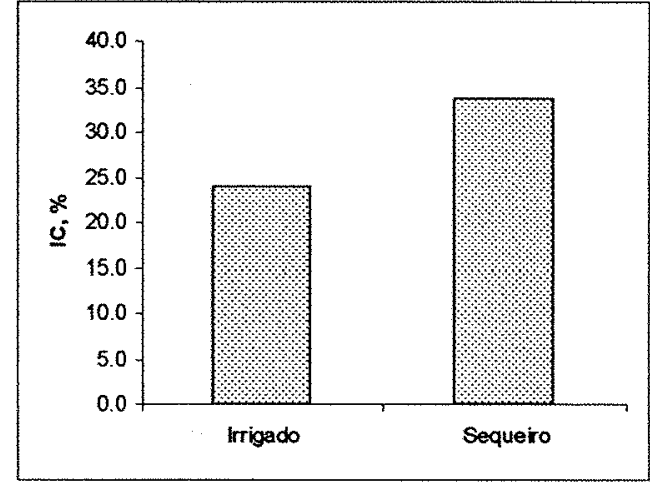

(B)

Figura 16. Rendimento de grãos (kg/ha) (A) e indice de colheita (\%) (B) referente à cultura de feijão sob condição de irrigação e de sequeiro.

\subsection{Experimento II}

A fenologia foi realizada diariamente. As determinações de massa de matéria seca da parte aérea, bem como dos teores de nitrogênio, fósforo, potássio, cálcio, magnésio e enxofre, foram realizadas periodicamente.

\subsubsection{Fenologia}

O ciclo da cultura teve duração de 84 dias. Para o cálculo do número de graus-dia acumulado diariamente, utilizou-se temperatura base inferior de $10^{\circ} \mathrm{C}$ e temperatura base superior de $28^{\circ} \mathrm{C}$. 
Tabela 22. Dias após a emergência (DAE), temperatura média do ar $\left(\mathrm{T},{ }^{\circ} \mathrm{C}\right)$, estádio fenológico, graus-dia (GD, ${ }^{\circ} \mathrm{C}$.dia) e desenvolvimento relativo (Dr) da cultura de feijão durante a fase vegetativa $(0)$.

\begin{tabular}{|c|c|c|c|c|c|c|c|}
\hline Dia & DAE & $\mathrm{T},{ }^{\circ} \mathrm{C}$ & Fase & Estádio & $\mathrm{T}-\mathrm{Tb}$ & GD & Dr \\
\hline 24/Abr & 0 & 20,9 & 0 & $V_{1}$ & 10,9 & 10,9 & 0,01 \\
\hline 25/Abr & 1 & 21,8 & 0 & & 11,8 & 22,7 & 0,03 \\
\hline 26/Abr & 2 & 21,8 & 0 & & 11,8 & 34,5 & 0,04 \\
\hline 27/Abr & 3 & 22,3 & 0 & & 12,3 & 46,8 & 0,06 \\
\hline 28/Abr & 4 & 22,5 & 0 & & 12,5 & 59,3 & 0,07 \\
\hline 29/Abr & 5 & 22,8 & 0 & & 12,8 & 72,1 & 0,09 \\
\hline 30/Abr & 6 & 23,3 & 0 & & 13,3 & 85,4 & 0,10 \\
\hline 01/Mai & 7 & 23,8 & 0 & & 13,8 & 99,2 & 0,12 \\
\hline 02/Mai & 8 & 22,8 & 0 & $\mathrm{~V}_{2}$ & 12,8 & 112,0 & 0,14 \\
\hline 03/Mai & 9 & 22,1 & 0 & & 12,1 & 124,1 & 0,15 \\
\hline 04/Mai & 10 & 21,5 & 0 & & 11,5 & 135,6 & 0,17 \\
\hline 05/Mai & 11 & 21,9 & 0 & & 11,9 & 147,5 & 0,18 \\
\hline 06/Mai & 12 & 21,3 & 0 & & 11,3 & 158,8 & 0,19 \\
\hline 07/Mai & 13 & 22,0 & 0 & & 12,0 & 170,8 & 0,21 \\
\hline 08/Mai & 14 & 21,6 & 0 & & 11,6 & 182,4 & 0,22 \\
\hline 09/Mai & 15 & 21,8 & 0 & & 11,8 & 194,2 & 0,24 \\
\hline 10/Mai & 16 & 18,1 & 0 & $V_{3}$ & 8,1 & 202,3 & 0,25 \\
\hline 11/Mai & 17 & 17,9 & 0 & & 7,9 & 210,2 & 0,26 \\
\hline 12/Mai & 18 & 19,9 & 0 & & 9,9 & 220,1 & 0,27 \\
\hline 13/Mai & 19 & 21,1 & 0 & & 11,1 & 231,2 & 0,28 \\
\hline 14/Mai & 20 & 21,6 & 0 & & 11,6 & 242,8 & 0,30 \\
\hline 15/Mai & 21 & 22,1 & 0 & & 12,1 & 254,9 & 0,31 \\
\hline 16/Mai & 22 & 22,5 & 0 & & 12,5 & 267,4 & 0,33 \\
\hline 17/Mai & 23 & 23,1 & 0 & & 13,1 & 280,5 & 0,34 \\
\hline 18/Mai & 24 & 19,7 & 0 & & 9,7 & 290,2 & 0,35 \\
\hline 19/Mai & 25 & 17,0 & 0 & & 7,0 & 297,2 & 0,36 \\
\hline 20/Mai & 26 & 15,2 & 0 & & 5,2 & 302,4 & 0,37 \\
\hline 21/Mai & 27 & 16,2 & 0 & & 6,2 & 308,6 & 0,38 \\
\hline 22/Mai & 28 & 16,4 & 0 & & 6,4 & 315,0 & 0,38 \\
\hline 23/Mai & 29 & 17,6 & 0 & & 7,6 & 322,6 & 0,39 \\
\hline 24/Mai & 30 & 18,9 & 0 & $V_{4}$ & 8,9 & 331,5 & 0,40 \\
\hline 25/Mai & 31 & 19,3 & 0 & & 9,3 & 340,8 & 0,42 \\
\hline 26/Mai & 32 & 17,9 & 0 & & 7,9 & 348,7 & 0,43 \\
\hline 27/Mai & 33 & 19,5 & 0 & & 9,5 & 358,2 & 0,44 \\
\hline 28/Mai & 34 & 19,6 & 0 & & 9,6 & 367,8 & 0,45 \\
\hline 29/Mai & 35 & 18,8 & 0 & & 8,8 & 376,6 & 0,46 \\
\hline 30/Mai & 36 & 18,1 & 0 & & 8,1 & 384,7 & 0,47 \\
\hline 31/Mai & 37 & 16,2 & 0 & & 6,2 & 390,9 & 0,48 \\
\hline 01/Jun & 38 & 17,5 & 0 & & 7,5 & 398,4 & 0,49 \\
\hline $02 / \mathrm{Jun}$ & 39 & 18,6 & 0 & & 8,6 & 407,0 & 0,50 \\
\hline
\end{tabular}


Tabela 23. Dias após a emergência (DAE), temperatura média do ar $\left(\mathrm{T},{ }^{\circ} \mathrm{C}\right)$, estádio fenológico, graus-dia (GD, ${ }^{\circ} \mathrm{C}$.dia) e desenvolvimento relativo (Dr) da cultura de feijão durante a fase reprodutiva (1).

\begin{tabular}{|c|c|c|c|c|c|c|c|}
\hline Dia & $\overline{\mathrm{DAE}}$ & $\mathrm{T},{ }^{\circ} \mathrm{C}$ & Fase & Estádio & $\mathrm{T}-\mathrm{Tb}$ & GD & $\mathrm{Dr}$ \\
\hline 03/Jun & 40 & 18,3 & 1 & $\mathrm{R}_{5}$ & 8,3 & 415,3 & 0,51 \\
\hline 04/Jun & 41 & 17,5 & 1 & & 7,5 & 422,8 & 0,52 \\
\hline $05 / \mathrm{Jun}$ & 42 & 16,3 & 1 & & 6,3 & 429,1 & 0,52 \\
\hline 06/Jun & 43 & 18,0 & 1 & & 8,0 & 437,1 & 0,53 \\
\hline 07/Jun & 44 & 19,4 & 1 & & 9,4 & 446,5 & 0,55 \\
\hline 08/Jun & 45 & 18,8 & 1 & & 8,8 & 455,3 & 0,56 \\
\hline 09/Jun & 46 & 19,7 & 1 & & 9,7 & 465,0 & 0,57 \\
\hline $10 /$ Jun & 47 & 18,4 & 1 & & 8,4 & 473,4 & 0,58 \\
\hline $11 /$ Jun & 48 & 19,5 & 1 & $\mathrm{R}_{6}$ & 9,5 & 482,9 & 0,59 \\
\hline $12 / \mathrm{Jun}$ & 49 & 19,1 & 1 & & 9,1 & 492,0 & 0,60 \\
\hline $13 / \mathrm{Jun}$ & 50 & 18,6 & 1 & & 8,6 & 500,6 & 0,61 \\
\hline 14/Jun & 51 & 19,1 & 1 & & 9,1 & 509,7 & 0,62 \\
\hline $15 /$ Jun & 52 & 19,1 & 1 & & 9,1 & 518,8 & 0,63 \\
\hline $16 /$ Jun & 53 & 21,6 & 1 & $\mathrm{R}_{7}$ & 11,6 & 530,4 & 0,65 \\
\hline 17/Jun & 54 & 18,8 & 1 & & 8,8 & 539,2 & 0,66 \\
\hline $18 /$ Jun & 55 & 18,8 & 1 & & 8,8 & 548,0 & 0,67 \\
\hline 19/Jun & 56 & 17,3 & 1 & & 7,3 & 555,3 & 0,68 \\
\hline 20/Jun & 57 & 16,5 & 1 & & 6,5 & 561,8 & 0,69 \\
\hline 21/Jun & 58 & 15,9 & 1 & & 5,9 & 567,7 & 0,69 \\
\hline $22 / \mathrm{Jun}$ & 59 & 19,1 & 1 & & 9,1 & 576,8 & 0,70 \\
\hline 23/Jun & 60 & 19,6 & 1 & & 9,6 & 586,4 & 0,72 \\
\hline 24/Jun & 61 & 19,7 & 1 & & 9,7 & 596,1 & 0,73 \\
\hline $25 / \mathrm{Jun}$ & 62 & 18,1 & 1 & & 8,1 & 604,2 & 0,74 \\
\hline 26/Jun & 63 & 19,4 & 1 & & 9,4 & 613,6 & 0,75 \\
\hline $27 / \mathrm{Jun}$ & 64 & 20,7 & 1 & & 10,7 & 624,3 & 0,76 \\
\hline 28/Jun & 65 & 21,1 & 1 & $\mathrm{R}_{8}$ & 11,1 & 635,4 & 0,78 \\
\hline $29 /$ Jun & 66 & 18,5 & 1 & & 8,5 & 643,9 & 0,79 \\
\hline 30/Jun & 67 & 17,3 & 1 & & 7,3 & 651,2 & 0,80 \\
\hline $01 / \mathrm{Jul}$ & 68 & 18,6 & 1 & & 8,6 & 659,8 & 0,81 \\
\hline 02/Jul & 69 & 19,8 & 1 & & 9,8 & 669,6 & 0,82 \\
\hline 03/Jul & 70 & 20,7 & 1 & & 10,7 & 680,3 & 0,83 \\
\hline 04/Jul & 71 & 19,8 & 1 & & 9,8 & 690,1 & 0,84 \\
\hline 05/Jul & 72 & 19,9 & 1 & & 9,9 & 700,0 & 0,85 \\
\hline 06/Jul & 73 & 22,3 & 1 & & 12,3 & 712,3 & 0,87 \\
\hline 07/Jul & 74 & 22,7 & 1 & & 12,7 & 725,0 & 0,89 \\
\hline 08/Jul & 75 & 15,3 & 1 & & 5,3 & 730,3 & 0,89 \\
\hline $09 / \mathrm{Jul}$ & 76 & 16,1 & 1 & & 6,1 & 736,4 & 0,90 \\
\hline $10 / \mathrm{Jul}$ & 77 & 19,0 & 1 & & 9,0 & 745,4 & 0,91 \\
\hline $11 / \mathrm{Jul}$ & 78 & 17,6 & 1 & & 7,6 & 753,0 & 0,92 \\
\hline $12 / \mathrm{Jul}$ & 79 & 18,7 & 1 & & 8,7 & 761,7 & 0,93 \\
\hline 13/Jul & 80 & 19,9 & 1 & & 9,9 & 771,6 & 0,94 \\
\hline 14/Jul & 81 & 20,5 & 1 & & 10,5 & 782,1 & 0,96 \\
\hline $15 / \mathrm{Jul}$ & 82 & 21,6 & 1 & & 11,6 & 793,7 & 0,97 \\
\hline 16/Jul & 83 & 23,2 & 1 & & 13,2 & 806,9 & 0,99 \\
\hline $17 / \mathrm{Jul}$ & 84 & 21,9 & 1 & $\mathrm{R}_{9}$ & 11,9 & 818,8 & 1,00 \\
\hline
\end{tabular}




\subsubsection{Massa de matéria seca}

\subsubsection{Folha}

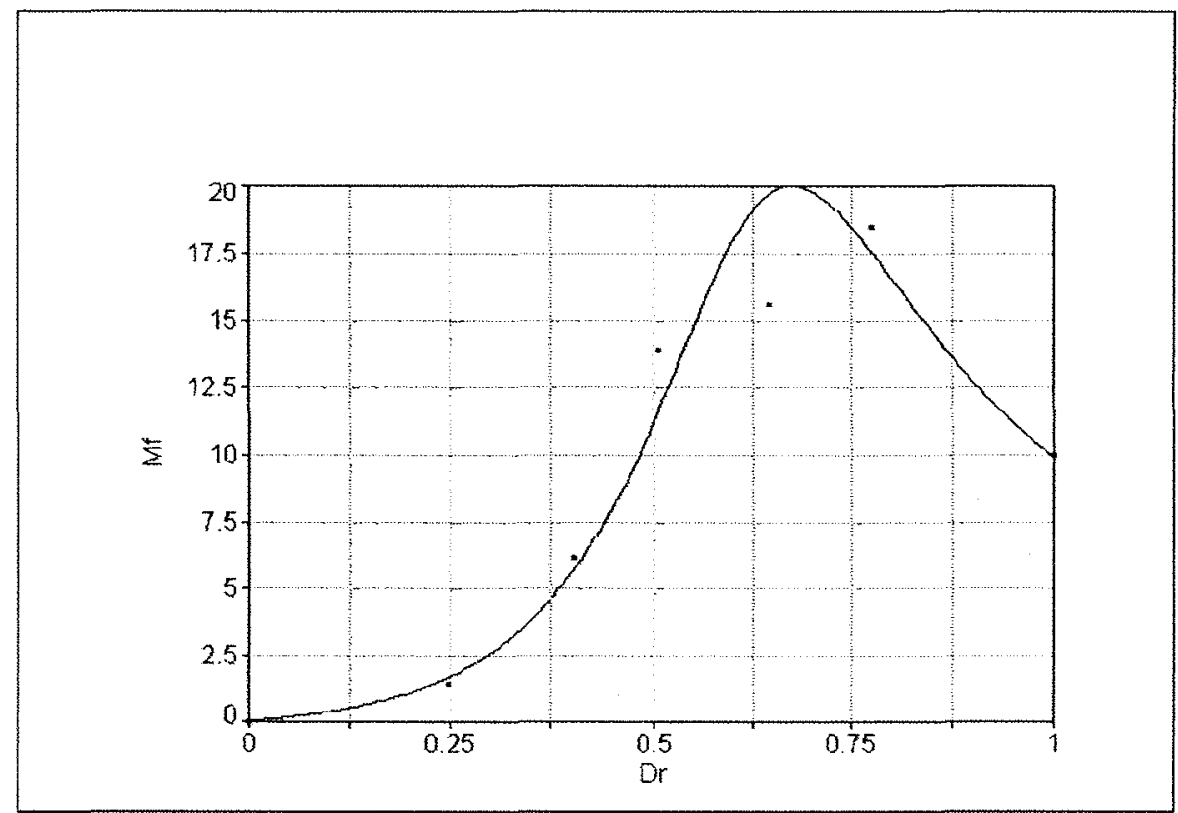

Figura 17. Variação da massa de matéria seca de folha ( $\mathrm{Mf}, \mathrm{g} / 5 \mathrm{pl}$ ) do feijoeiro sob irrigação em função do desenvolvimento relativo da cultura (Dr).

Tabela 24. Análise de variância e parâmetros empíricos (a, b, c, d e e) referentes ao modelo para estimativa da massa de matéria seca de folha ( $\mathrm{Mf}, \mathrm{g} / 5 \mathrm{pl}$ ) do feijoeiro sob irrigação em função do desenvolvimento relativo da cultura (Dr).

\begin{tabular}{|c|c|c|c|c|c|c|}
\hline FV $^{1}$ & $\mathrm{SQ}^{2}$ & $\mathrm{GL}^{3}$ & $\mathrm{QM}^{4}$ & \multicolumn{2}{|c|}{$\mathrm{F}$} & $\mathrm{r}^{2}$ \\
\hline Regressão & 280,32436 & 4 & 70,081089 & \multicolumn{2}{|c|}{6,06609} & 0,5431070417 \\
\hline Erro & 23,105855 & 2 & 11,552927 & \multicolumn{3}{|c|}{ Modelo } \\
\hline Total & 303,43021 & 6 & \multicolumn{4}{|c|}{$M f=\frac{a+c D r+e D r^{2}}{1+b D r+d D r^{2}}$} \\
& & & & \multicolumn{3}{|c|}{$M r^{2}$} \\
\hline \multicolumn{2}{|c|}{ Parâmetro empírico } & Erro padrão & Valor t & Intervalo de confiança (95\%) \\
\hline a & 0,003546275 & 3,366280633 & 0,001053470 & $-13,9542597$ & 13,96135229 \\
\hline b & $-2,84549833$ & 2,139536389 & $-1,32996024$ & $-11,7167830$ & 6,025786376 \\
\hline c & 2,284770758 & 25,35162319 & 0,090123253 & $-102,832145$ & 107,4016868 \\
\hline d & 2,302142255 & 3,159644868 & 0,728607914 & $-10,7988778$ & 15,40316233 \\
\hline e & 2,226254464 & 32,10362426 & 0,069345892 & $-130,886878$ & 135,3393870 \\
\hline
\end{tabular}

Fonte de variação

2 Soma dos quadrados

${ }^{3}$ Graus de liberdade

${ }^{4}$ Quadrado médio

* Nível de significância: 1\% 


\subsubsection{Haste}

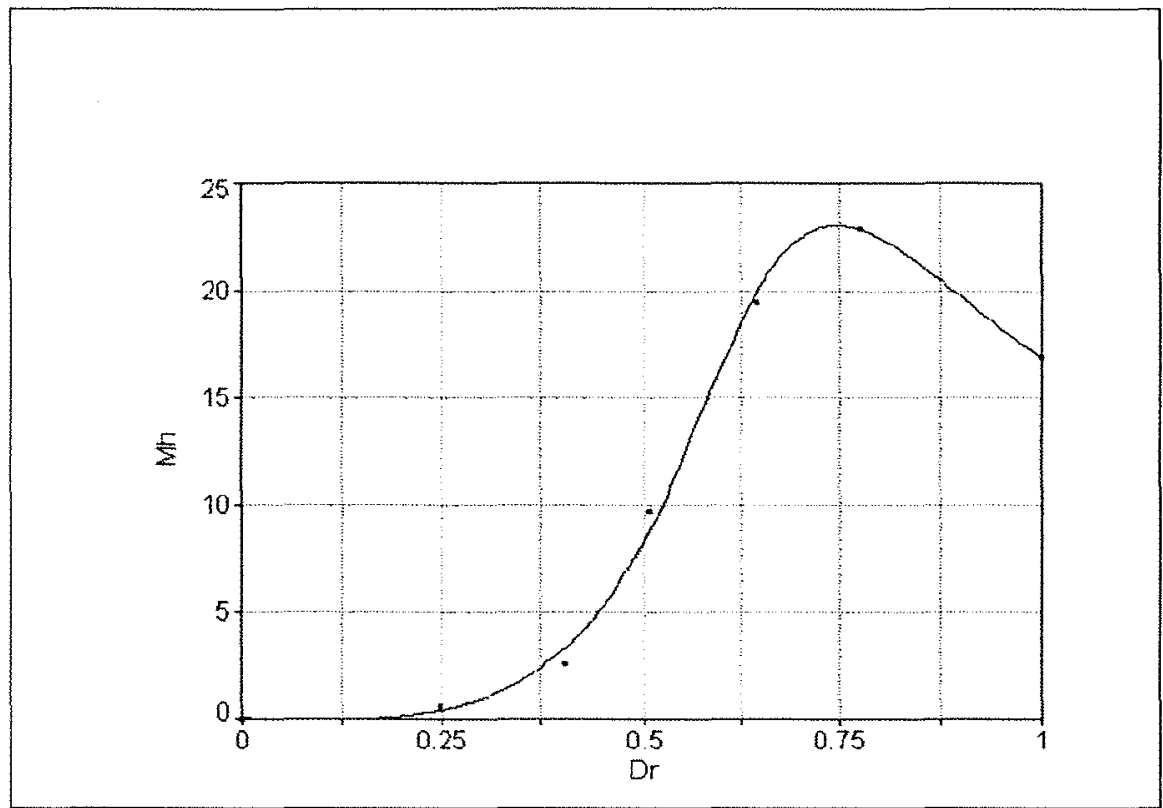

Figura 18. Variação da massa de matéria seca das hastes $(\mathrm{Mh}, \mathrm{g} / 5 \mathrm{pl})$ do feijoeiro sob irrigação em função do desenvolvimento relativo da cultura (Dr).

Tabela 25. Análise de variância e parâmetros empíricos (a, b, c, d e e) referentes ao modelo para estimativa da massa de matéria seca das hastes $(\mathrm{Mh}, \mathrm{g} / 5 \mathrm{pl})$ do feijoeiro sob irrigação em função do desenvolvimento relativo da cultura (Dr).

\begin{tabular}{|c|c|c|c|c|c|c|}
\hline $\mathrm{FV}^{1}$ & $\mathrm{SQ}^{2}$ & $\mathrm{GL}^{3}$ & $\mathrm{QM}^{4}$ & \multicolumn{2}{|c|}{$\mathbf{F}$} & $r^{2}$ \\
\hline Regressão & 542,30907 & 4 & 135,57727 & \multicolumn{2}{|c|}{159,96} & 0,9813037521 \\
\hline Erro & 1,6951396 & 2 & 0,8475698 & \multicolumn{3}{|c|}{ Modelo } \\
\hline Total & 544,00421 & 6 & \multicolumn{4}{|c|}{$M h=\frac{a+c D r+e D r^{2}}{1+b D r+d D r^{2}}$} \\
\hline \multicolumn{3}{|c|}{ Parâmetro empírico } & Erro padrão & Valor $\mathrm{t}$ & \multicolumn{2}{|c|}{ Intervalo de confiança (95\%) } \\
\hline $\mathrm{a}$ & 0,02319 & & 0,906325190 & 0,025591436 & $-3,73475491$ & 3,781143237 \\
\hline $\mathrm{b}$ & $-2,7431$ & & 0,471095719 & $-5,82299693$ & $-4,69652062$ & $-0,78985723$ \\
\hline c & $-1,6155$ & & 7,063639475 & $-0,22870788$ & $-30,9038910$ & 27,67287093 \\
\hline $\mathrm{d}$ & 2,16754 & & 0,810325793 & 2,674909151 & $-1,19235329$ & 5,527449047 \\
\hline $\mathrm{e}$ & 8,72621 & & 12,28437628 & 0,710350542 & $-42,2092136$ & 59,66164029 \\
\hline
\end{tabular}

\footnotetext{
Fonte de variação

${ }^{2}$ Soma dos quadrados

${ }^{3}$ Graus de liberdade

${ }^{4}$ Quadrado médio

* Nível de significância: $1 \%$
} 


\subsubsection{Botão floral}

Em função da existência apenas de dois pontos, foi tirada a média entre os valores observados.

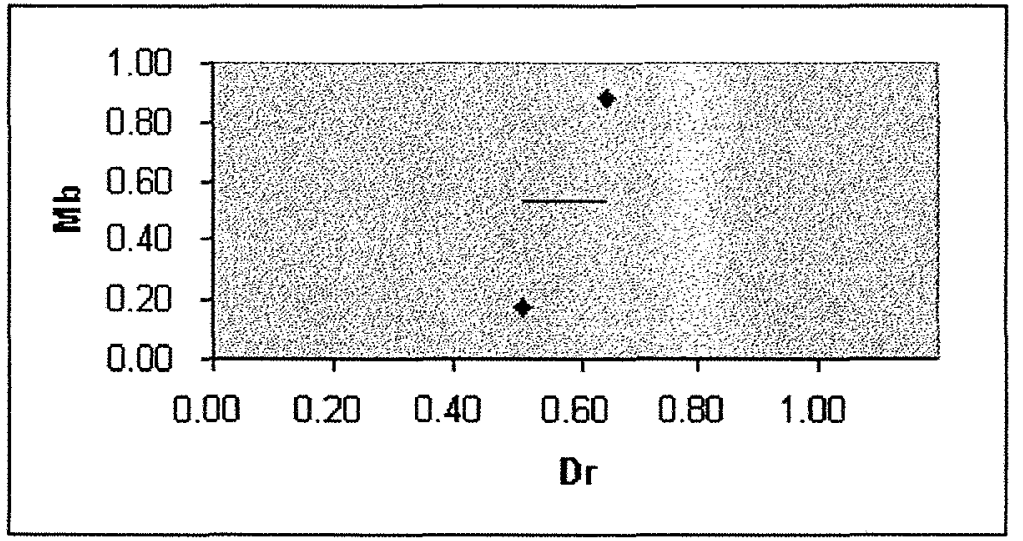

Figura 19. Variação da massa de matéria seca de botão floral $(\mathrm{Mb}, \mathrm{g} / 5 \mathrm{pl})$ do feijoeiro em função do desenvolvimento relativo da cultura (Dr). 


\subsubsection{Vagem}

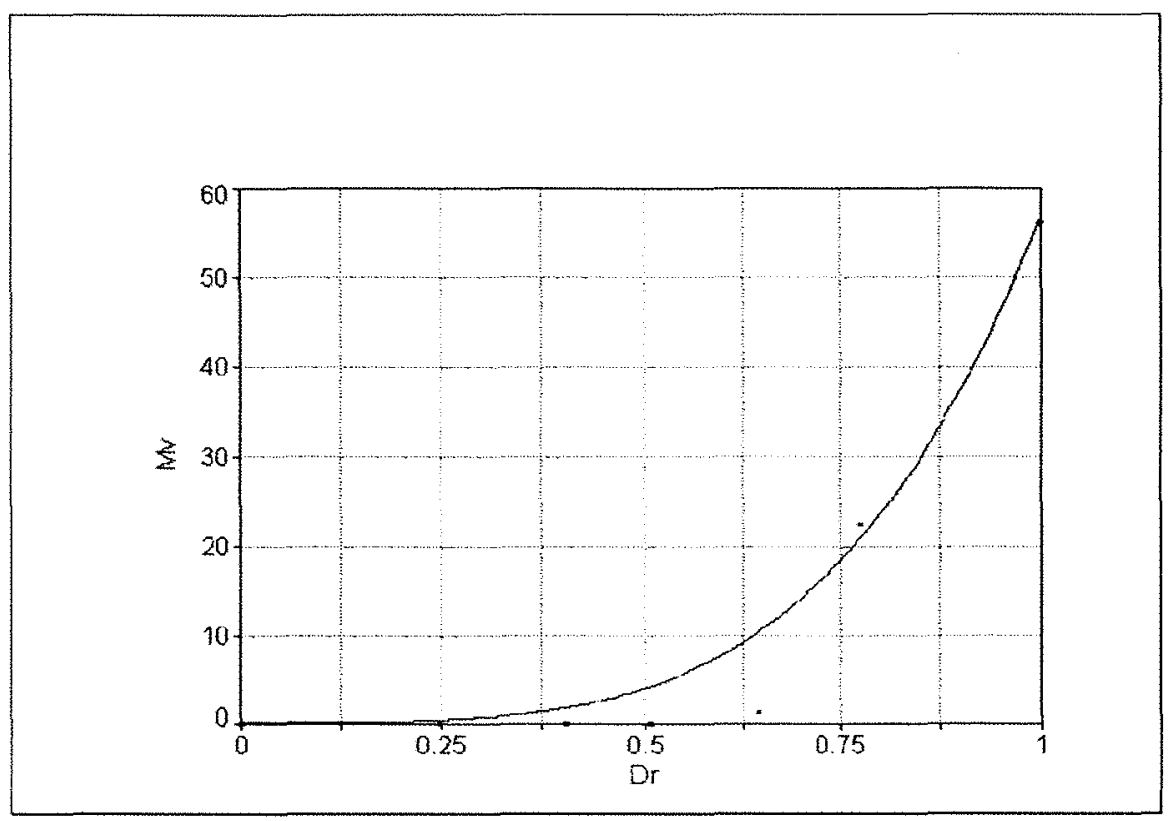

Figura 20. Variação da massa de matéria seca de vagem $(\mathrm{Mv}, \mathrm{g} / 5 \mathrm{pl})$ do feijoeiro sob irrigação em função do desenvolvimento relativo da cultura (Dr).

Tabela 26. Análise de variância e parâmetros empíricos (a e b) referentes ao modelo para estimativa da massa de matéria seca de vagem $(\mathrm{Mv}, \mathrm{g} / 5 \mathrm{pl})$ do feijoeiro sob irrigação em função do desenvolvimento relativo da cultura (Dr).

\begin{tabular}{|c|c|c|c|c|c|c|}
\hline FV $^{1}$ & $\mathrm{SQ}^{2}$ & $\mathrm{GL}^{3}$ & $\mathrm{QM}^{4}$ & \multicolumn{2}{|c|}{$\mathrm{F}$} & $\mathrm{r}^{2}$ \\
\hline Regressão & 2648,0557 & 1 & 2648,0557 & \multicolumn{2}{|c|}{126,545} & 0,9429854855 \\
\hline Erro & 104,62864 & 5 & 20,925728 & \multicolumn{3}{|c|}{ Modelo } \\
\hline Total & 2752,6843 & 6 & \multicolumn{5}{|c|}{$M v^{0,5}=a+b D r^{2}$} \\
\hline \multicolumn{2}{|c|}{ Parâmetro empírico } & Erro padrão & Valor t & Intervalo de confiança (95\%) \\
\hline a & 0,086627828 & 2,473083346 & 0,035028269 & $-6,29416419$ & 6,467419845 \\
\hline b & 7,431350484 & 2,748087870 & 2,704189544 & 0,341020443 & 14,52168052 \\
\hline
\end{tabular}

Fonte de variação

${ }^{2}$ Soma dos quadrados

${ }^{3}$ Graus de liberdade

${ }^{4}$ Quadrado médio

* Nível de significância: $1 \%$ 


\subsubsection{Total}

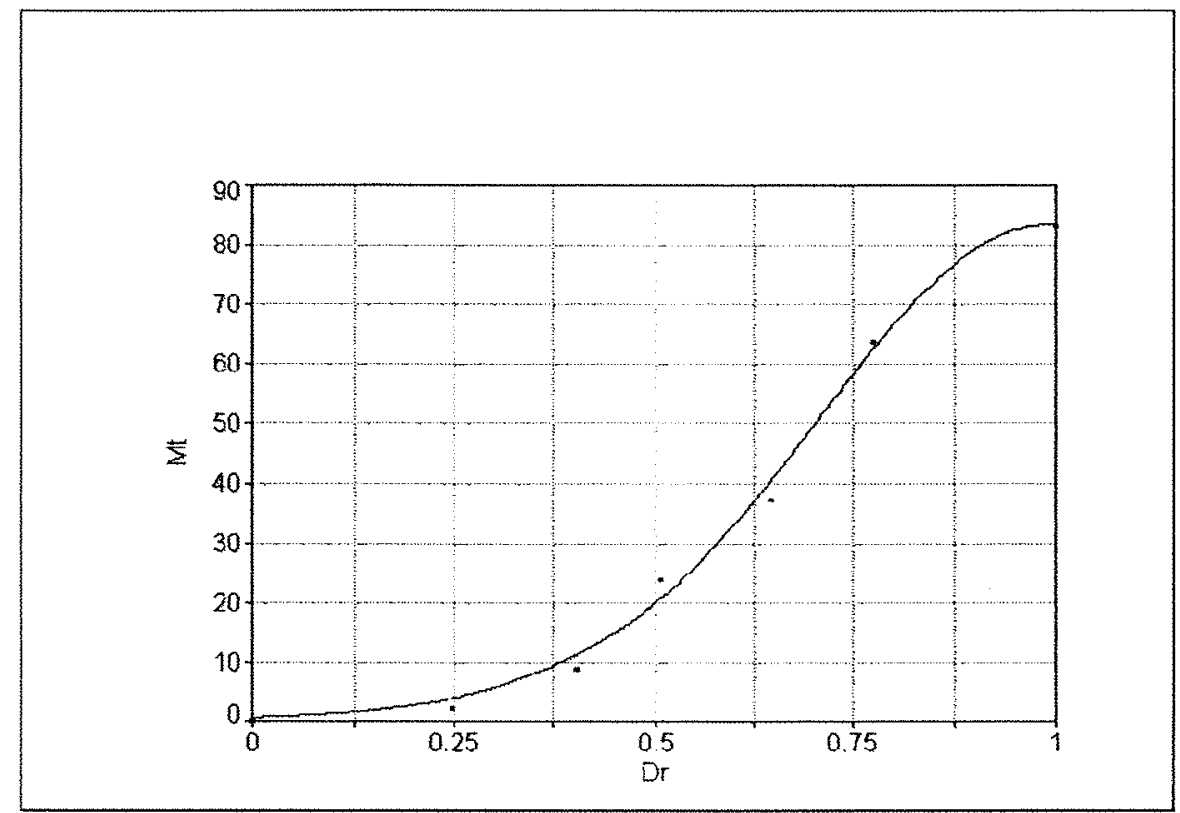

Figura 21. Variação da massa de matéria seca total (Mt, g/5 pl) do feijoeiro sob irrigação em função do desenvolvimento relativo da cultura (Dr).

Tabela 27. Análise de variância e parâmetros empíricos (a,b e c) referentes ao modelo para estimativa da massa de matéria seca total $(\mathrm{Mt}, \mathrm{g} / 5 \mathrm{pl})$ do feijoeiro sob irrigação em função do desenvolvimento relativo da cultura (Dr).

\begin{tabular}{|c|c|c|c|c|c|c|}
\hline $\mathrm{FV}^{1}$ & $\mathbf{S Q}^{2}$ & $\mathrm{GL}^{3}$ & $\mathrm{QM}^{4}$ & \multicolumn{2}{|c|}{$\mathbf{F}$} & $r^{2}$ \\
\hline Regressão & 6122,7106 & 2 & 3061,3553 & \multicolumn{2}{|c|}{374,738} & 0,9893825449 \\
\hline Erro & 32,677277 & 4 & 8,1693193 & \multicolumn{3}{|c|}{ Modelo } \\
\hline Total & 6155,3879 & 6 & \multicolumn{4}{|c|}{$\ln M t=a+b D r+c D r^{2,5}$} \\
\hline \multicolumn{3}{|c|}{ Parâmetro empírico } & Erro padrão & Valor $\mathrm{t}$ & \multicolumn{2}{|c|}{ Intervalo de confiança (95\%) } \\
\hline $\mathrm{a}$ & \multicolumn{2}{|c|}{$-0,75600401$} & 0,574987182 & $-1,31481889$ & $-2,35437816$ & 0,842370148 \\
\hline $\mathrm{b}$ & \multirow{2}{*}{\multicolumn{2}{|c|}{$\begin{array}{l}8,733393153 \\
-3.55735972\end{array}$}} & 1,211592234 & 7,208195059 & 5,365356831 & 12,10142948 \\
\hline c & & & 0,653215982 & $-5,44591654$ & $-5,37319767$ & $-1,74152178$ \\
\hline
\end{tabular}

Fonte de variação

${ }^{2}$ Soma dos quadrados

${ }^{3}$ Graus de liberdade

${ }^{4}$ Quadrado médio

* Nível de significância: $1 \%$ 


\subsubsection{Teor de macronutrientes na parte aérea do feijoeiro}

A variação temporal (explicitada em termos de fenologia) dos teores médios dos seis macronutrientes (nitrogênio, fósforo, potássio, cálcio, magnésio e enxofre) na haste (Figura 22, Figura 27, Figura 32, Figura 37 e Figura 42), folha (Figura 23, Figura 28, Figura 33, Figura 38 e Figura 42), botão floral (Figura 24, Figura 29, Figura 34, Figura 39 e Figura 42), vagem (Figura 25, Figura 30, Figura 35, Figura 40 e Figura 42) e grão (Figura 26, Figura 31, Figura 36, Figura 41 e Figura 42) referentes às diferentes doses de nitrogênio utilizadas $(0,45,90,135$ e $180 \mathrm{~kg} / \mathrm{ha})$.

Em função de não ter havido diferença estatística entre os diferentes tratamentos $(0,45,90,135$ e $180 \mathrm{~kg} / \mathrm{ha}$ de nitrogênio), ao nível de significância de $5 \%$ pelo teste de Tukey, analisando cada época isoladamente, calculou-se a média para cada uma das seis épocas $\left(V_{3}, V_{4}, R_{5}, R_{7}, R_{8}\right.$ e $R_{9}$ ) para cada macronutriente (N, P, K, Ca, Mg e $S$ ) (Figura 43). 


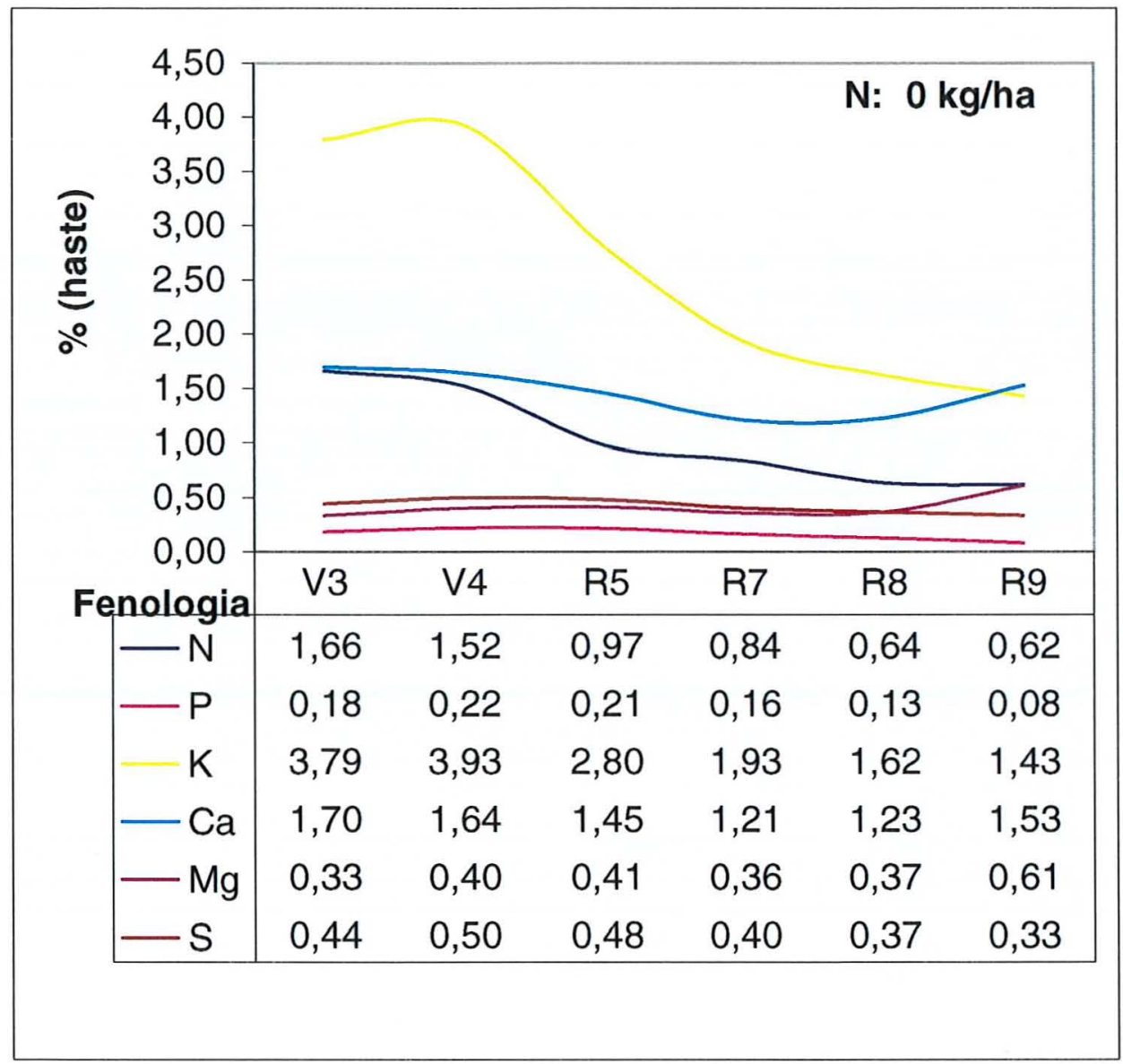

Figura 22. Variação dos teores $(\%)$ de nitrogênio $(\mathrm{N})$, fósforo $(\mathrm{P})$, potássio $(\mathrm{K})$, cálcio $(\mathrm{Ca})$, magnésio $(\mathrm{Mg})$ e enxofre $(\mathrm{S})$ na haste do feijoeiro em função da fenologia referente à testemunha $(0 \mathrm{~kg} / \mathrm{ha}$ de nitrogênio $)$. 


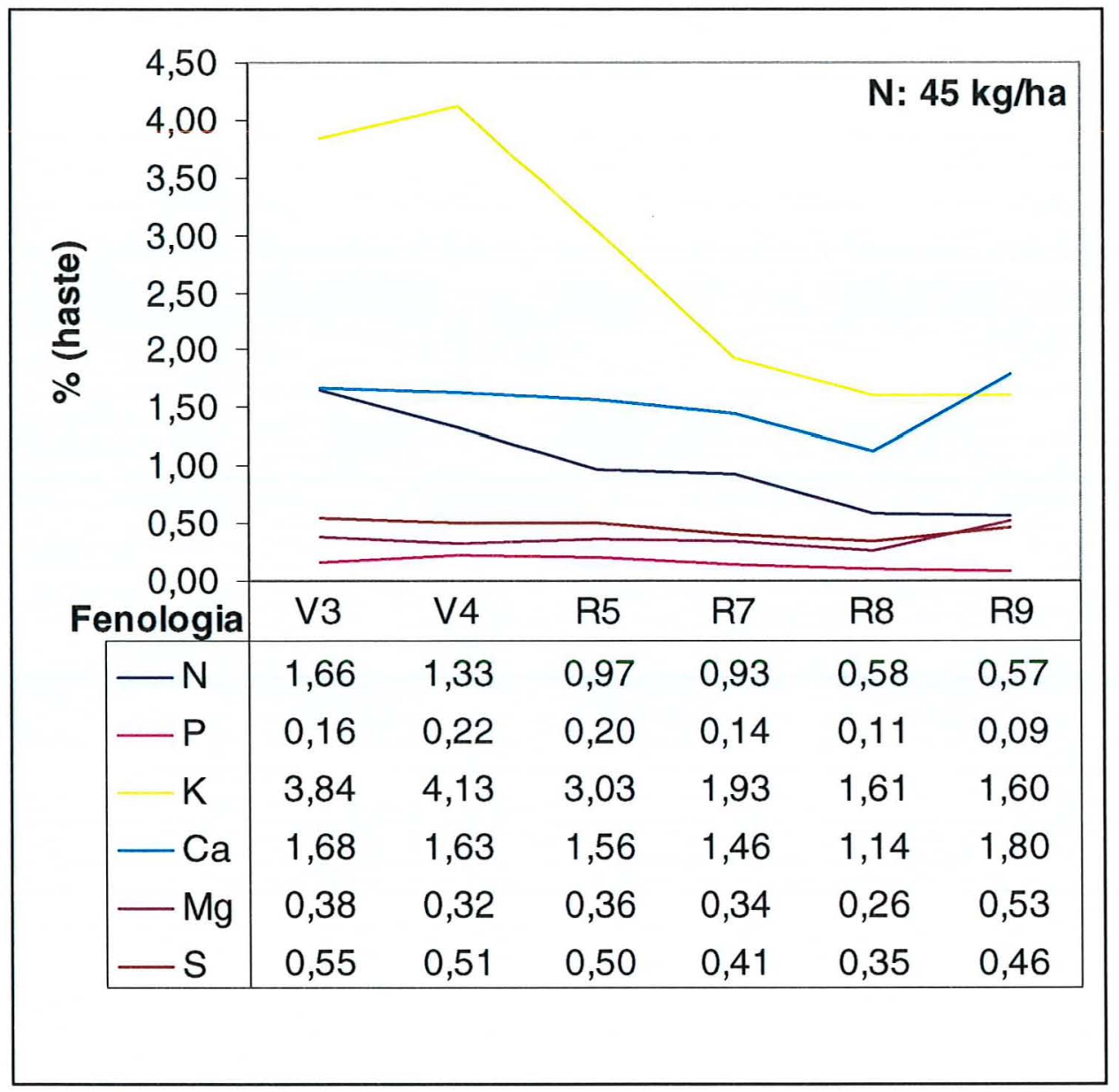

Figura 23. Variação dos teores $(\%)$ de nitrogênio $(\mathrm{N})$, fósforo $(\mathrm{P})$, potássio $(\mathrm{K})$, cálcio (Ca), magnésio $(\mathrm{Mg})$ e enxofre $(\mathrm{S})$ na haste do feijoeiro em função da fenologia referente à dose de $45 \mathrm{~kg} / \mathrm{ha}$ de nitrogênio.

Os teores de nitrogênio e potássio na haste decresceram durante o ciclo da cultura para todas as doses de nitrogênio $(0,45,90,135$ e $180 \mathrm{~kg} / \mathrm{ha})$.

O teor de cálcio na haste também decresceu durante o ciclo. Porém, apresentou um acréscimo no final.

Os teores de magnésio, fósforo e enxofre na haste tenderam a permanecer constantes durante o ciclo da cultura. 


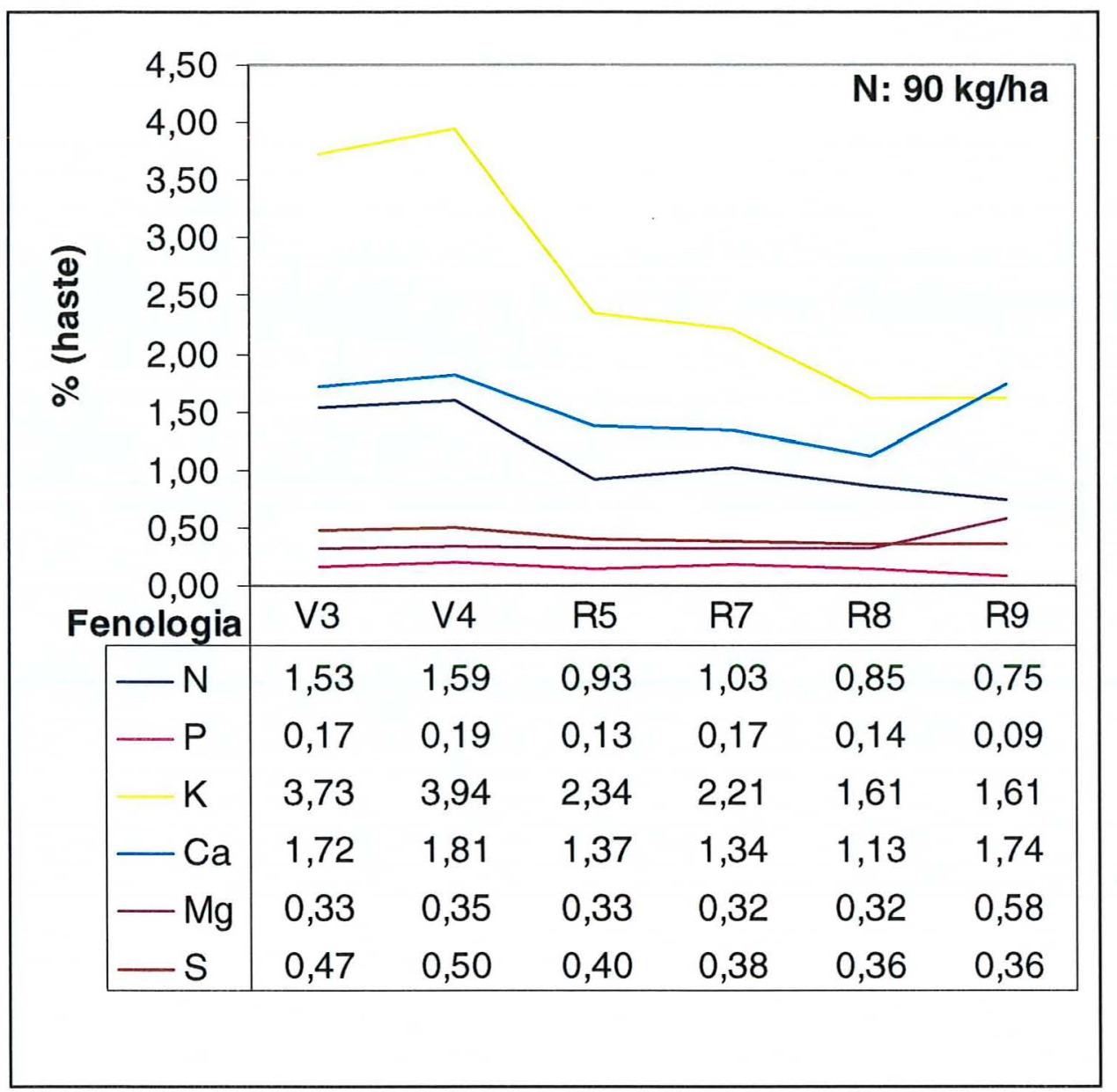

Figura 24. Variação dos teores $(\%)$ de nitrogênio $(\mathrm{N})$, fósforo $(\mathrm{P})$, potássio $(\mathrm{K})$, cálcio (Ca), magnésio $(\mathrm{Mg})$ e enxofre $(\mathrm{S})$ na haste do feijoeiro em função da fenologia referente à dose de $90 \mathrm{~kg} / \mathrm{ha}$ de nitrogênio.

O decréscimo dos teores observados de nitrogênio e potássio na haste ocorreu provavelmente por se tratar de elementos de alta mobilidade na planta, os quais foram translocados para as partes mais jovens da planta como botão floral, vagem, grão e até mesmo folha jovem. 


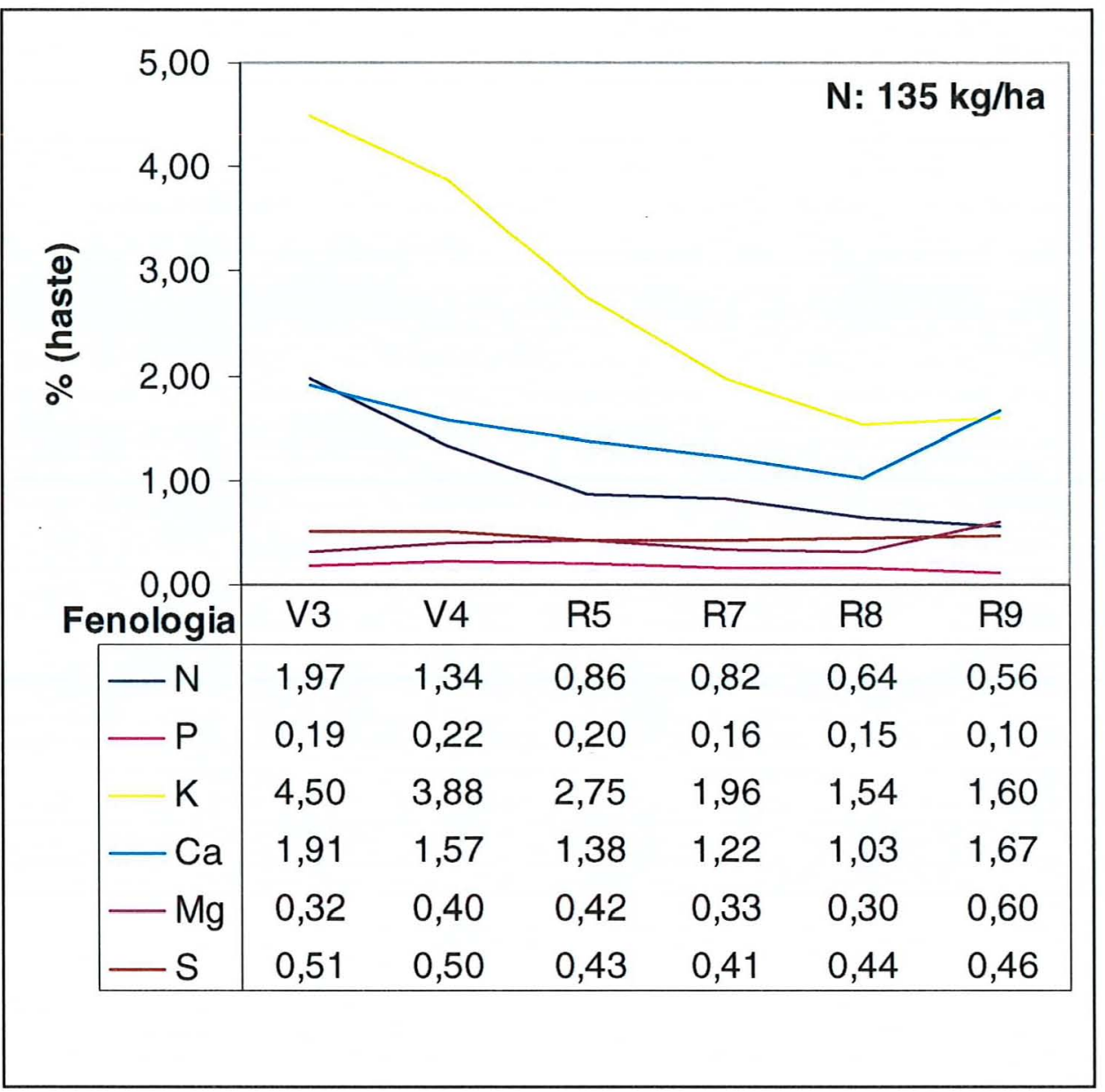

Figura 25. Variação dos teores $(\%)$ de nitrogênio $(\mathrm{N})$, fósforo $(\mathrm{P})$, potássio $(\mathrm{K})$, cálcio $(\mathrm{Ca})$, magnésio $(\mathrm{Mg})$ e enxofre $(\mathrm{S})$ na haste do feijoeiro em função da fenologia referente à dose de $135 \mathrm{~kg} / \mathrm{ha}$ de nitrogênio.

$\mathrm{Na}$ haste, para todas as doses de nitrogênio, o potássio foi o elemento que apresentou maior teor. 


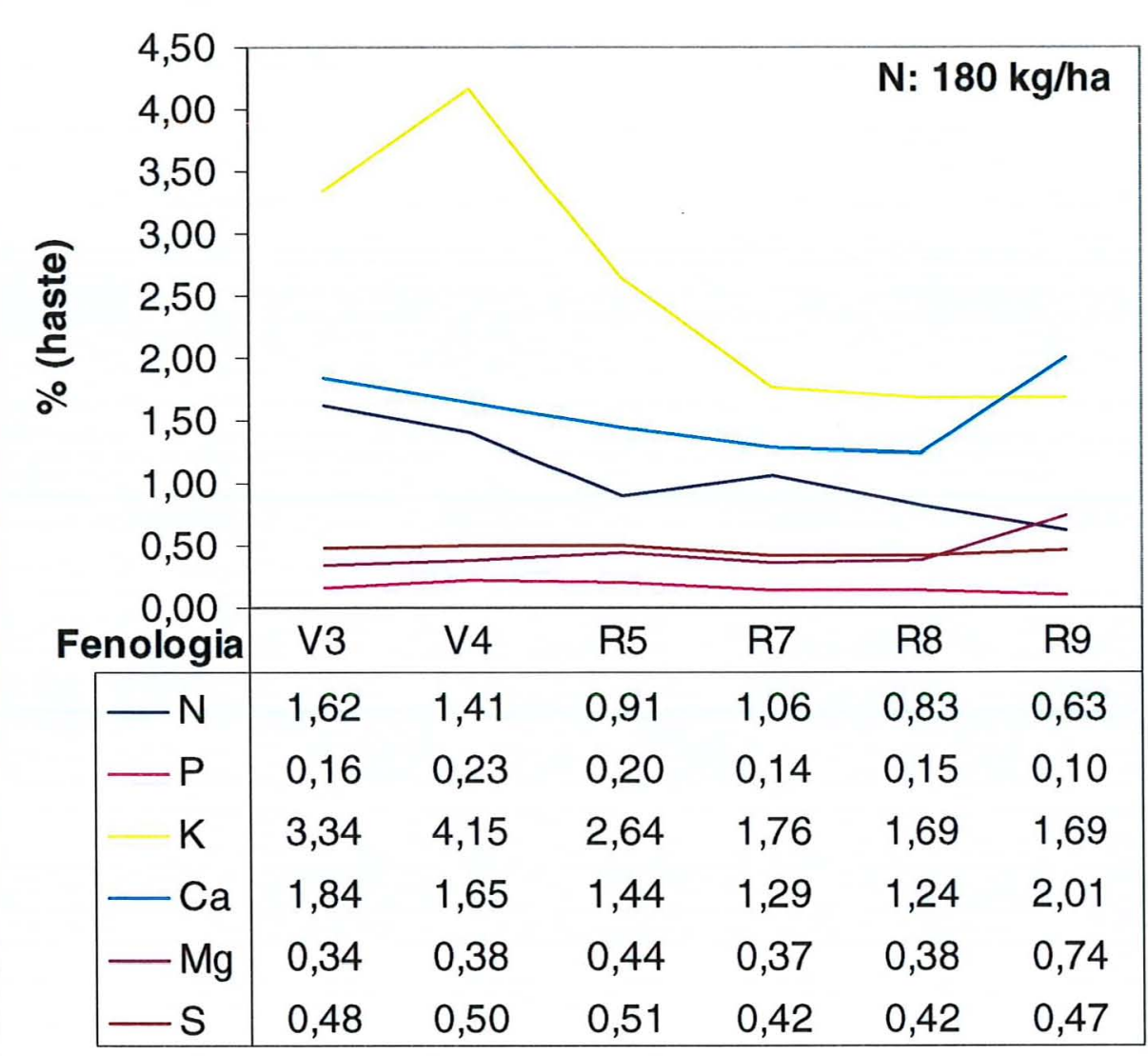

Figura 26. Variação dos teores $(\%)$ de nitrogênio $(\mathrm{N})$, fósforo $(\mathrm{P})$, potássio $(\mathrm{K})$, cálcio (Ca), magnésio $(\mathrm{Mg})$ e enxofre $(\mathrm{S})$ na haste do feijoeiro em função da fenologia referente à dose de $180 \mathrm{~kg} / \mathrm{ha}$ de nitrogênio.

Parte da variação observada dos teores dos diferentes elementos na haste pode ser devido a problemas referentes à amostragem, variabilidade genética do material amostrado ou variabilidade espacial do solo (fertilidade principalmente). 


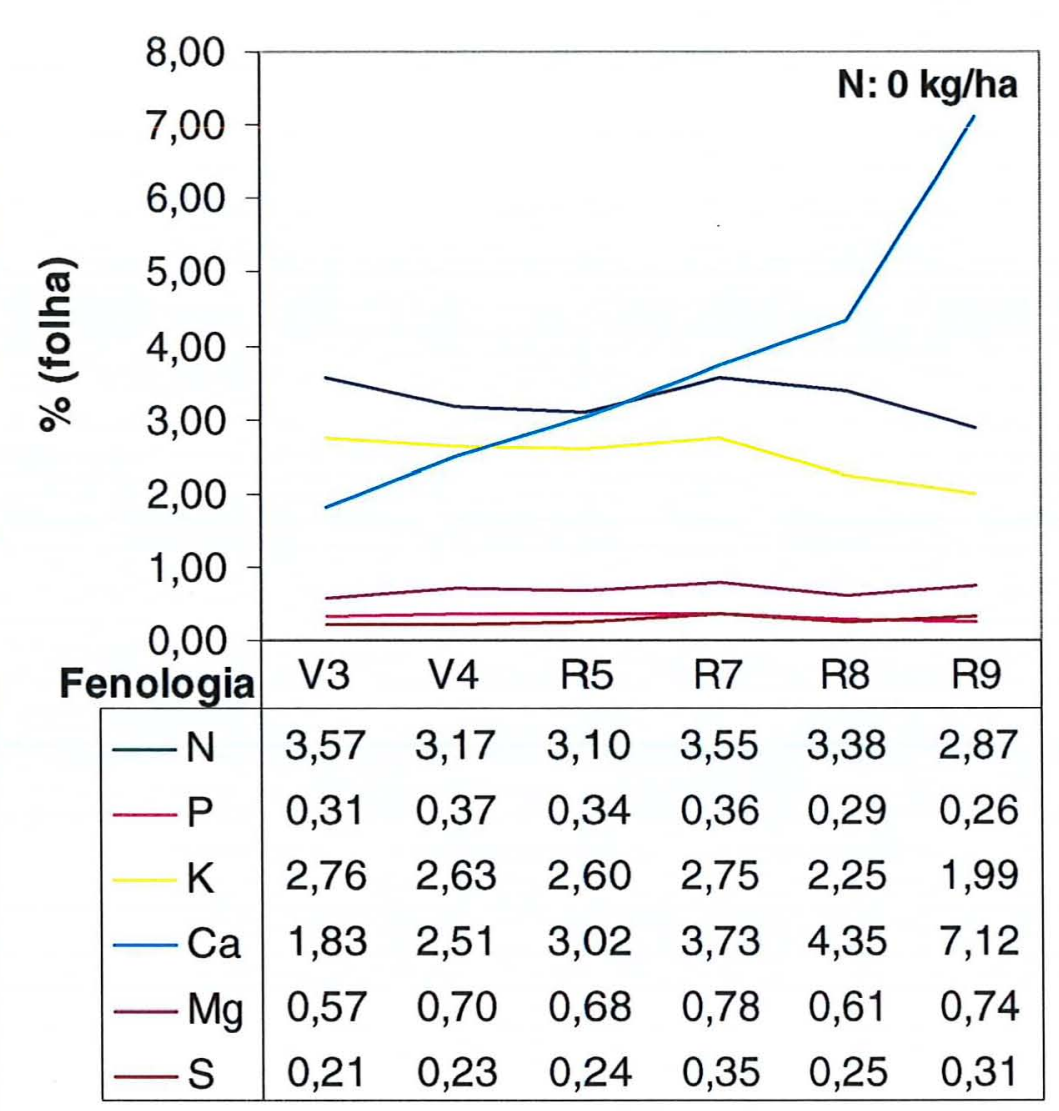

Figura 27. Variação dos teores $(\%)$ de nitrogênio $(\mathrm{N})$, fósforo $(\mathrm{P})$, potássio $(\mathrm{K})$, cálcio $(\mathrm{Ca})$, magnésio $(\mathrm{Mg})$ e enxofre $(\mathrm{S})$ na folha do feijoeiro em função da fenologia referente à testemunha $(0 \mathrm{~kg} / \mathrm{ha}$ de nitrogênio $)$.

$\mathrm{Na}$ folha, os teores de nitrogênio, fósforo, potássio, magnésio e enxofre se apresentaram constantes durante o ciclo da cultura em todos as doses de nitrogênio $(0$, $45,90,135$ e $180 \mathrm{~kg} / \mathrm{ha})$.

O teor de cálcio na folha apresentou um acréscimo durante o ciclo da cultura em todas as doses de nitrogênio. 


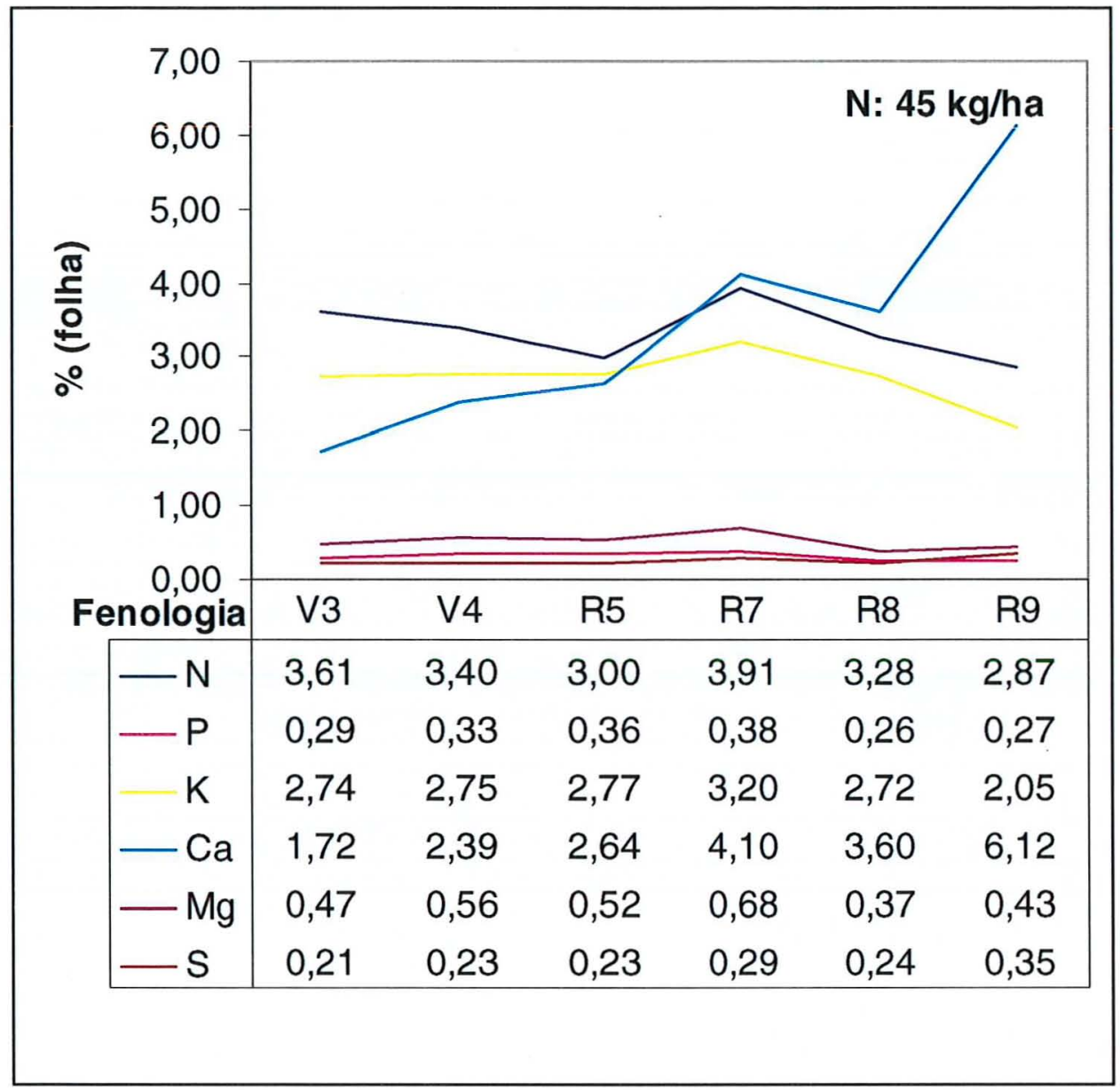

Figura 28. Variação dos teores $(\%)$ de nitrogênio $(\mathrm{N})$, fósforo $(\mathrm{P})$, potássio $(\mathrm{K})$, cálcio $(\mathrm{Ca})$, magnésio $(\mathrm{Mg})$ e enxofre $(\mathrm{S})$ na folha do feijoeiro em função da fenologia referente à dose de $45 \mathrm{~kg} / \mathrm{ha}$ de nitrogênio.

Os teores de nitrogênio e potássio na folha se mantiveram próximos à relação $1,2: 1,0$ em torno de $3 \%$.

Em ordem decrescente, os teores de magnésio, fósforo e enxofre na folha se mantiveram constantes e próximos durante todo o ciclo para todas as doses de nitrogênio. 


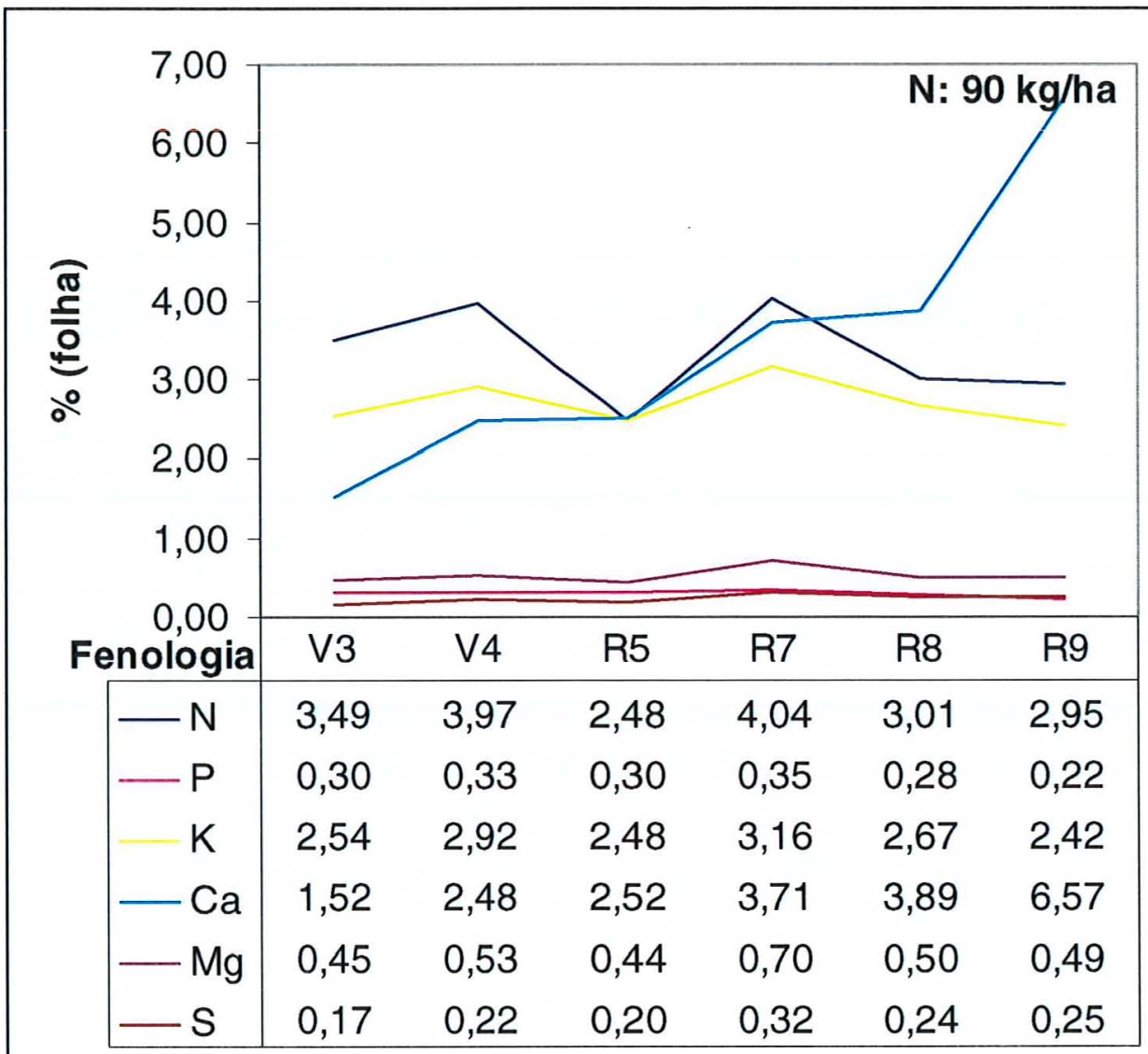

Figura 29. Variação dos teores $(\%)$ de nitrogênio $(\mathrm{N})$, fósforo $(\mathrm{P})$, potássio $(\mathrm{K})$, cálcio (Ca), magnésio $(\mathrm{Mg})$ e enxofre (S) na folha do feijoeiro em função da fenologia referente à dose de $90 \mathrm{~kg} / \mathrm{ha}$ de nitrogênio. 


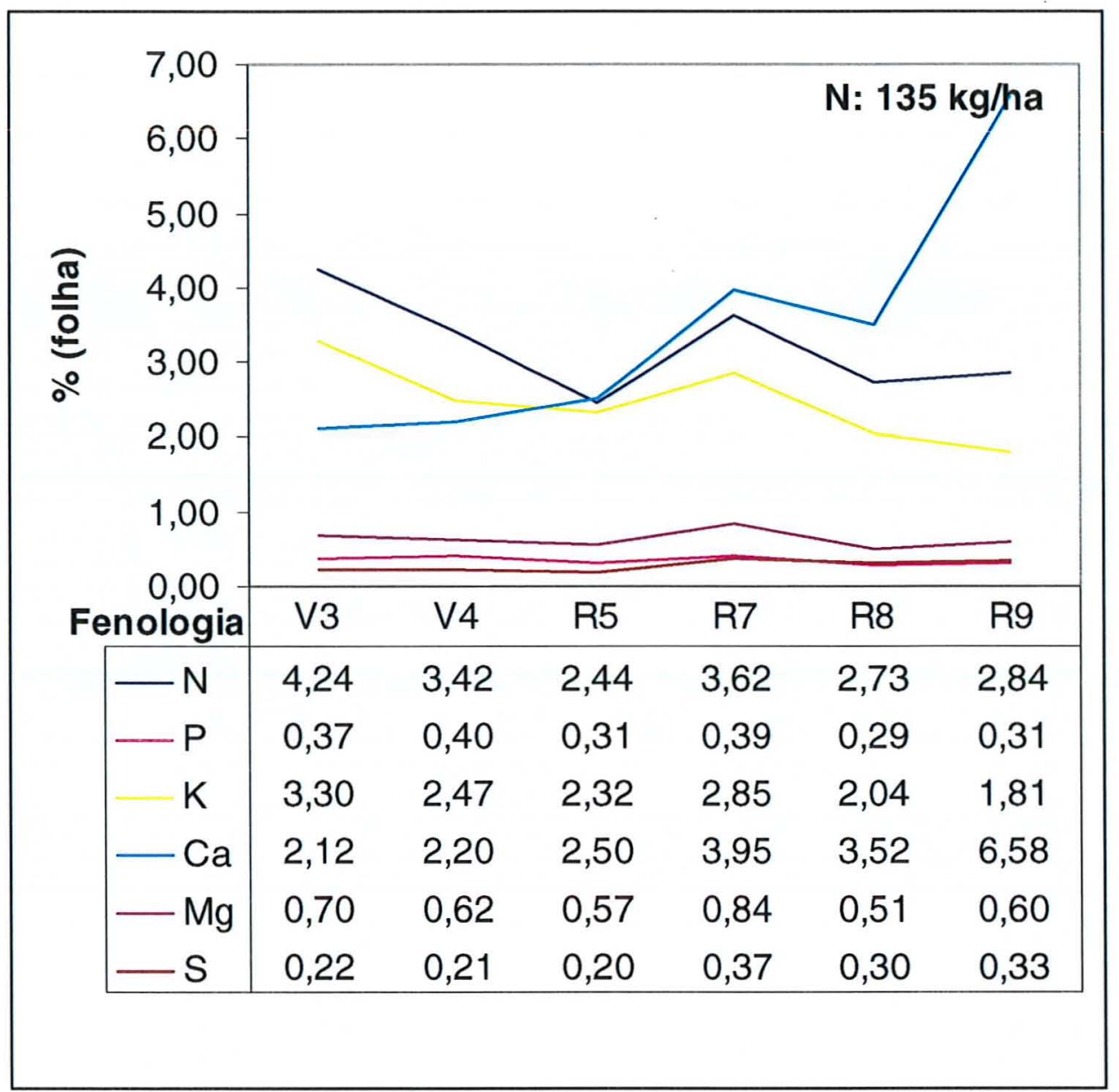

Figura 30. Variação dos teores $(\%)$ de nitrogênio $(\mathrm{N})$, fósforo $(\mathrm{P})$, potássio $(\mathrm{K})$, cálcio $(\mathrm{Ca})$, magnésio $(\mathrm{Mg})$ e enxofre $(\mathrm{S})$ na folha do feijoeiro em função da fenologia referente à dose de $135 \mathrm{~kg} / \mathrm{ha}$ de nitrogênio. 


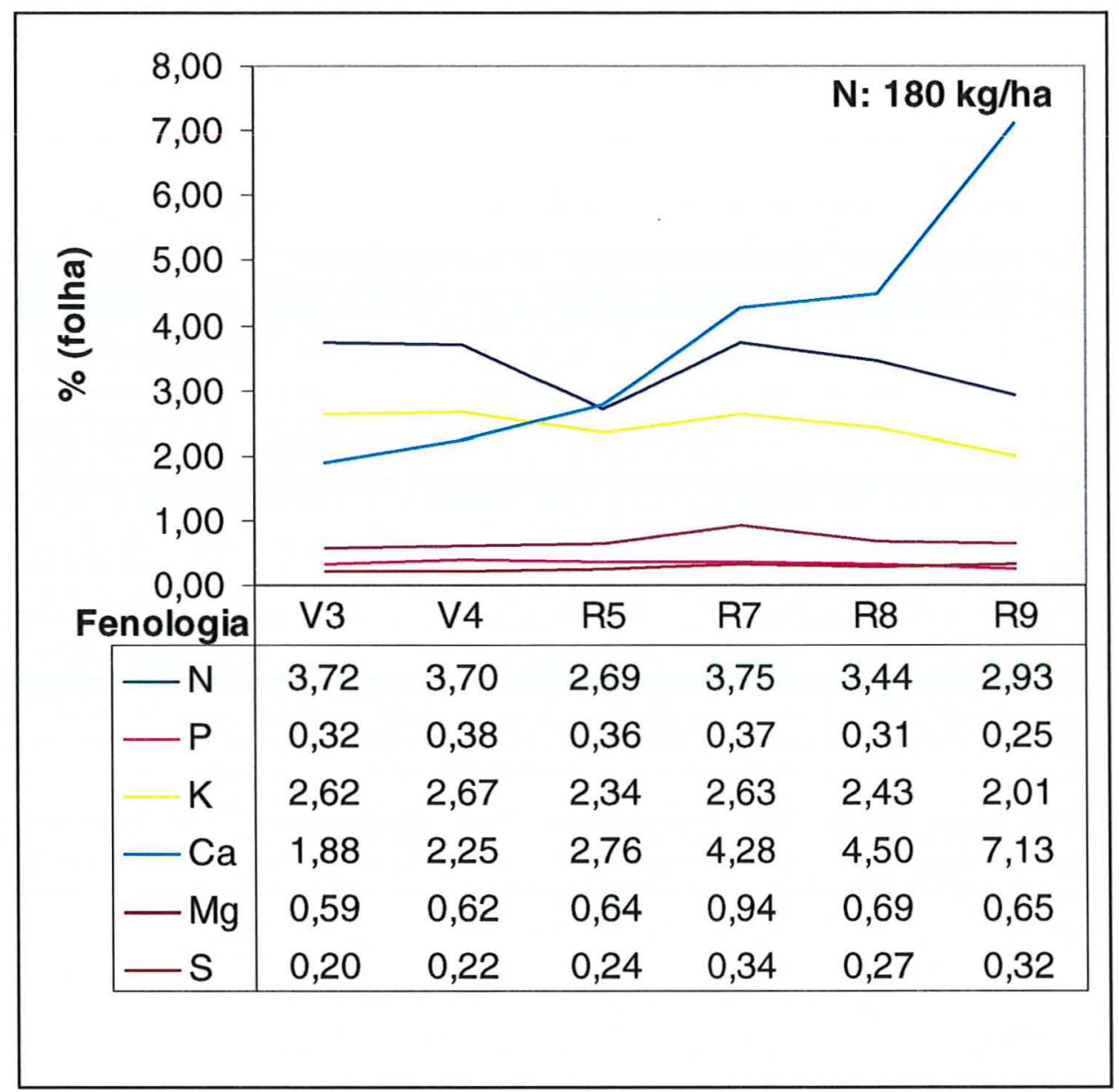

Figura 31. Variação dos teores $(\%)$ de nitrogênio $(\mathrm{N})$, fósforo $(\mathrm{P})$, potássio $(\mathrm{K})$, cálcio $(\mathrm{Ca})$, magnésio $(\mathrm{Mg})$ e enxofre $(\mathrm{S})$ na folha do feijoeiro em função da fenologia referente à dose de $180 \mathrm{~kg} / \mathrm{ha}$ de nitrogênio. 


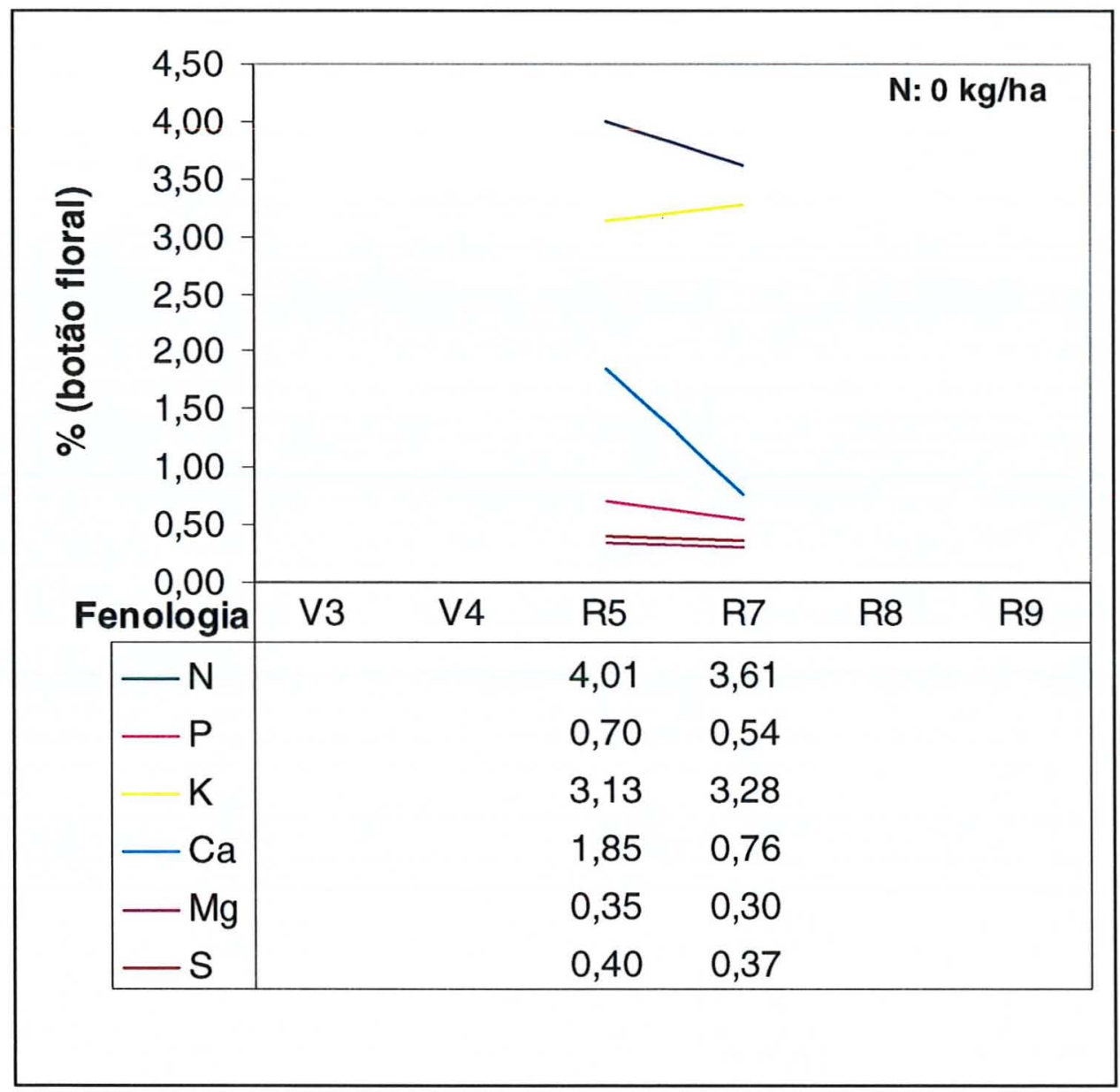

Figura 32. Variação dos teores $(\%)$ de nitrogênio $(\mathrm{N})$, fósforo $(\mathrm{P})$, potássio $(\mathrm{K})$, cálcio $(\mathrm{Ca})$, magnésio $(\mathrm{Mg})$ e enxofre $(\mathrm{S})$ no botão floral do feijoeiro em função da fenologia referente à testemunha $(0 \mathrm{~kg} / \mathrm{ha}$ de nitrogênio $)$.

Em ordem decrescente, os teores de nitrogênio, potássio, cálcio, fósforo, enxofre e magnésio mantiveram um decréscimo (mais pronunciado para cálcio e nitrogênio), com exceção do potássio que apresentou um acréscimo, durante o ciclo da cultura para todas as doses de nitrogênio. 


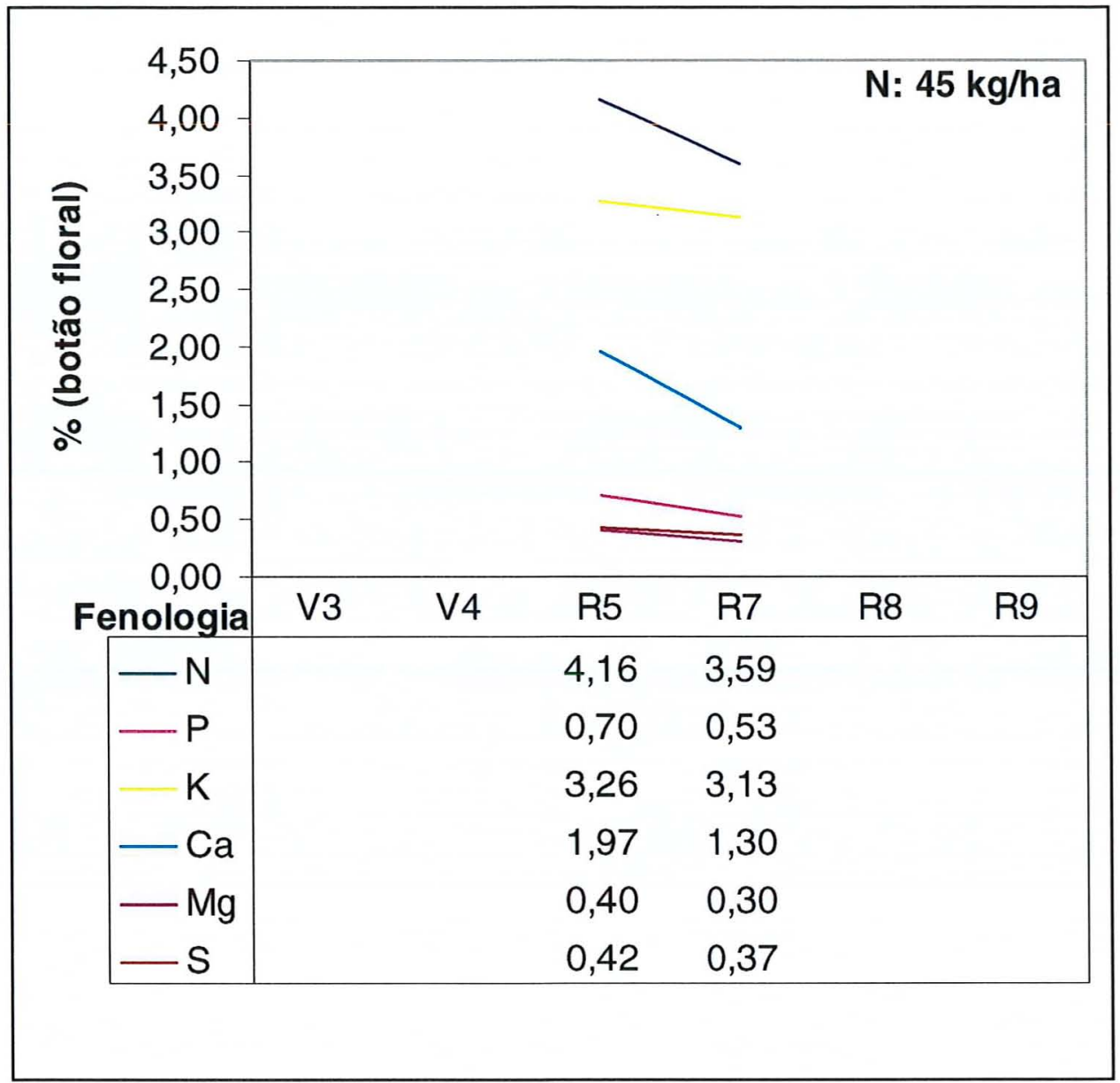

Figura 33. Variação dos teores $(\%)$ de nitrogênio $(\mathrm{N})$, fósforo $(\mathrm{P})$, potássio $(\mathrm{K})$, cálcio $(\mathrm{Ca})$, magnésio $(\mathrm{Mg})$ e enxofre $(\mathrm{S})$ no botão floral do feijoeiro em função da fenologia referente à dose de $45 \mathrm{~kg} / \mathrm{ha}$ de nitrogênio. 


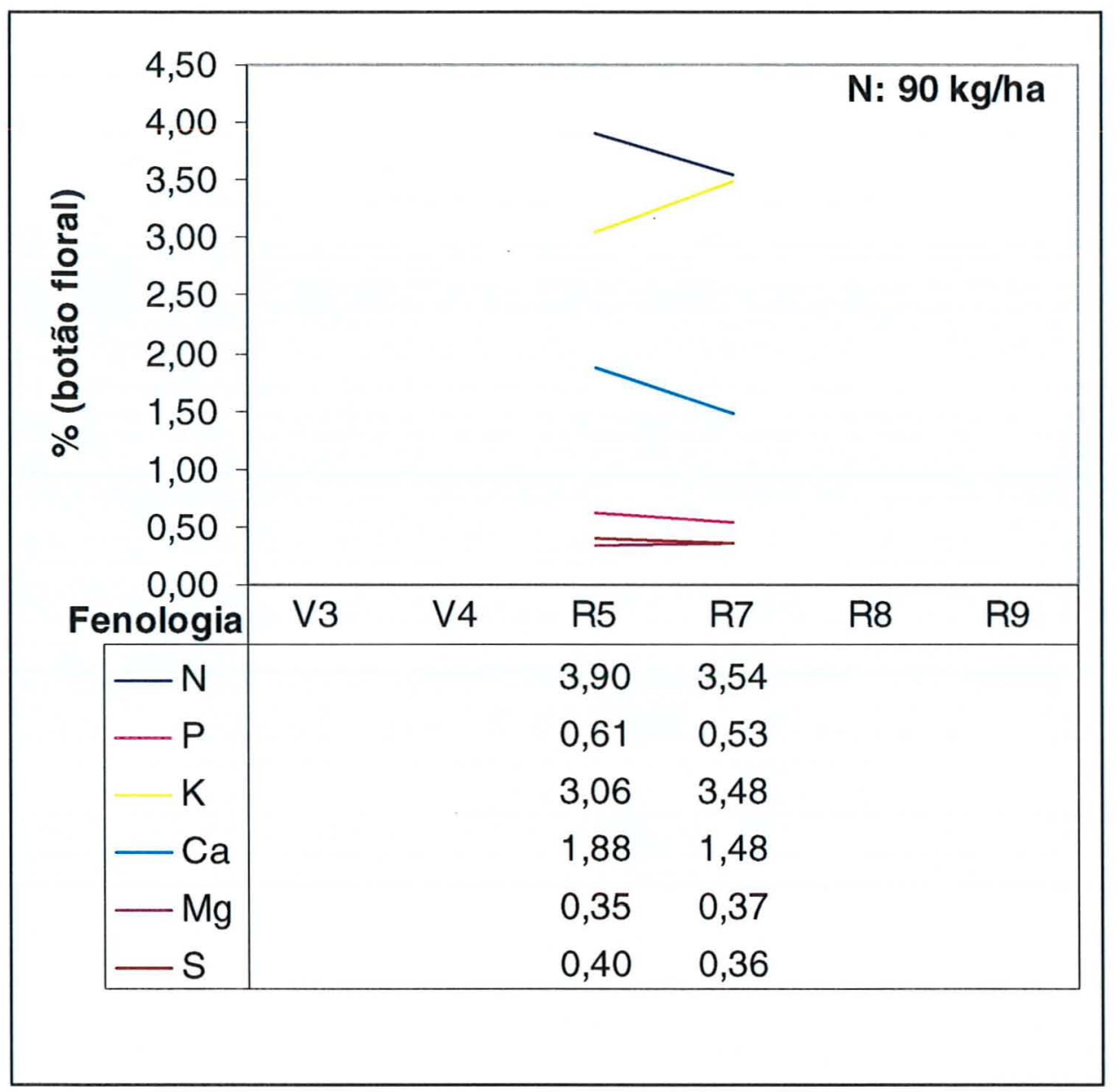

Figura 34. Variação dos teores $(\%)$ de nitrogênio $(\mathrm{N})$, fósforo $(\mathrm{P})$, potássio $(\mathrm{K})$, cálcio $(\mathrm{Ca})$, magnésio $(\mathrm{Mg})$ e enxofre $(\mathrm{S})$ no botão floral do feijoeiro em função da fenologia referente à dose de $90 \mathrm{~kg} / \mathrm{ha}$ de nitrogênio. 


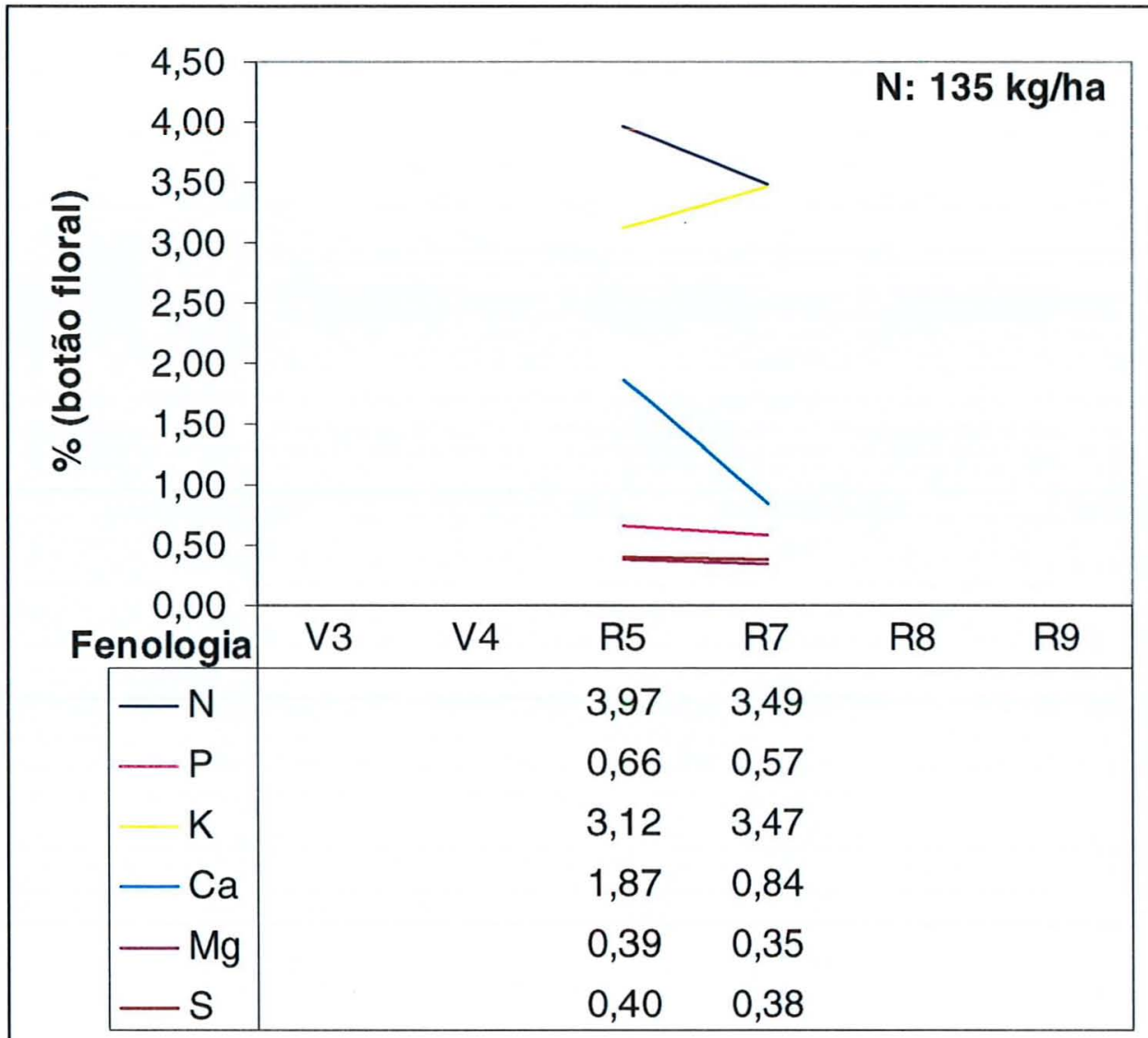

Figura 35. Variação dos teores $(\%)$ de nitrogênio $(\mathrm{N})$, fósforo $(\mathrm{P})$, potássio $(\mathrm{K})$, cálcio $(\mathrm{Ca})$, magnésio $(\mathrm{Mg})$ e enxofre $(\mathrm{S})$ no botão floral do feijoeiro em função da fenologia referente à dose de $135 \mathrm{~kg} / \mathrm{ha}$ de nitrogênio. 


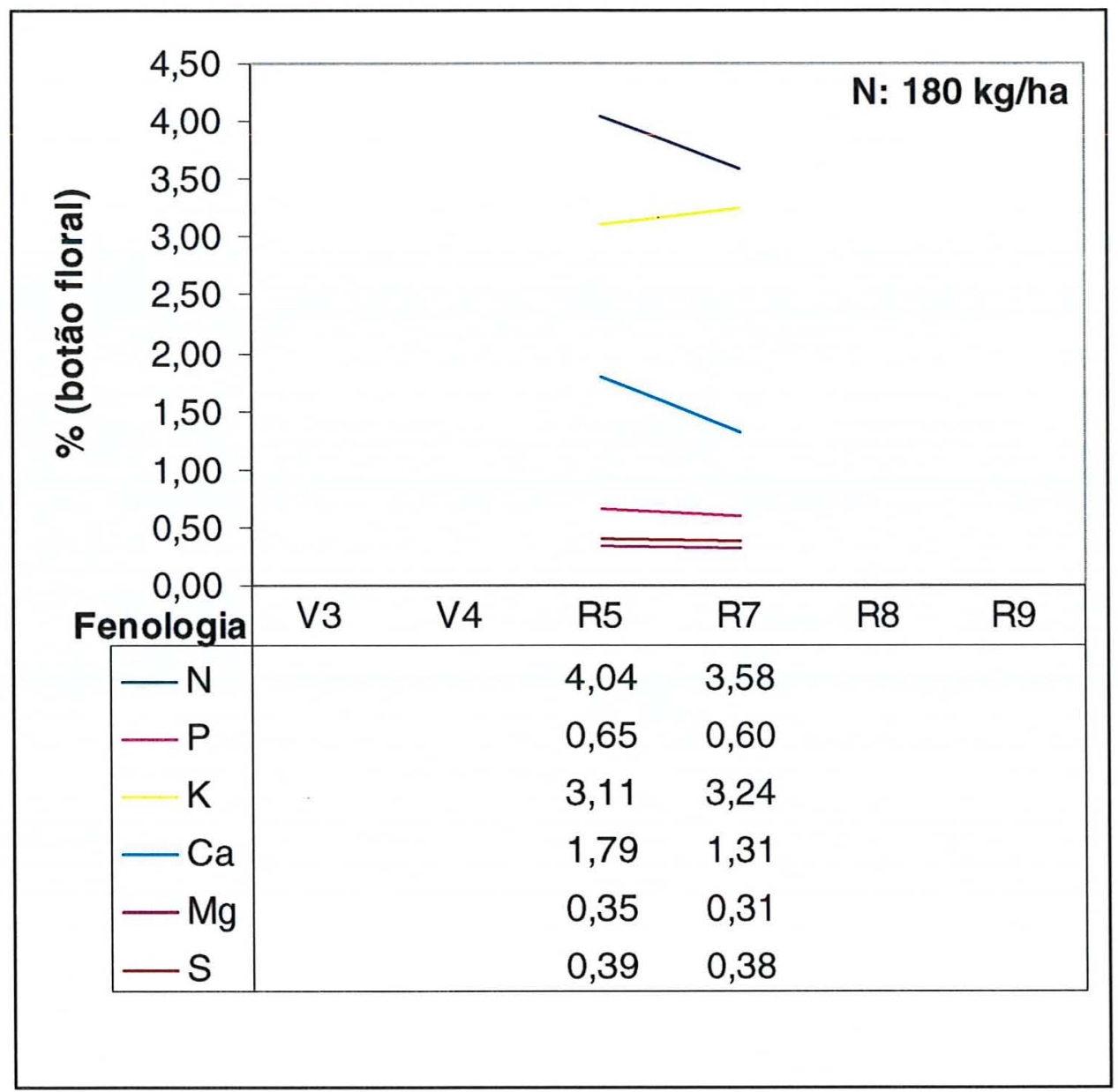

Figura 36. Variação dos teores $(\%)$ de nitrogênio $(\mathrm{N})$, fósforo $(\mathrm{P})$, potássio $(\mathrm{K})$, cálcio $(\mathrm{Ca})$, magnésio $(\mathrm{Mg})$ e enxofre $(\mathrm{S})$ no botão floral do feijoeiro em função da fenologia referente à dose de $180 \mathrm{~kg} / \mathrm{ha}$ de nitrogênio. 


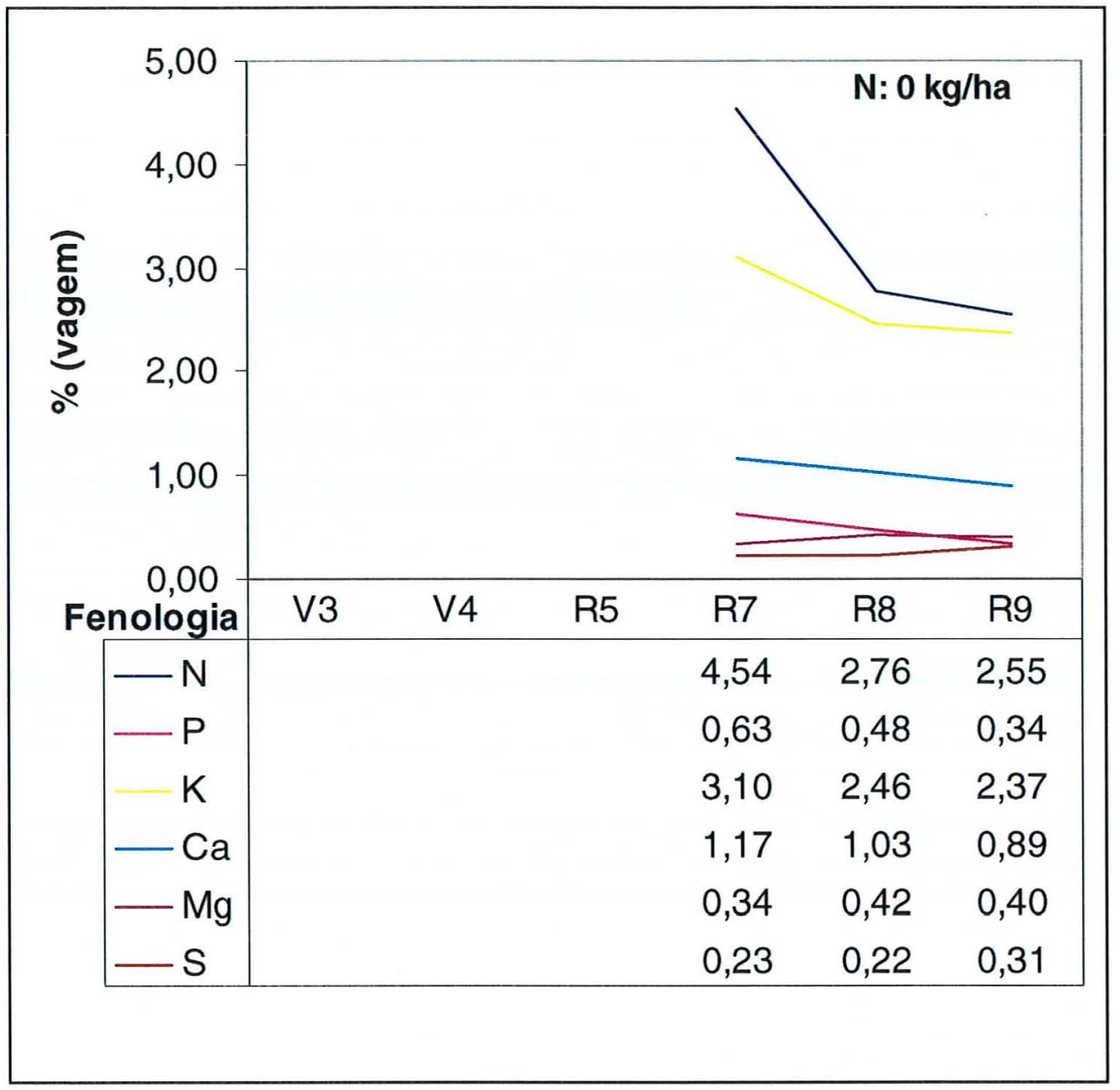

Figura 37. Variação dos teores $(\%)$ de nitrogênio $(\mathrm{N})$, fósforo $(\mathrm{P})$, potássio $(\mathrm{K})$, cálcio (Ca), magnésio $(\mathrm{Mg})$ e enxofre $(\mathrm{S})$ na vagem do feijoeiro em função da fenologia referente à testemunha $(0 \mathrm{~kg} / \mathrm{ha}$ de nitrogênio $)$.

Em ordem decrescente, os teores de nitrogênio, potássio, cálcio, fósforo, magnésio e enxofre na vagem apresentaram comportamento decrescente (nitrogênio, potássio, cálcio e fósforo) ou constante (magnésio e enxofre) durante o ciclo para todas as doses de nitrogênio. 


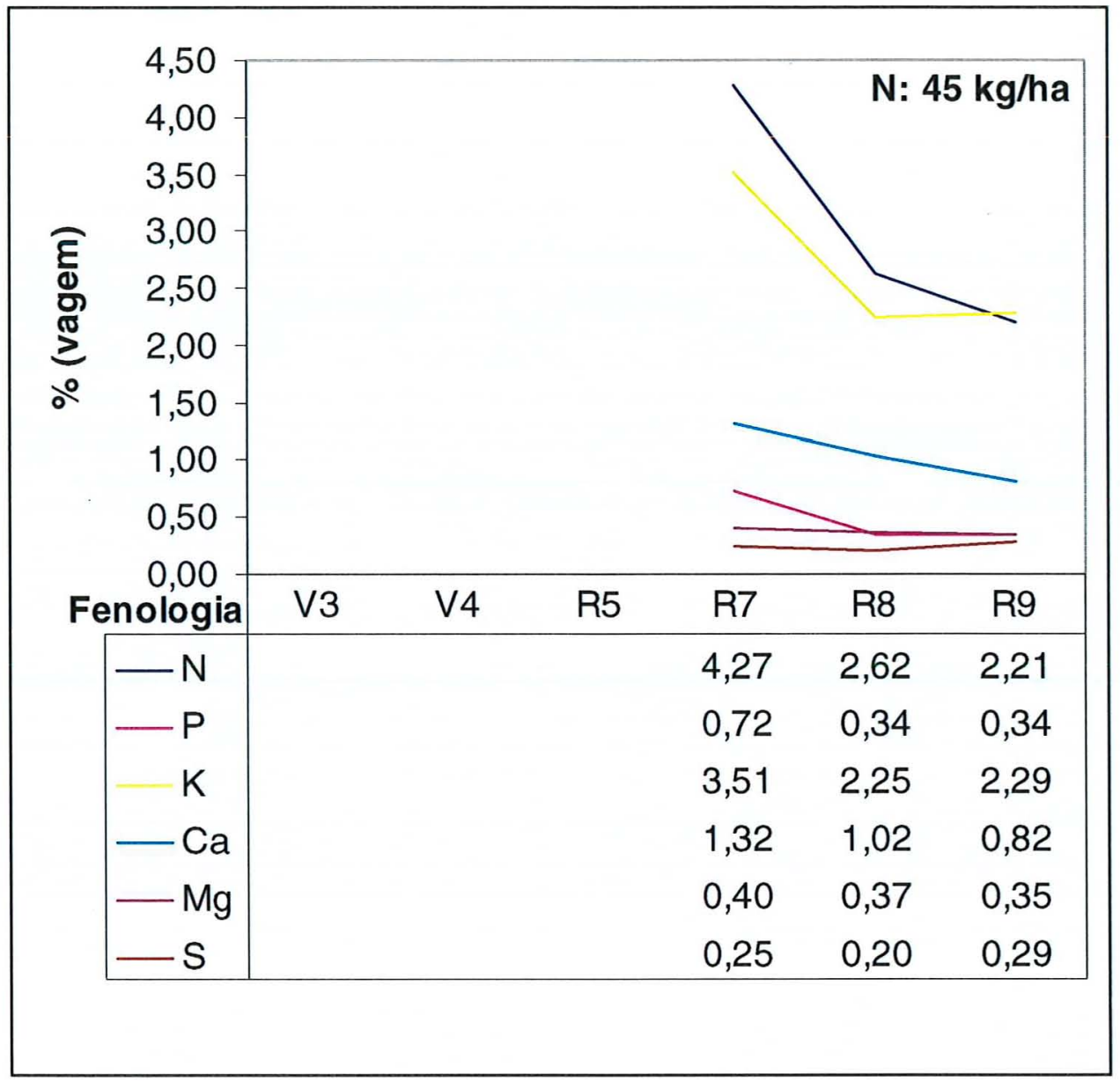

Figura 38. Variação dos teores $(\%)$ de nitrogênio $(\mathrm{N})$, fósforo $(\mathrm{P})$, potássio $(\mathrm{K})$, cálcio $(\mathrm{Ca})$, magnésio $(\mathrm{Mg})$ e enxofre $(\mathrm{S})$ na vagem do feijoeiro em função da fenologia referente à dose de $45 \mathrm{~kg} / \mathrm{ha}$ de nitrogênio. 


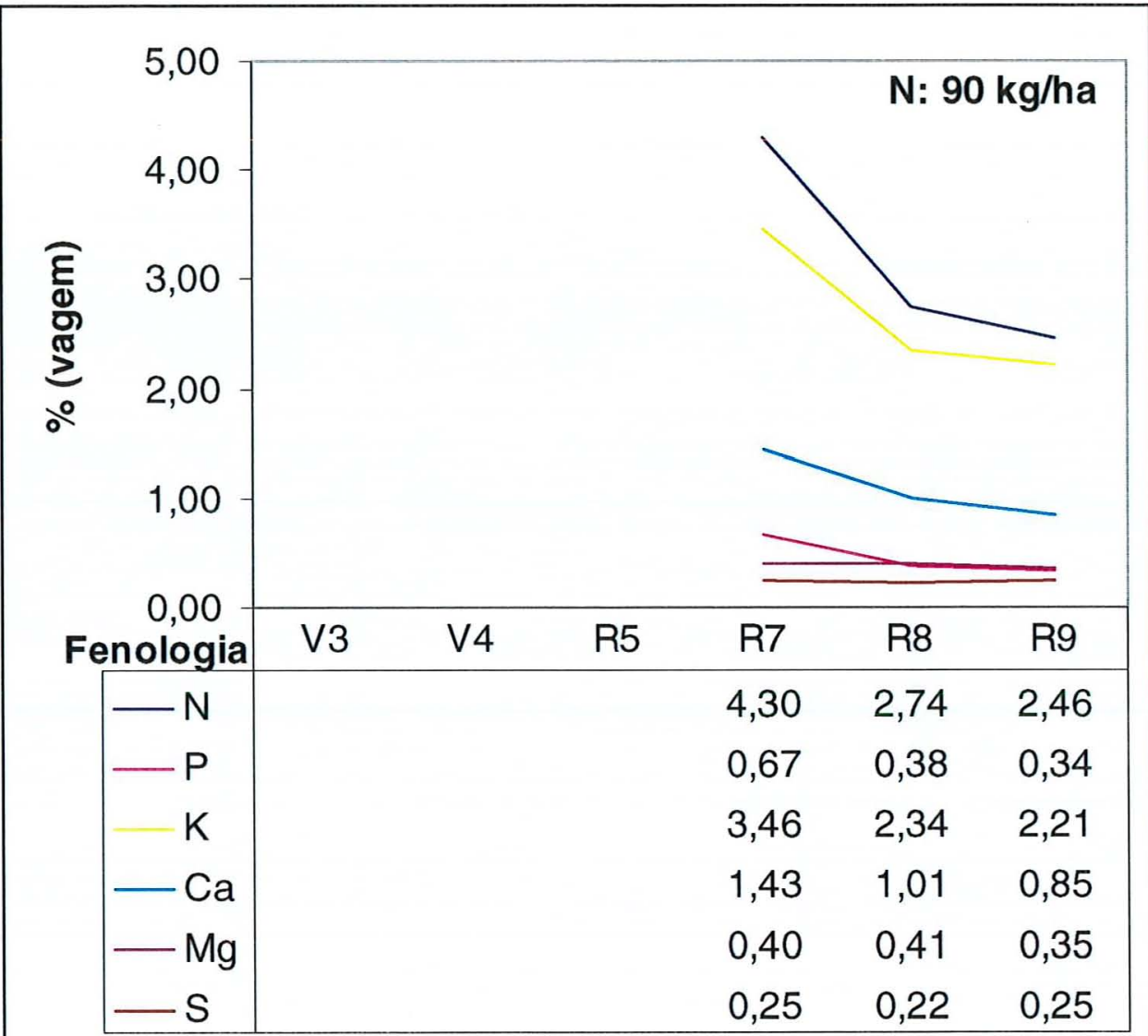

Figura 39. Variação dos teores $(\%)$ de nitrogênio $(\mathrm{N})$, fósforo $(\mathrm{P})$, potássio $(\mathrm{K})$, cálcio $(\mathrm{Ca})$, magnésio $(\mathrm{Mg})$ e enxofre $(\mathrm{S})$ na vagem do feijoeiro em função da fenologia referente à dose de $90 \mathrm{~kg} / \mathrm{ha}$ de nitrogênio. 


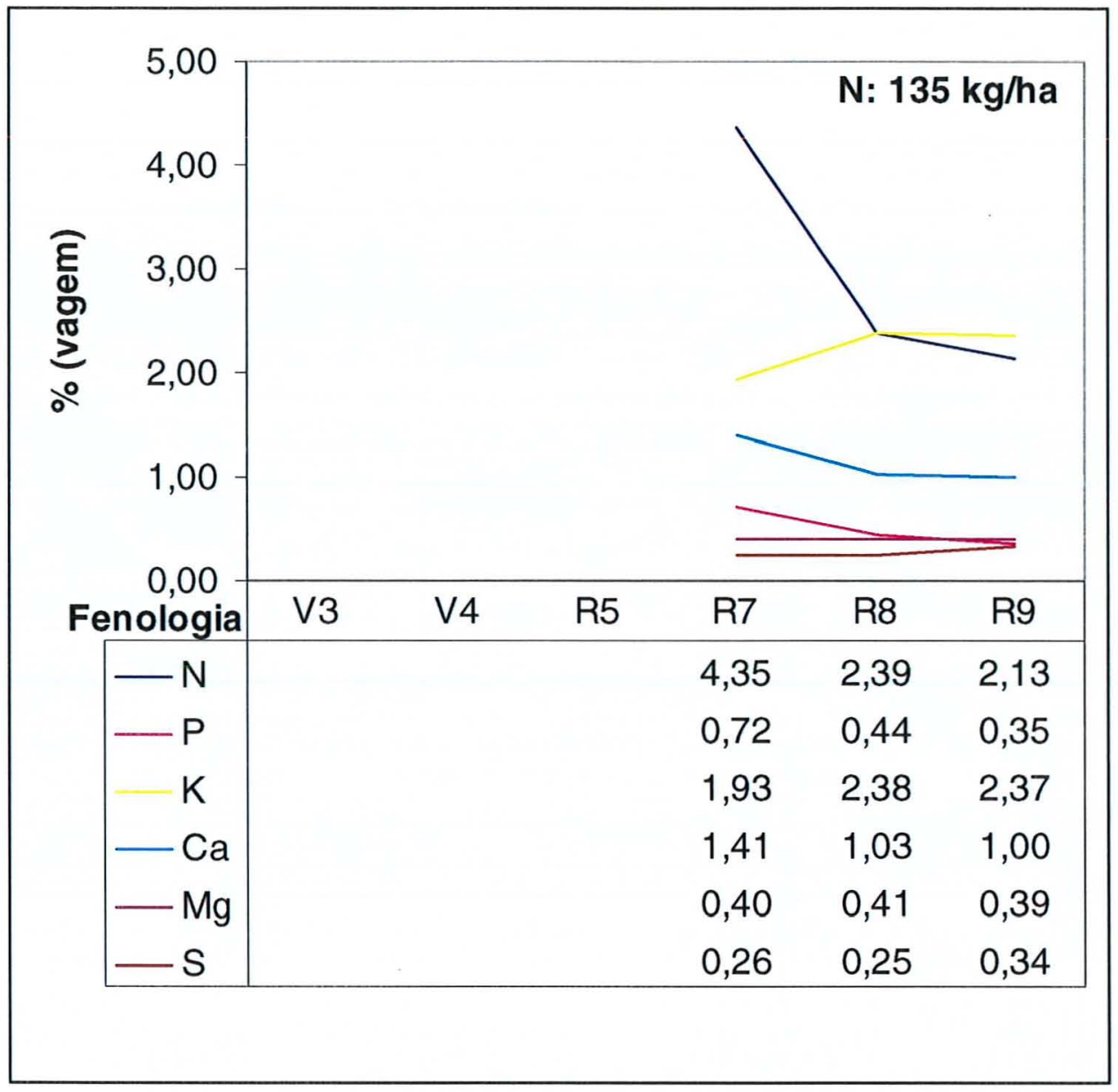

Figura 40. Variação dos teores $(\%)$ de nitrogênio $(\mathrm{N})$, fósforo $(\mathrm{P})$, potássio $(\mathrm{K})$, cálcio (Ca), magnésio $(\mathrm{Mg})$ e enxofre (S) na vagem do feijoeiro em função da fenologia referente à dose de $135 \mathrm{~kg} / \mathrm{ha}$ de nitrogênio. 


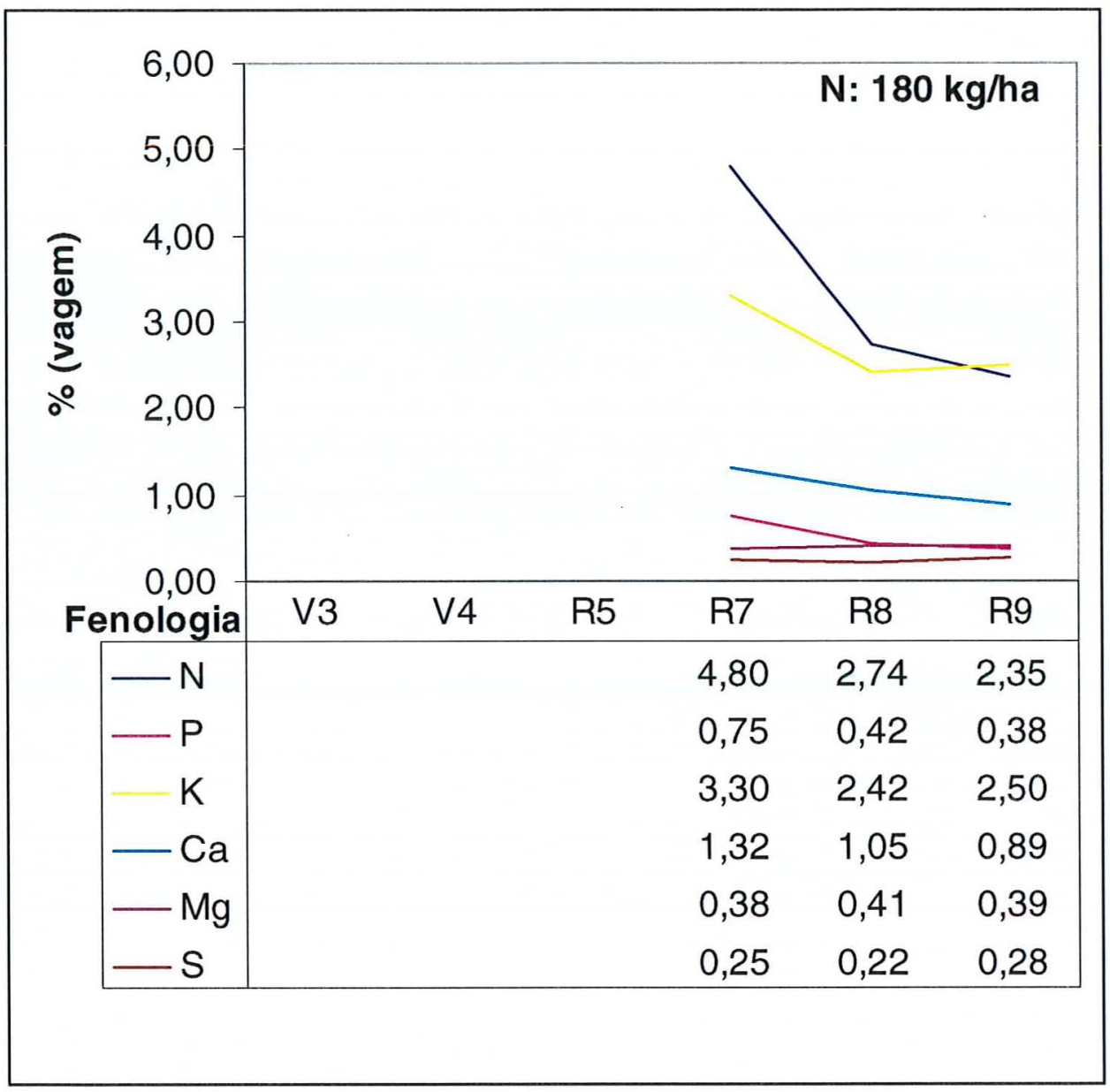

Figura 41. Variação dos teores $(\%)$ de nitrogênio $(\mathrm{N})$, fósforo $(\mathrm{P})$, potássio $(\mathrm{K})$, cálcio (Ca), magnésio $(\mathrm{Mg})$ e enxofre $(\mathrm{S})$ na vagem do feijoeiro em função da fenologia referente à dose de $180 \mathrm{~kg} / \mathrm{ha}$ de nitrogênio. 


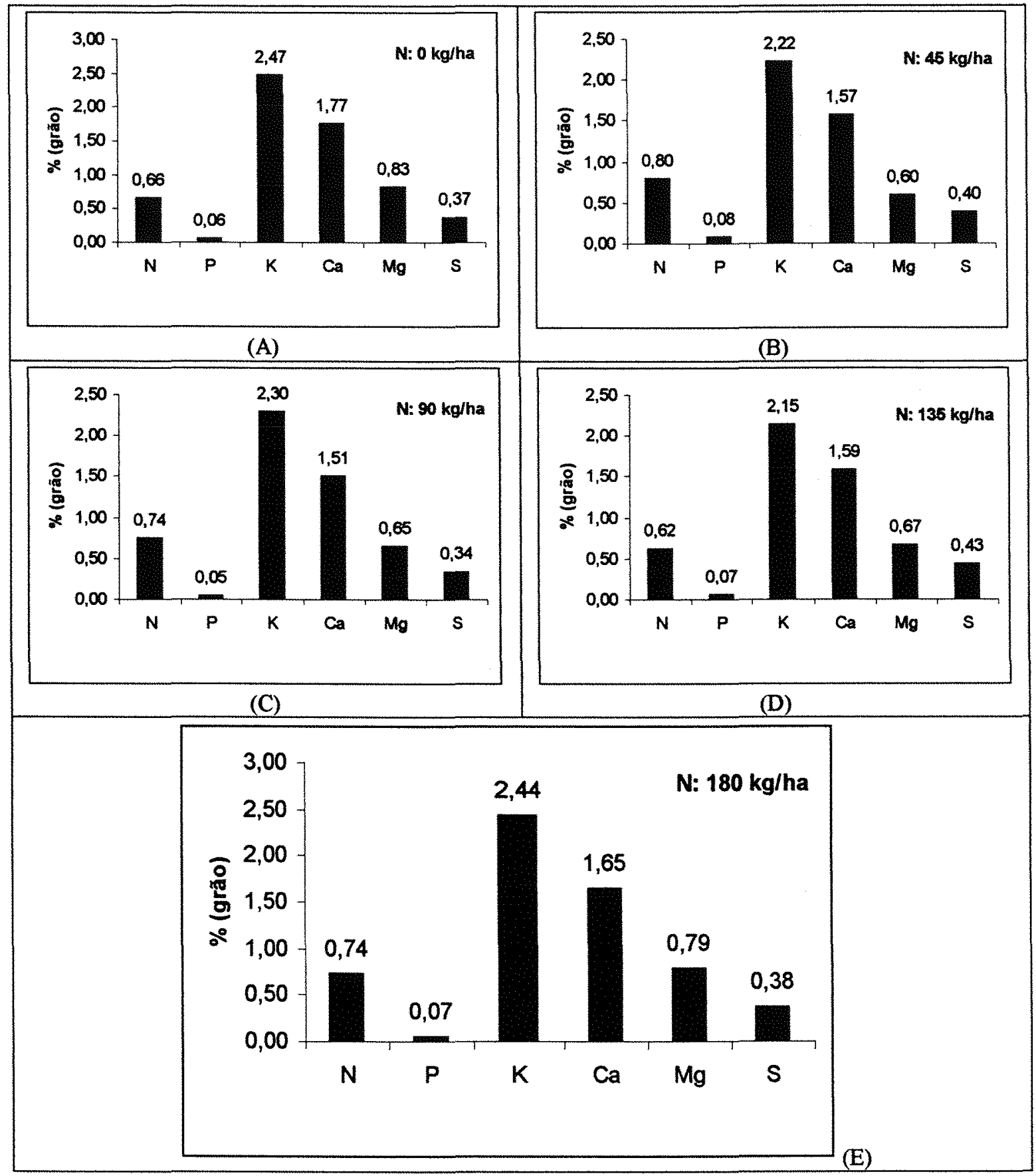

Figura 42. Teores $(\%)$ de nitrogênio $(\mathrm{N})$, fósforo $(\mathrm{P})$, potássio $(\mathrm{K})$, cálcio $(\mathrm{Ca})$, magnésio $(\mathrm{Mg})$ e enxofre (S) no grão do feijoeiro referentes à $(\mathrm{A}) 0 \mathrm{~kg} / \mathrm{ha}$ de nitrogênio, (B) $45 \mathrm{~kg} / \mathrm{ha}$ de nitrogênio, (C) $90 \mathrm{~kg} / \mathrm{ha}$ de nitrogênio, (D) $135 \mathrm{~kg} / \mathrm{ha}$ de nitrogênio, e (E) $180 \mathrm{~kg} / \mathrm{ha}$ de nitrogênio. 

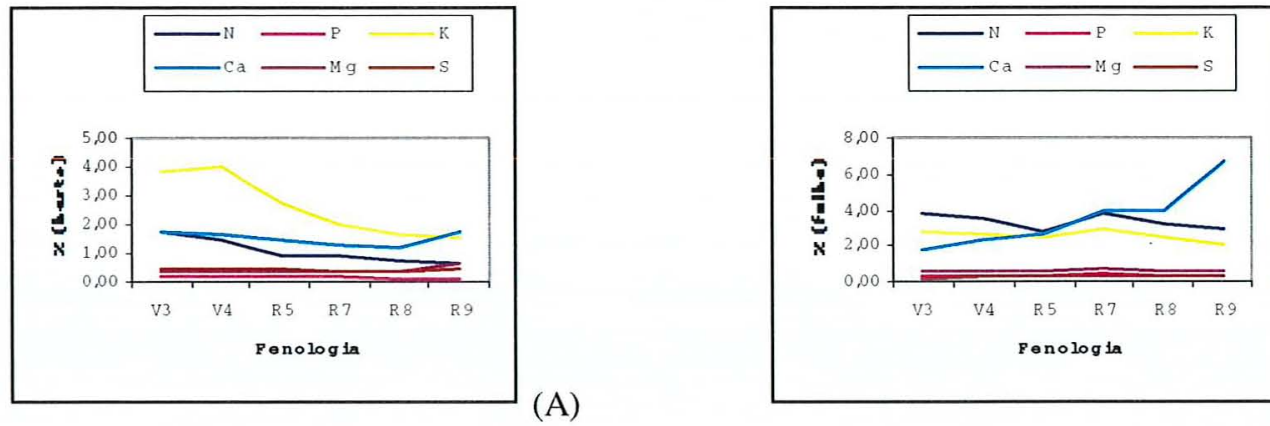

(B)

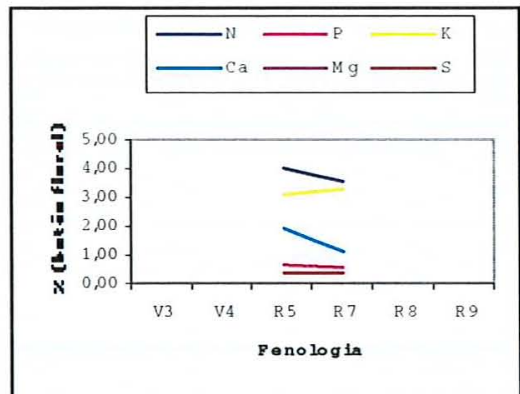

(A)

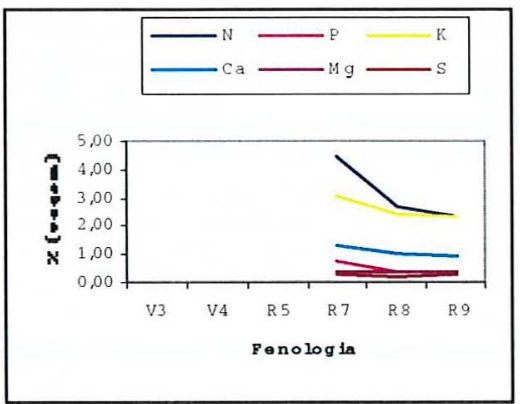

(D)

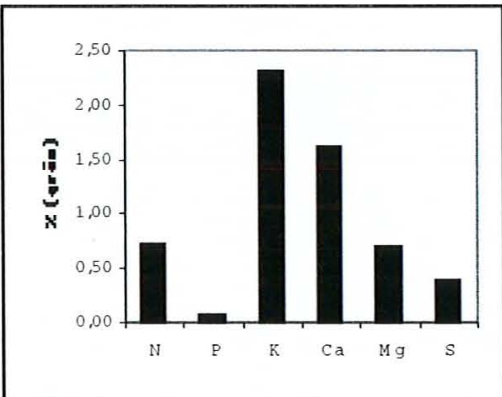

(E)

Figura 43. Teores médios (\%) (média de todos os tratamentos) de nitrogênio (N), fósforo $(\mathrm{P})$, potássio $(\mathrm{K})$, cálcio $(\mathrm{Ca})$, magnésio $(\mathrm{Mg})$ e enxofre $(\mathrm{S})$ na haste $(\mathrm{A})$, folha (B), botão floral (C), vagem (D) e grão (E) do feijoeiro em função da fenologia. 


\subsubsection{Rendimento de grãos}

Tabela 28. Valores médios de plantas por unidade de área $\left(P\right.$, plantas $\left./ \mathrm{m}^{2}\right)$, vagens totais (Vt, vagens/planta) e chochas (Vc, vagens/planta) por planta, sementes por vagem (sementes/vagem), massa da matéria seca de 200 sementes $\left(\mathbf{M}_{200}, \mathrm{~g}\right)$ e de uma semente (Ms, g/semente) e rendimentos obtido nos diferentes tratamentos $\left(\mathrm{R}, \mathrm{g} \cdot \mathrm{m}^{-2}\right)$, e corrigindo o conteúdo de água - base úmida - do grão para $14 \%\left(\mathrm{Rm}, \mathrm{kg} \cdot \mathrm{ha}^{-1}\right.$ ) (método de estimativa de rendimento pela pesagem dos grãos) (Pimenta, 1998).

\begin{tabular}{|c|c|c|c|c|c|c|c|c|}
\hline Tratamento & $\begin{array}{c}\mathrm{P} \\
\mathrm{pl} / \mathrm{m}^{2}\end{array}$ & $\begin{array}{c}\mathrm{Vt} \\
\mathrm{vg} / \mathrm{pl}\end{array}$ & $\begin{array}{c}\mathrm{Vc} \\
\mathrm{vg} / \mathrm{pl}\end{array}$ & $\begin{array}{c}\mathrm{S} \\
\mathrm{s} / \mathrm{vg}\end{array}$ & $\begin{array}{c}\mathrm{M}_{200} \\
\mathrm{~g} / 200 \mathrm{~s}\end{array}$ & $\begin{array}{c}\mathrm{Ms} \\
\mathrm{g} / \mathrm{s}\end{array}$ & $\begin{array}{c}\mathrm{R} \\
\mathrm{g} / \mathrm{m}^{2}\end{array}$ & $\begin{array}{c}\mathrm{R}^{\prime} \\
\mathrm{kg} / \mathrm{ha}\end{array}$ \\
\hline 0 & 23,7 & 12,6 & 2,1 & 4,9 & 35,5 & 0,2 & 249,6 & 2495,2 \\
\hline 45 & 24,3 & 15,6 & 2,1 & 4,8 & 34,3 & 0,2 & 314,3 & 3142,4 \\
\hline 90 & 20,8 & 15,4 & 2,3 & 5,2 & 37,1 & 0,2 & 299,5 & 2994,3 \\
\hline 135 & 23,7 & 13,2 & 2,0 & 4,8 & 34,5 & 0,2 & 263,9 & 2638,9 \\
\hline 180 & 22,9 & 14,2 & 1,9 & 5,0 & 35,9 & 0,2 & 290,3 & 3257,2 \\
\hline
\end{tabular}

1 Rendimento médio: $2905,6 \mathrm{~kg} / \mathrm{ha}$

\subsubsection{Extração e exportação de macronutrientes}

Tabela 29. Extração e exportação de nitrogênio $(\mathrm{N})$, fósforo $(\mathrm{P})$, potássio $(\mathrm{K})$, cálcio $(\mathrm{Ca})$, magnésio $(\mathrm{Mg})$ e enxofre $(\mathrm{S})$ nas diferentes partes da planta (haste, folha, botão floral, vagem e grão).

\begin{tabular}{|c|c|c|c|c|c|c|}
\hline Nutriente & Haste & Folha & Botão floral & Vagem & Grão $^{1}$ & Extração \\
\hline $\mathrm{N}$ & 24,0 & 75,5 & 86,6 & 71,9 & 16,2 & 274,3 \\
\hline $\mathrm{P}$ & 3,6 & 7,3 & 13,9 & 11,1 & 1,4 & 37,3 \\
\hline $\mathrm{K}$ & 59,8 & 58,5 & 73,8 & 59,2 & 52,9 & 304,3 \\
\hline $\mathrm{Ca}$ & 34,5 & 81,9 & 34,3 & 24,7 & 36,9 & 21,3 \\
\hline $\mathrm{Mg}$ & 9,0 & 13,8 & 7,9 & 8,8 & 16,1 & 55,7 \\
\hline $\mathrm{S}$ & 10,1 & 5,8 & 8,8 & 5,8 & 8,7 & 39,2 \\
\hline
\end{tabular}

\footnotetext{
Exportação
} 
A Tabela 29 ilustra a extração e exportação total de nitrogênio, fósforo, potássio, cálcio, magnésio e enxofre para um rendimento médio de grãos de $2905,6 \mathrm{~kg} / \mathrm{ha}$, o que está de acordo com os valores comumente informados na literatura.

\subsection{Considerações finais}

Os resultados obtidos permitiram que os modelos fitotécnicos propostos são utilizáveis para caracterizar fitotecnicamente a cultura de feijão em termos de altura de planta e produção de massa de matéria seca de raiz, folha, haste, vagem e total sob deficiência e suficiência hídrica.

Essa caracterização tem importância prática no sentido de melhor orientar ações de manejo como a correta definição da população de plantas (em função da altura da planta) e verificar quando deve ser evitada a competição (a cultura deve estar livre da competição a partir do estádio $\mathrm{V}_{4}$ ) da cultura com plantas daninhas por água e nutrientes (em função da variação temporal da produção de massa de matéria seca).

Os resultados mostraram ainda que os modelos fitotécnicos propostos são úteis para determinar a ordem de grandeza da extração (norteia a definição da época crítica logo após o $\mathrm{V}_{4}$ - em que se deve recomendar a adubação em cobertura) e exportação (subsídio para recomendação de adubação de manutenção) da cultura de feijão. 


\section{CONCLUSÕES}

Em função dos resultados obtidos, pode-se concluir que os modelos fitotécnicos propostos são utilizáveis para:

(i) caracterização fitotécnica em termos de altura de planta e produção de massa de matéria seca de raiz, folha, haste, vagem e total sob deficiência e suficiência hídrica;

(ii) determinar a ordem de grandeza da extração e exportação da cultura de feijão. 


\section{REFERÊNCIAS BIBLIOGRÁFICAS}

ABELES, F.B.; GAHAGAN, H.E. Abscision; the role of ethylene, ethylene analogues, carbon dioxide and oxygen. Plant Physiology, v.43, p.1255-1258, 1968.

AMBROSANO, E.J.; TANAKA, R.T.; MASCARENHAS, H. A.A.; et. al. Leguminosas e oleaginosas. In: RAIJ, B. van et al. (Ed.). Recomendações de adubação e calagem para o estado de São Paulo. 2. ed. Campinas: Instituto Agronômico \& Fundação IAC, 1996. p.187-203.

AWAD, M.; CASTRO, P.R.C. Introdução à fisiologia vegetal. São Paulo. Nobel, 1983. $177 \mathrm{p}$.

CENTRO INTERNACIONAL DE AGRICULTURA IRRIGADA. Morfologia de la planta de frijol comum (Phaseolus vulgaris L.). Cali, 1981. 50p. (Guia de Estudio).

COMISSÃO DE FERTLIDADE DO SOLO DO ESTADO DE MINAS GERAIS. Recomendações para o uso de corretivos e fertilizantes em Minas Gerais: 5a. aproximação. Viçosa, 1999. 359p.

COMISSÃO DE FERTILIDADE DO SOLO DO ESTADO DO RIO GRANDE DO SUL E DE SANTA CATARINA. Recomendação de adubação e calagem para os Estados do Rio Grande do Sul e de Santa Catarina. 3. ed. Passo Fundo: SBCSNúcleo Regional Sul, 1994. 224p. 
CROOKSTON, R.K.; O' TOOLE, J. ; OZBUN, J.L. Characterization of the bean pod as a photosynthetic organ. Crop Science, v.14, p.708-712, 1974.

CROOKSTON, R.K.; TREHARNE, K.J.; LUDFOR, P.; OZBUN, J.L. Response of beans of shading. Crop Science, v. 15, p.412-416, 1975.

DICKSON, M.K.; BOETTGER, M.A. Effect of high and low temperatures on pollen germination and seed set in snaps beans. Journal of the American Society for Horticultural Science. v.109, n.3, p.372-374, 1984.

DUBETZ, S.; MAHALE, R.S. Effect of soil water stress on beans (Phaseolus vulgaris L.) at three stages of growth. Journal of the American Society for Horticultural Science.. v.94, p.479-81, 1969.

FANCELLI, A.L.; DOURADO NETO, D. Tecnologia da produção do feijão irrigado. Piracicaba: FEALQ,ESALQ, Departamento de Agricultura, 1997. 153p.

FANCELLI, A..L.; DOURADO NETO, D. Feijão irrigado: estratégias básicas de manejo. Piracicaba: FEALQ,ESALQ, Departamento de Agricultura, 1999. 194p.

FIELD, R.J. A relationship between membrane permeability and ethylene production of high temperature in leaf tissue of Phaseolus vulgaris L. Annals of Botany, v.48, p.33-9, 1981.

FU, Q.A.; EHLERINGER, J.R. Heliotropic leaf movements in common beans controlled by air temperature. Plant Physiology. v.91, p.1162-7, 1989. 
GARRIDO, M.A.T.; PURCINO, J.R.C.; LIMA, C.A.S. Efeitos de diferentes regimes de irrigação sobre o rendimento do feijoeiro na região Norte de Minas Gerais. In: Empresa de Pesquisa Agropecuária de Minas Gerais. Projeto feijão: relatório 77/78. Belo Horizonte, 1979. p.27-29.

GEPTS, P.; FERNÁNDEZ, F. Etapas de desarrollo de la planta de frijol comum (Phaseolus vulgaris L.). Cali: CIAT, 1982. 10p.

GRIFFITH, M.; BOESE, S.R.; HUNER, N.P.A. Chilling sensitivity of the frost-tolerant potato (Solamum commersonii). Plant Physiology, v.90, p.319-26, 1994.

HALTERLEIN, A.J.; CLAYBERG, C.D.; TEARE, I.D. Influence of high temperature on pollen grain viability and pollen tube growth in styles of Phaseolus vulgaris L.). J. Amer. Soc. Hort. Science. v.105, n.1, p. 12-4, 1980.

HOSTALÁCIO, S.; VÁLIO, I.F.M. Desenvolvimento de plantas de feijão cv. Goiano Precoce, em diferentes regimes de irrigação. Pesquisa Agropecuária Brasileira, Brasilia, v.19, n.2, p.211-8, 1984.

KANEMASU, E.T.; TANNER, C.B. Stomatal diffusion resistance of snap beans. II. Effect of light. Plant Physiology, v.44, p.1542-6, 1969.

KOSTER, K.L.; LYNCH, D.V. Solute accumulation and compartimentation during the cold acclimation of puma rye. Plant Physiology, v.98, p.108-13, 1992.

LIN, T,Y.; MARKHART, A.B. Temperature effects on mitocondrial respiration in Phaseolus acutifolius A. Gray and Phaseolus vulgaris L. Plant Physiology, v.94, p.54-58, 1990. 
LOPES, A.S.; GUILHERME, L.R.G.; MARQUES, R. Guia de fertilidade do solo. versão multimídia. Lavras: UFLA, ANDA, POTAFOS, 1999.

MAGALHÃES, A.C.; MILLAR, A.A.; CHOUDHURY, E.N. Efeito do déficit fenológico de água sobre a produção de feijão. Turrialba, v.29, n.4, p.269-73, 1979.

MALAVOLTA, E.; LIMA FILHO, O.F. Nutrição e adubação do feijoeiro. In: Tecnologia da produção do feijão irrigado. FANCELLI, A.L.; DOURADO NETO, D. (Ed.) Piracicaba: ESALQ; 1997. p.22-51.

MARIOT, E.J. Ecofisiologia do feijoeiro. In: Instituto Agronômico do Paraná. O feijão no Paraná. Londrina, 1989. p.25-42. (Circular Técnica, 23).

MARSCHNER, H. Mineral nutrition of higher plants. San Diego: Academic Press, 1986. $674 \mathrm{p}$.

MEIDNER, H.; MANSFIELD, T.A. Physiology of stomata. London: Mc Hill, 1978. $179 \mathrm{p}$.

MONTERROSO, V.A.; WIEN, H.C. Flower and pod abscission due to heat stress in beans. Journal of the American Society for Horticultural Science. v.115, n.4, p.631-634, 1990.

OLIVEIRA, E. F. de ;COSTA, J. M. Treinamento de fertilidade e nutrição de plantas. Campo Mourão: COODETEC/COAMO, 1998. 59p.

PASTENES, C.; HORTON, P. Effect of high temperature on photosynthesis in bean. Plant Physiology, v.112, p.1245-51, 1996. 
PIMENTA, H.S. Modelo empírico, determinístico e dinâmico para estimar o acúmulo de matéria seca do feijoeiro comum. Piracicaba, 1998. 110p. Tese (Doutorado) - Escola Superior de Agricultura "Luiz de Queiroz", Universidade de São Paulo.

ROSOLÉM, C.A.; MARUBAYASHI, O.M. Seja o doutor do seu feijoeiro. Arquivo do Agrônomo n.7. Encarte de Informações Agronômicas, n.68. POTAFOS. 1994. 1$16 \mathrm{p}$.

SAUTER, K.J.; DAVIS, D.W.; LI, P.H.; WALLERSTEIN, I.S. HortScience, v.25, n.10, p.1282-1284, 1990.

SCHERER, E.E.; BARTZ, H.R. Adubação do feijoeiro com esterco de aves, nitrogênio, fósforo e potássio. 2. ed. Florianópolis: EMPASC, 1982. 15p. (Boletim Técnico, 10).

SCHWARTZ, H.F.; GalVEZ, G.E. Problemas de producción del frijol. Cali: CIAT, 1980. 424p.

SIEBENEICHLER, S.C. Alterações bioquímicas e fisiológicas induzidas por baixa temperatura em feijoeiros (Phaseolus vulgaris L.). Viçosa, 1996. 55p. Dissertação (Mestrado). Universidade Federal de Viçosa.

SILVA, E.L. Suscetibilidade do feijoeiro (Phaseolus vulgaris L.) cv. Goiano Precoce à inundações temporárias do sistema radicular em diferentes fases do seu ciclo vegetativo. Piracicaba, 1982. 76p. Dissertação (Mestrado) - Escola Superior de Agricultura "Luiz de Queiroz", Universidade de São Paulo. 
SILVEIRA, P.M. da.; SILVA, J.G. da. Efeito do preparo do solo e da rotação de cultura sobre o rendimento do feijoeiro irrigado. In: REUNIÃO NACIONAL DE PESQUISA DE FEIJÃO, 5, Goiânia, 1996. Anais. Goiânia: EMBRAPA, CPAF, 1996. v.1, p.462-464. (EMBRAPA, CNPAF. Documentos, 69).

SILVEIRA, P.M. da; COBUCCI, T.; RIOS, G.P.; STONE, L.F; SILVA, O.F. da. Sistemas agrícolas irrigados no cerrado. Santo Antônio de Goiás: Embrapa Arroz e Feijão, 1999. 63p.

SOUZA, D.M.G.; LOBATO, E.; MIRANDA, L.N. de. Interpretação de análise de terra e recomendação de adubos fosfatados para as culturas anuais nos cerrados. Planaltina: EMBRAPA, CPAC, 1997. 7p. (EMBRAPA-CPAC. Comunicado Técnico, $51)$.

SOUZA, D.M.G.; LOBATO, E.; REIN, T. A. Uso do gesso agrícola nos solos do cerrados. Planaltina: EMBRAPA, CPAC, 1996. 20p. (EMBRAPA-CPAC. Circular técnica 32).

SUTCLIFFFE, J. As plantas e a água. São Paulo: Edusp, 1980. 126 p.

TAIZ, L.; ZEIGER, E. Plant physiology. Berkeley: The Benjamin/Cummings Publ., 1991. 189p.

THUNG, D.T.M.; OLIVEIRA, P.I. Problemas abióticos que afetam a produção do feijoeiro e seus métodos de controle. Santo Antônio de Goiás: EMBRAPA, CNPAF, 1998. p.105-134.

VIEIRA, C. Cultura do feijão. Viçosa: Imprensa Universitária, 1978. 146p. 
VITTI, G.C.; MALAVOLTA, E.; REZENDE, L.O. de; TREVISAN, W. Manejo da fertilidade do solo na cultura do feijão irrigado. In: FANCELLI, A.L.; DOURADO NETO, D. (Ed.). Feijão irrigado: estratégias básicas de manejo Piracicaba: Publique, 1999. p.108-125.

WHITE, J.W. Conceptos básicos de fisiologia del frijol. In: LÓPEZ, M.; FERNANDEZ, F.; van SCHOONHOVEN. Frijol: investigación y producción. Colômbia. CIAT, 1985. p.43-60. 


\section{APÊNDICE: Dados climatológicos}

Tabela 30. Radiação solar (Rs, cal $/ \mathrm{cm}^{2}$.dia), insolação (L, horas/dia), chuva (C, mm), umidade relativa (UR, \%), velocidades do vento máxima $(V \max , \mathrm{km} / \mathrm{h})$ e média (Vmed, $\mathrm{m} / \mathrm{s}$ ), temperaturas máxima $\left(\mathrm{T} \max ,{ }^{\circ} \mathrm{C}\right)$, mínima $\left(\mathrm{Tmin},{ }^{\circ} \mathrm{C}\right) \mathrm{e}$ média (Tmed, ${ }^{\circ} \mathrm{C}$ ), evaporação do tanque classe $\mathrm{A}$ e direção do vento (Dv) às $7\left(D_{7}\right), 14\left(D_{14}\right)$ e $21\left(D_{21}\right)$ horas referentes ao mês de abril de 1995 em Piracicaba, SP.

\begin{tabular}{|c|c|c|c|c|c|c|c|c|c|c|c|c|c|}
\hline \multirow[t]{2}{*}{ dia } & Rs & I & C & UR & $V \max$ & Vmed & Tmax & $T \min$ & Tmed & $\mathrm{ECA}$ & \multicolumn{3}{|c|}{ Dv } \\
\hline & $\mathrm{cal} / \mathrm{cm}^{2} \cdot \mathrm{d}$ & $\mathrm{h} / \mathrm{d}$ & $\mathrm{mm}$ & $\%$ & $\mathrm{~m} / \mathrm{s}$ & $\mathrm{km} / \mathrm{h}$ & ${ }^{\circ} \mathrm{C}$ & ${ }^{\circ} \mathrm{C}$ & ${ }^{\circ} \mathrm{C}$ & $\mathrm{mm}$ & $\mathrm{D}_{7}$ & $\mathrm{D}_{14}$ & $D_{21}$ \\
\hline 1 & 227 & 2,0 & 15,6 & 92 & 8,7 & 12,4 & 27,5 & 19,2 & 23,4 & 6,52 & $\mathbf{N}$ & NW & $\mathbf{W}$ \\
\hline 2 & 491 & 10,5 & - & 74 & 5,0 & 7,3 & 28,0 & 19,0 & 23,5 & 6,46 & $\mathrm{~N}$ & W & W \\
\hline 3 & 473 & 10,9 & - & 75 & 5,7 & 9,1 & 28,4 & 12,9 & 20,7 & 5,46 & $\mathrm{E}$ & $\mathrm{S}$ & $\mathrm{SE}$ \\
\hline 4 & 449 & 10,1 & - & 77 & 7,2 & 9,5 & 29,4 & 16,1 & 22,8 & 4,91 & $\mathrm{E}$ & $\mathrm{E}$ & $\mathrm{E}$ \\
\hline 5 & 438 & 10,0 & - & 76 & 7,2 & 5,9 & 30,6 & 16,1 & 23,4 & 4,78 & $\mathrm{C}$ & $\mathrm{NE}$ & $\mathrm{E}$ \\
\hline 6 & 345 & 6,2 & - & 81 & 2,0 & 4,1 & 30,4 & 16,9 & 23,7 & 2,87 & $\mathrm{C}$ & $\mathrm{E}$ & E \\
\hline 7 & 405 & 5,9 & - & 81 & 5,8 & 4,6 & 31,5 & 19,2 & 25,4 & 5,67 & $\mathrm{E}$ & NE & E \\
\hline 8 & 302 & 3,9 & - & 88 & 4,4 & 5,0 & 30,9 & 17,4 & 24,2 & 3,40 & $\mathrm{NE}$ & $\mathrm{N}$ & W \\
\hline 9 & 341 & 4,0 & 8,0 & 89 & 10,7 & 7,8 & 31,2 & 18,6 & 24,9 & 4,30 & $\mathbf{N}$ & $\mathbf{N}$ & $\mathbf{S}$ \\
\hline 10 & 398 & 8,0 & 0,2 & 90 & 5,7 & 6,8 & 31,4 & 18,3 & 24,9 & 4,44 & $\mathrm{NE}$ & $\mathrm{N}$ & $\mathrm{NE}$ \\
\hline 11 & 408 & 8,5 & 7,7 & 84 & 7,8 & 9,1 & 31,2 & 19,0 & 25,1 & 5,56 & NE & W & NW \\
\hline 12 & 356 & 6,9 & - & 76 & 7,6 & 8,4 & 25,8 & 18,8 & 22,3 & 5,36 & $\mathrm{C}$ & SW & $\mathbf{S}$ \\
\hline 13 & 461 & 10,2 & - & 77 & 9,7 & 11,3 & 26,0 & 10,4 & 18,2 & 5,08 & $\mathrm{~S}$ & SE & SE \\
\hline 14 & 462 & 10,5 & - & 74 & 9,9 & 10,3 & 27,2 & 13,4 & 20,3 & 5,30 & SE & SE & $\mathrm{SE}$ \\
\hline 15 & 437 & 10,5 & $=$ & 77 & 4,8 & 5,4 & 28,8 & 11,8 & 20,3 & 3,32 & SE & $\mathbf{N}$ & $S$ \\
\hline 16 & 438 & 10,2 & - & 78 & 3,9 & 5,7 & 29,2 & 12,8 & 21,0 & 4,60 & $S$ & SW & $S$ \\
\hline 17 & 413 & 8,1 & - & 77 & 4,1 & 5,0 & 29,8 & 14,0 & 21,9 & 4,30 & SE & $\mathrm{E}$ & $E$ \\
\hline 18 & 384 & 8,6 & - & 77 & 3,6 & 4,3 & 30,0 & 15,8 & 22,9 & 3,80 & $\mathbf{S}$ & $\mathrm{N}$ & SE \\
\hline 19 & 374 & 9,7 & 7,4 & 75 & 5,4 & 5,8 & 32,5 & 18,8 & 25,7 & 3,83 & $E$ & $\mathbf{N}$ & $\mathrm{NE}$ \\
\hline 20 & 80 & 0,3 & 46,8 & 99 & 5,0 & 2,4 & 27,8 & 20,0 & 23,9 & 5,83 & $\mathrm{SE}$ & NW & SW \\
\hline 21 & 222 & 3,2 & - & 90 & 3,6 & 7,5 & 26,2 & 18,0 & 22,1 & 2,92 & NW & $\mathrm{SE}$ & $\mathrm{SE}$ \\
\hline 22 & 323 & 6,9 & - & 87 & 1,0 & 4,4 & 27,0 & 14,8 & 20,9 & 2,66 & $\mathbf{S}$ & NW & W \\
\hline 23 & 377 & 8,4 & - & 80 & 5,0 & 6,1 & 28,0 & 15,0 & 21,5 & 4,48 & $E$ & NW & W \\
\hline 24 & 408 & 10,3 & - & 76 & 2,0 & 4,8 & 28,5 & 13,2 & 20,9 & 4,04 & $S$ & NW & $\mathbf{S}$ \\
\hline 25 & 389 & 8,9 & - & 82 & 4,9 & 6,8 & 29,8 & 13,7 & 21,8 & 4,44 & W & NE & SE \\
\hline 26 & 351 & 8,6 & - & 85 & 4,0 & 4,5 & 30,1 & 13,5 & 21,8 & 3,36 & NW & NW & SW \\
\hline 27 & 330 & 6,2 & - & 84 & 7,0 & 7,2 & 28,1 & 16,4 & 22,3 & 2,76 & C & NW & $\mathrm{SE}$ \\
\hline 28 & 356 & 8,6 & $=$ & 84 & 1,0 & 4,3 & 29,7 & 15,2 & 22,5 & 8,02 & NW & NW & $\mathrm{S}$ \\
\hline 29 & 365 & 8,5 & $=$ & 80 & 3,6 & 7,2 & 30,0 & 15,5 & 22,8 & 4,20 & $\mathrm{E}$ & W & $E$ \\
\hline 30 & 381 & 9,9 & $=$ & 76 & 1,0 & 4,8 & 31,4 & 15,1 & 23,3 & 3,00 & $\mathrm{E}$ & NE & $E$ \\
\hline
\end{tabular}

Fonte: Departamento de Física e Meteorologia, ESALQ, USP (Extraído de Pimenta, 1998) 
Tabela 31. Radiação solar (Rs, cal/ $\mathrm{cm}^{2}$.dia), insolação (I, horas/dia), chuva (C, mm), umidade relativa (UR, \%), velocidades do vento máxima (Vmax, $\mathrm{km} / \mathrm{h}$ ) e média (Vmed, $\mathrm{m} / \mathrm{s})$, temperaturas máxima $\left(\operatorname{Tmax},{ }^{\circ} \mathrm{C}\right)$, mínima $\left(\mathrm{Tmin},{ }^{\circ} \mathrm{C}\right) \mathrm{e}$ média (Tmed, ${ }^{\circ} \mathrm{C}$ ), evaporação do tanque classe A e direção do vento (Dv) às $7\left(D_{7}\right), 14\left(D_{14}\right)$ e $21\left(D_{21}\right)$ horas referentes ao mês de maio de 1995 em Piracicaba, SP.

\begin{tabular}{|c|c|c|c|c|c|c|c|c|c|c|c|c|c|}
\hline \multirow[t]{2}{*}{ dia } & Rs & $\mathrm{I}$ & $\mathrm{C}$ & UR & $V \max$ & Vmed & $\operatorname{Tmax}$ & Tmin & Tmed & $\overline{\mathrm{ECA}}$ & \multicolumn{3}{|c|}{ Dv } \\
\hline & $\mathrm{cal} / \mathrm{cm}^{2} \cdot \mathrm{d}$ & $\mathrm{h} / \mathrm{d}$ & $\mathrm{mm}$ & $\%$ & $\mathrm{~m} / \mathrm{s}$ & $\mathrm{km} / \mathrm{h}$ & ${ }^{\circ} \mathrm{C}$ & ${ }^{\circ} \mathrm{C}$ & ${ }^{\circ} \mathrm{C}$ & $\mathrm{mm}$ & $\overline{D_{7}}$ & $D_{14}$ & $\mathrm{D}_{21}$ \\
\hline 1 & 362 & 9,6 & - & 76 & 3,0 & 5,3 & 32,0 & 15,5 & 23,8 & 4,00 & $\mathrm{E}$ & NE & SE \\
\hline 2 & 332 & 9,4 & - & 78 & 4,6 & 7,3 & 30,1 & 15,5 & 22,8 & 4,45 & $\mathrm{E}$ & W & SE \\
\hline 3 & 365 & 10,1 & - & 83 & 4,2 & 6,2 & 28,0 & 16,1 & 22,1 & 4,09 & $S$ & $S$ & $\mathrm{~S}$ \\
\hline 4 & 311 & 6,3 & - & 80 & 1,0 & 5,8 & 29,6 & 13,3 & 21,5 & 1,94 & $\mathrm{E}$ & $\mathrm{NE}$ & $\mathrm{E}$ \\
\hline 5 & 273 & 3,2 & 0,4 & 81 & 1,0 & 5,0 & 29,5 & 14,2 & 21,9 & 3,06 & $\mathrm{E}$ & NW & NE \\
\hline 6 & 125 & - & 7,5 & 97 & 1,0 & 5,8 & 23,3 & 19,2 & 21,3 & 0,26 & $\mathrm{E}$ & $\mathrm{NE}$ & $\mathrm{E}$ \\
\hline 7 & 156 & 0,3 & 0,5 & 96 & 1,0 & 5,0 & 24,0 & 19,9 & 22,0 & 1,14 & $\mathrm{E}$ & $\mathbf{N}$ & $\mathrm{NE}$ \\
\hline 8 & 276 & 5,3 & - & 88 & 2,0 & 3,8 & 26,7 & 16,4 & 21,6 & 2,58 & $\mathrm{E}$ & $\mathrm{E}$ & $\mathrm{S}$ \\
\hline 9 & 311 & 6,9 & 5,3 & 86 & 13,2 & 4,7 & 27,7 & 15,8 & 21,8 & 3,54 & $\mathrm{C}$ & $\mathbf{N}$ & $S$ \\
\hline 10 & 92 & 0,2 & 15,2 & 98 & 7,2 & 6,7 & 18,7 & 17,5 & 18,1 & 0,68 & $\mathrm{~S}$ & NE & $S$ \\
\hline 11 & 249 & 5,3 & - & 90 & 1,5 & 4,4 & 23,3 & 12,5 & 17,9 & 0,62 & $\mathrm{SE}$ & W & $S$ \\
\hline 12 & 323 & 7,1 & - & 85 & 1,0 & 3,2 & 26,9 & 12,8 & 19,9 & 3,22 & SW & $\mathrm{NE}$ & $S$ \\
\hline 13 & 351 & 7,8 & - & 82 & 3,1 & 5,3 & 29,0 & 13,1 & 21,1 & 3,34 & $\mathrm{C}$ & $\mathrm{E}$ & SE \\
\hline 14 & 324 & 6,7 & - & 83 & 1,0 & 4,9 & 29,4 & 13,7 & 21,6 & 3,02 & C & NW & SE \\
\hline 15 & 297 & 5,5 & - & 83 & 1,0 & 5,7 & 29,5 & 14,6 & 22,1 & 3,11 & $\mathrm{E}$ & $\mathrm{NE}$ & $\mathrm{E}$ \\
\hline 16 & 255 & 5,2 & 30,6 & 91 & 11,3 & 6,2 & 29,3 & 15,6 & 22,5 & 4,97 & $\mathrm{E}$ & NE & $\mathrm{N}$ \\
\hline 17 & 323 & 8,5 & - & 85 & 3,5 & 4,3 & 29,3 & 16,9 & 23,1 & 3,19 & $\mathrm{E}$ & SW & SE \\
\hline 18 & 122 & 0,1 & 4,5 & 90 & 7,7 & 10,6 & 22,7 & 16,7 & 19,7 & 2,12 & $S$ & $\mathrm{SE}$ & SE \\
\hline 19 & & 9,7 & - & 79 & 3,2 & 7,7 & 22,0 & 11,9 & 17,0 & 4,63 & $\mathrm{~S}$ & $S$ & $S$ \\
\hline 20 & 288 & 7,8 & 0,2 & 79 & 2,0 & 5,1 & 22,2 & 8,1 & 15,2 & 2,56 & SE & $\mathrm{S}$ & $\mathrm{SE}$ \\
\hline 21 & 260 & 5,4 & - & 83 & 1,0 & 4,3 & 22,3 & 10,0 & 16,2 & 1,26 & $\mathrm{E}$ & SE & SE \\
\hline 22 & 336 & 7,4 & - & 82 & 1,0 & 4,4 & 23,8 & 8,9 & 16,4 & 2,31 & $S$ & $\mathbf{N}$ & $S$ \\
\hline 23 & 297 & 6,1 & - & 88 & 4,2 & 5,8 & 25,1 & 10,0 & 17,6 & 2,35 & W & SW & $\mathrm{SE}$ \\
\hline 24 & 276 & 6,8 & - & 85 & 1,0 & 4,8 & 25,7 & 12,0 & 18,9 & 2,08 & SW & $\mathrm{NE}$ & $\mathrm{S}$ \\
\hline 25 & 275 & 5,4 & - & 84 & 9,0 & 9,0 & 25,2 & 13,4 & 19,3 & 2,46 & SW & $\mathbf{S}$ & SE \\
\hline 26 & 291 & 7,2 & - & 81 & 6,0 & 14,4 & 22,4 & 13,4 & 17,9 & 4,26 & $\mathrm{~S}$ & SE & SE \\
\hline 27 & 324 & 9,3 & - & 83 & 4,6 & 4,1 & 26,2 & 12,7 & 19,5 & 2,66 & $\mathrm{SE}$ & $\mathrm{E}$ & $\mathrm{SE}$ \\
\hline 28 & 300 & 7,6 & - & 80 & 2,5 & 3,8 & 27,4 & 11,8 & 19,6 & 2,26 & $\mathrm{C}$ & NW & $S$ \\
\hline 29 & 266 & 6,2 & $=$ & 86 & 3,2 & 6,0 & 25,0 & 12,5 & 18,8 & 1,76 & C & W & C \\
\hline 30 & 344 & 9,4 & - & 78 & 6,2 & 6,8 & 24,0 & 12,1 & 18,1 & 3,12 & $\mathrm{C}$ & $\mathrm{S}$ & $\mathrm{E}$ \\
\hline 31 & 350 & 9,5 & - & 81 & 3,6 & 6,1 & 23,7 & 8,7 & 16,2 & 2,85 & SW & W & $S$ \\
\hline
\end{tabular}

Fonte: Departamento de Física e Meteorologia, ESALQ, USP (Extraído de Pimenta, 1998) 
Tabela 32. Radiação solar (Rs, cal/ $\mathrm{cm}^{2}$.dia), insolação (I, horas/dia), chuva (C, mm), umidade relativa (UR, \%), velocidades do vento máxima (Vmax, $\mathrm{km} / \mathrm{h}$ ) e média (Vmed, m/s), temperaturas máxima $\left(\mathrm{Tmax},{ }^{\circ} \mathrm{C}\right)$, mínima $\left(\mathrm{T} \min ,{ }^{\circ} \mathrm{C}\right) \mathrm{e}$ média (Tmed, ${ }^{\circ} \mathrm{C}$ ), evaporação do tanque classe $\mathrm{A}$ e direção do vento (Dv) às $7\left(D_{7}\right), 14\left(D_{14}\right)$ e $21\left(D_{21}\right)$ horas referentes ao mês de junho de 1995 em Piracicaba, SP.

\begin{tabular}{|c|c|c|c|c|c|c|c|c|c|c|c|c|c|}
\hline \multirow[t]{2}{*}{ dia } & Rs & I & $\mathrm{C}$ & UR & Vmax & Vmed & Tmax & Tmin & Tmed & $\mathrm{ECA}$ & \multicolumn{3}{|c|}{ Dv } \\
\hline & $\mathrm{cal} / \mathrm{cm}^{2} \cdot \mathrm{d}$ & $\mathrm{h} / \mathrm{d}$ & $\mathrm{mm}$ & $\%$ & $\mathrm{~m} / \mathrm{s}$ & $\mathrm{km} / \mathrm{h}$ & ${ }^{\circ} \mathrm{C}$ & ${ }^{\circ} \mathrm{C}$ & ${ }^{\circ} \mathrm{C}$ & $\mathrm{mm}$ & $\mathrm{D}_{7}$ & $\mathrm{D}_{14}$ & $\mathrm{D}_{21}$ \\
\hline 1 & 338 & 9,3 & - & 78 & 6,0 & 8,1 & 26,0 & 9,0 & 17,5 & 2,94 & $E$ & $\mathrm{~W}$ & $S$ \\
\hline 2 & 318 & 8,4 & - & 73 & 4,7 & 6,9 & 26,8 & 10,3 & 18,6 & 3,57 & $\mathrm{E}$ & W & $\mathrm{SE}$ \\
\hline 3 & 312 & 9,4 & - & 82 & 4,5 & 5,8 & 25,2 & 11,4 & 18,3 & 2,98 & $S$ & $\mathrm{~S}$ & $\mathrm{SE}$ \\
\hline 4 & 318 & 6,8 & - & 75 & 2,2 & 6,4 & 25,4 & 9,6 & 17,5 & 3,60 & $\mathrm{E}$ & SW & SE \\
\hline 5 & 323 & 8,4 & - & 75 & 3,0 & 7,7 & 26,2 & 6,4 & 16,3 & 1,36 & $E$ & $\mathrm{NE}$ & $\mathrm{E}$ \\
\hline 6 & 315 & 9,7 & - & 74 & 5,2 & 8,2 & 27,0 & 8,9 & 18,0 & 3,26 & $\mathrm{E}$ & $\mathrm{N}$ & $\mathrm{NE}$ \\
\hline 7 & 329 & 9,7 & - & 75 & 4,5 & 7,9 & 28,0 & 10,8 & 19,4 & 3,50 & $E$ & $\mathrm{~N}$ & $E$ \\
\hline 8 & 282 & 8,5 & - & 77 & 5,4 & 11,3 & 27,6 & 9,9 & 18,8 & 1,80 & $E$ & $\mathrm{~N}$ & SE \\
\hline 9 & 315 & 8,2 & - & 73 & 3,7 & 7,3 & 28,2 & 11,2 & 19,7 & 5,06 & E & NE & $\mathrm{NE}$ \\
\hline 10 & 339 & 9,2 & $=$ & 68 & 3,7 & 8,6 & 27,6 & 9,2 & 18,4 & 3,97 & $E$ & $\mathrm{~N}$ & SE \\
\hline 11 & 311 & 9,7 & - & 73 & 4,2 & 6,5 & 28,4 & 10,6 & 19,5 & 3,27 & $\mathrm{E}$ & SE & $\mathrm{SE}$ \\
\hline 12 & 291 & 8,8 & - & 82 & 1,0 & 5,8 & 27,6 & 10,6 & 19,1 & 2,64 & SE & W & $\mathrm{S}$ \\
\hline 13 & 290 & 9,3 & - & 78 & 3,9 & 7,6 & 27,6 & 9,6 & 18,6 & 2,44 & $\mathrm{E}$ & W & $\mathrm{SE}$ \\
\hline 14 & 306 & 8,8 & - & 77 & 1,0 & 7,8 & 27,5 & 10,6 & 19,1 & 3,22 & $\mathrm{E}$ & SW & $\mathrm{E}$ \\
\hline 15 & 309 & 8,5 & - & 73 & 3,0 & 7,6 & 28,1 & 10,1 & 19,1 & 3,00 & $E$ & $\mathrm{~N}$ & $\mathrm{E}$ \\
\hline 16 & 242 & 8,1 & - & 68 & 5,0 & 7,9 & 28,5 & 14,7 & 21,6 & 3,82 & $\mathrm{E}$ & NW & $\mathrm{NE}$ \\
\hline 17 & 122 & 1,6 & 2,7 & 92 & 11,2 & 7,0 & 24,6 & 12,9 & 18,8 & 0,49 & E & SW & $\mathrm{E}$ \\
\hline 18 & 105 & 0,1 & 10,2 & 98 & 4,3 & 4,9 & 21,6 & 16,0 & 18,8 & 0,99 & $\mathrm{E}$ & $E$ & W \\
\hline 19 & 177 & 2,6 & - & 88 & 4,7 & 10,1 & 21,4 & 13,2 & 17,3 & 2,40 & SW & $\mathrm{SE}$ & $\mathrm{S}$ \\
\hline 20 & 342 & 9,0 & - & 83 & 6,0 & 9,0 & 22,6 & 10,4 & 16,5 & 3,00 & SW & SE & SE \\
\hline 21 & 227 & 3,5 & - & 87 & 2,2 & 4,8 & 22,8 & 9,0 & 15,9 & 1,64 & $\mathrm{~S}$ & $E$ & $E$ \\
\hline 22 & 296 & 6,9 & - & 83 & 2,0 & 6,6 & 27,0 & 11,2 & 19,1 & 2,12 & $E$ & $\mathrm{NE}$ & $S$ \\
\hline 23 & 318 & 8,8 & - & 80 & 3,4 & 7,4 & 28,0 & 11,1 & 19,6 & 3,16 & $\mathrm{E}$ & NE & $\mathrm{E}$ \\
\hline 24 & 303 & 8,1 & - & 70 & 4,3 & 11,7 & 27,4 & 12,0 & 19,7 & 3,99 & $\mathrm{E}$ & $\mathrm{NE}$ & $\mathrm{E}$ \\
\hline 25 & 93 & 0,2 & 10,6 & 97 & 22,6 & 5,7 & 18,8 & 17,3 & 18,1 & 2,17 & NE & NW & $\mathrm{E}$ \\
\hline 26 & 246 & 6,2 & - & 88 & 3,2 & 3,0 & 24,8 & 14,0 & 19,4 & 1,82 & $\mathrm{E}$ & $\mathrm{C}$ & $S$ \\
\hline 27 & 308 & 8,3 & - & 81 & 1 & 6,6 & 29,2 & 12,1 & 20,7 & 2,86 & $E$ & $\mathrm{NE}$ & $\mathrm{E}$ \\
\hline 28 & 320 & 9,6 & - & 73 & 4,8 & 8,1 & 29,8 & 12,4 & 21,1 & 2,98 & $\mathrm{E}$ & $\mathrm{N}$ & $\mathrm{SE}$ \\
\hline 29 & 170 & 0,4 & - & 86 & 3,9 & 10,7 & 21,9 & 15,1 & 18,5 & 1,01 & $\mathrm{SE}$ & $\mathbf{S}$ & SE \\
\hline 30 & 276 & 6,5 & - & 87 & 4,0 & 9,9 & 23,1 & 11,4 & 17,3 & 3,97 & $\mathrm{C}$ & SE & SE \\
\hline
\end{tabular}

Fonte: Departamento de Física e Meteorologia, ESALQ, USP (Extraído de Pimenta, 1998) 
Tabela 33. Radiação solar (Rs, cal $/ \mathrm{cm}^{2}$.dia), insolação (I, horas $/$ dia), chuva (C, mm), umidade relativa (UR, \%), velocidades do vento máxima $(V \max , \mathrm{km} / \mathrm{h})$ e média (Vmed, $\mathrm{m} / \mathrm{s})$, temperaturas máxima $\left(\mathrm{T} \max ,{ }^{\circ} \mathrm{C}\right)$, mínima $\left(\mathrm{Tmin},{ }^{\circ} \mathrm{C}\right) \mathrm{e}$ média (Tmed, ${ }^{\circ} \mathrm{C}$ ), evaporação do tanque classe $\mathrm{A}$ e direção do vento (Dv) às $7\left(D_{7}\right), 14\left(D_{14}\right)$ e $21\left(D_{21}\right)$ horas referentes ao mês de julho de 1995 em Piracicaba, SP.

\begin{tabular}{|c|c|c|c|c|c|c|c|c|c|c|c|c|c|}
\hline \multirow[t]{2}{*}{ dia } & $\mathrm{Rs}$ & I & $\mathrm{C}$ & UR & Vmax & Vmed & Tmax & Tmin & Tmed & $\mathrm{ECA}$ & \multicolumn{3}{|c|}{ Dv } \\
\hline & $\mathrm{cal} / \mathrm{cm}^{2} \cdot \mathrm{d}$ & $\mathrm{h} / \mathrm{d}$ & $\mathrm{mm}$ & $\%$ & $\mathrm{~m} / \mathrm{s}$ & $\mathrm{km} / \mathrm{h}$ & ${ }^{\circ} \mathrm{C}$ & ${ }^{\circ} \mathrm{C}$ & ${ }^{\circ} \mathrm{C}$ & $\mathrm{mm}$ & $\mathrm{D}_{7}$ & $D_{14}$ & $\mathrm{D}_{21}$ \\
\hline 1 & 315 & 8,1 & - & 78 & 1,0 & 7,1 & 26,8 & 10,4 & 18,6 & 3,06 & $E$ & $\mathrm{NE}$ & $E$ \\
\hline 2 & 311 & 9,0 & - & 77 & 3,1 & 6,7 & 28,5 & 11,0 & 19,8 & 2,86 & $\mathrm{E}$ & $\mathbf{N}$ & $\mathrm{E}$ \\
\hline 3 & 305 & 9,6 & - & 77 & 3,4 & 5,7 & 28,4 & 13,0 & 20,7 & 3,40 & $\mathrm{E}$ & W & $\mathrm{S}$ \\
\hline 4 & 311 & 9,3 & - & 81 & 4,8 & 8,8 & 26,3 & 13,3 & 19,8 & 3,54 & $\mathrm{E}$ & $E$ & SE \\
\hline 5 & 317 & 8,2 & - & 72 & 5 & 9,3 & 28,3 & 11,5 & 19,9 & 3,33 & $\mathrm{E}$ & $\mathrm{N}$ & $\mathrm{NE}$ \\
\hline 6 & 297 & 8,5 & - & 66 & 9,7 & 11,0 & 29,0 & 15,6 & 22,3 & 3,61 & $E$ & NW & $\mathrm{NE}$ \\
\hline 7 & 258 & 6,6 & 0,5 & 70 & 10,0 & 7,3 & 29,5 & 15,9 & 22,7 & 4,30 & $\mathrm{E}$ & NW & $\mathrm{N}$ \\
\hline 8 & 81 & - & 7,2 & 98 & 4,0 & 7,0 & 16,7 & 13,8 & 15,3 & 0,24 & SW & NW & SE \\
\hline 9 & 62 & - & 44,1 & 90 & 2,0 & 4,5 & 17,4 & 14,7 & 16,1 & 2,94 & $\mathrm{SE}$ & $E$ & $\mathrm{E}$ \\
\hline 10 & 153 & 3,0 & 1,0 & 93 & 1,0 & 5,5 & 22,7 & 15,2 & 19,0 & 0,89 & $\mathbf{S}$ & NE & SE \\
\hline 11 & 327 & 7,2 & - & 86 & 1,0 & 5,1 & 25,2 & 10,0 & 17,6 & 2,37 & $\mathrm{E}$ & NE & $\mathrm{SE}$ \\
\hline 12 & 318 & 7,8 & $=$ & 77 & 2,5 & 7,0 & 27,1 & 10,2 & 18,7 & 2,97 & $E$ & $\mathrm{E}$ & SE \\
\hline 13 & 312 & 9,6 & - & 77 & 1,0 & 7,5 & 28,7 & 11,1 & 19,9 & 1,75 & E & NE & $\mathrm{E}$ \\
\hline 14 & 291 & 6,8 & - & 74 & 2,0 & 6,3 & 29,0 & 12,0 & 20,5 & 4,17 & $\mathrm{E}$ & NE & $\mathrm{E}$ \\
\hline 15 & 189 & 1,8 & . & 81 & 1,0 & 6,1 & 28,2 & 15,0 & 21,6 & 2,11 & E & $E$ & SE \\
\hline 16 & 194 & 2,2 & - & 80 & 1,0 & 5,8 & 28,8 & 17,6 & 23,2 & 2,72 & $\mathrm{E}$ & NE & $\mathrm{SE}$ \\
\hline 17 & 302 & 7,8 & - & 74 & 4,2 & 6,0 & 29,3 & 14,4 & 21,9 & 3,08 & $\mathrm{E}$ & NE & $\mathrm{E}$ \\
\hline 18 & 284 & 6,1 & - & 72 & 5,1 & 8,3 & 26,7 & 14,1 & 20,4 & 3,52 & $\mathrm{E}$ & $\mathbf{N}$ & $\mathrm{E}$ \\
\hline 19 & 257 & 3,6 & - & 62 & 12 & 10,1 & 28,0 & 12,0 & 20,0 & 4,28 & $\mathrm{E}$ & $\mathbf{N}$ & E \\
\hline 20 & 134 & 0,8 & 0,4 & 82 & 12,7 & 9,3 & 20,4 & 17,9 & 19,2 & 1,78 & $\mathrm{E}$ & SW & $E$ \\
\hline 21 & 185 & 2,9 & 5,9 & 95 & 7,2 & 8,7 & 21,2 & 11,2 & 16,2 & 1,72 & $S$ & SW & $E$ \\
\hline 22 & 219 & 4,8 & - & 92 & 2,0 & 5,3 & 20,2 & 11,0 & 15,6 & 1,28 & $S$ & W & $\mathrm{C}$ \\
\hline 23 & 305 & 5,9 & - & 82 & 1,0 & 5,1 & 25,1 & 7,7 & 16,4 & 2,28 & $\mathrm{E}$ & SW & $E$ \\
\hline 24 & 344 & 9,7 & - & 72 & 2,5 & 6,8 & 29,3 & 9,7 & 19,5 & 3,32 & $E$ & $\mathbf{N}$ & $E$ \\
\hline 25 & 338 & 9,6 & - & 72 & 1,0 & 7,3 & 29,6 & 11,1 & 20,4 & 3,96 & $E$ & $\mathrm{E}$ & $E$ \\
\hline 26 & 342 & 8,8 & - & 71 & 3,8 & 7,4 & 29,4 & 12,6 & 21,0 & 3,72 & $E$ & NE & $E$ \\
\hline 27 & 317 & 9,1 & - & 72 & 6,6 & 7,8 & 29,5 & 12,0 & 20,8 & 3,39 & $\mathrm{E}$ & $\mathbf{N}$ & $E$ \\
\hline 28 & 374 & 9,7 & - & 63 & 7,1 & 9,1 & 29,7 & 15,1 & 22,4 & 6,13 & $E$ & $\mathbf{N}$ & $\mathrm{E}$ \\
\hline 29 & 359 & 8,7 & - & 67 & 2,5 & 8,0 & 31,0 & 14,8 & 22,9 & 4,60 & $\mathrm{E}$ & $\mathrm{N}$ & $E$ \\
\hline 30 & 347 & 9,7 & - & 74 & 2,9 & 7,2 & 30,0 & 12,9 & 21,5 & 2,40 & $\mathrm{E}$ & W & $S$ \\
\hline 31 & 345 & 9,5 & - & 72 & 1,0 & 6,6 & 30,3 & 12,3 & 21,3 & 3,94 & $E$ & $\mathbf{N}$ & $S$ \\
\hline
\end{tabular}

Fonte: Departamento de Física e Meteorologia, ESALQ, USP (Extraído de Pimenta, 1998) 
Tabela 34. Radiação solar (Rs, cal $/ \mathrm{cm}^{2}$.dia), insolação (I, horas/dia), chuva (C, $\mathrm{mm}$ ), umidade relativa (UR, \%), velocidades do vento máxima (Vmax, $\mathrm{km} / \mathrm{h}$ ) e média (Vmed, $\mathrm{m} / \mathrm{s})$, temperaturas máxima $\left(\mathrm{T} \max ,{ }^{\circ} \mathrm{C}\right)$, mínima $\left(\mathrm{Tmin},{ }^{\circ} \mathrm{C}\right) \mathrm{e}$ média (Tmed, ${ }^{\circ} \mathrm{C}$ ), evaporação do tanque classe $\mathrm{A}$ e direção do vento (Dv) às $7\left(D_{7}\right), 14\left(D_{14}\right)$ e $21\left(D_{21}\right)$ horas referentes ao mês de agosto de 1995 em Piracicaba, SP.

\begin{tabular}{|c|c|c|c|c|c|c|c|c|c|c|c|c|c|}
\hline \multirow[t]{2}{*}{ dia } & Rs & I & C & UR & $V \max$ & Vmed & $T \max$ & Tmin & Tmed & ECA & \multicolumn{3}{|c|}{ Dv } \\
\hline & $\mathrm{cal} / \mathrm{cm}^{2} \cdot \mathrm{d}$ & $\mathrm{h} / \mathrm{d}$ & $\mathrm{mm}$ & $\%$ & $\mathrm{~m} / \mathrm{s}$ & $\mathrm{km} / \mathrm{h}$ & ${ }^{\circ} \mathrm{C}$ & ${ }^{\circ} \mathrm{C}$ & ${ }^{\circ} \mathrm{C}$ & $\mathrm{Mm}$ & $\mathrm{D}_{7}$ & $\mathrm{D}_{14}$ & $D_{21}$ \\
\hline 1 & 356 & 9,8 & - & 69 & 4,0 & 8,1 & 29,2 & 12,4 & 20,8 & 5,10 & $\mathrm{E}$ & NE & $\mathrm{E}$ \\
\hline 2 & 360 & 9,8 & - & 71 & 6,2 & 8,2 & 29,4 & 10,3 & 19,9 & 4,66 & $\mathrm{E}$ & W & SE \\
\hline 3 & 335 & 7,8 & $=$ & 68 & 3,0 & 7,9 & 31,5 & 13,0 & 22,3 & 3,14 & $\mathrm{E}$ & NW & NW \\
\hline 4 & 302 & 5,4 & 0,9 & 84 & 8,3 & 12,6 & 23,4 & 14,9 & 19,2 & 5,08 & $\mathrm{SE}$ & $\mathrm{SE}$ & $\mathrm{SE}$ \\
\hline 5 & 128 & - & 0,3 & 92 & 5,5 & 10,3 & 16,8 & 13,5 & 15,2 & 1,92 & $\mathrm{~S}$ & $\mathbf{S}$ & SE \\
\hline 6 & 326 & 6,3 & - & 88 & 4,8 & 8,2 & 23,8 & 12,0 & 17,9 & 2,76 & $\mathrm{~S}$ & $S$ & SE \\
\hline 7 & 348 & 9,5 & - & 82 & 5,0 & 7,6 & 31,6 & 12,5 & 22,1 & 4,04 & $S$ & $\mathrm{~N}$ & $\mathrm{SE}$ \\
\hline
\end{tabular}

Fonte: Departamento de Física e Meteorologia, ESALQ, USP (Extraído de Pimenta, 1998) 